\title{
Hanford Radiological Protection Support Services Annual Report for 1990
}
M. Lyon
T. J. Froelich
D. E. Bihl
J. A. Leonowich
J. J. Fix
T. P. Lynch
R. K. Piper

July 1991

Prepared for the

U.S. Department of Energy

under Contract DE-AC06-76RLO 1830

Pacific Northwest Laboratory

Operated for the U.S. Department of Energy

by Battelle Memorial Institute 


\title{
DISCLAIMER
}

This report was prepared as an account of work sponsored by an agency of the United States Government. Neither the United States Government nor any agency thereof, nor Battelle Memorial Institute, nor any of their employees, makes any warranty, expressed or implied, or assumes any legal liability or responsibility for the accuracy, completeness, or usefulness of any information, a pparatus, product, ot process disclosed, or represents that its use would not infringe privately owned rights. Reference herein to any specific commercial product, process, or service by trade name, trademark, manufacturer, or otherwise does not necessarily constitute or imply its endorsement, recommendation, or favoring hy the United States Government or any agency thercof, or Battelle Memorial Institute. The views and opinions of authors expressed hercin do not necessarily state or reflect those of the United States Government or any agency thereoí.

\author{
PACIFIC NORTHWEST LABORATORY \\ operated by \\ BATTELLE MEMORIAL INSTITUTE \\ for the \\ UNITED STATES DEPARTMENT OF ENERGY \\ under Contract DE-ACO6-76RLO 1830
}

Printed in the Uniled States of America

Available to DOE and DOE contractors from the

Office of Scientific and Technical Information, P.O. Box 62, Oak Ridge, IN 37831; prices available from (615) 576-8401. FTS 626-8401.

Available to the public from the National Technical Information Service,

U.S. Department of Commerce, 5285 Port Royal Rd., Springfield, VA 22161. 
PNL -7752

UC -607

HANFORD RADIOLOGICAL

PROTECTION SUPPORT SERVICES

ANNUAL REPORT FOR 1990
M. Lyon
T. J. Froelich
D. E. Bihl
J. A. Leonowich
J. J. Fix
T. P. Lynch
R. K. Piper

July 1991

Prepared for

the U.S. Department of Energy

under Contract DE-AC06-76RLO 1830

Pacific Northwest Laboratory

Richland, Washington 99352 



\section{ABSTRACT}

Various Hanford site-wide radiation protection services provided by the Pacific Northwest Laboratory for the U.S. Department of Energy-Richland Operations Office and Hanford contractors are described in this annual report for calendar year 1990. These activities include internal dosimetry measurements and evaluations, in vivo measurements, external dosimetry measurements and evaluations, instrument calibration and evaluation, radiation source calibration, and radiological records keeping. For each of these activities, the routine program, program changes and enhancements, associated tasks, investigations and studies, and related publications, presentations, and other staff professional activities are discussed as applicable. 

This report documents the performance of various Hanford site-wide radiological protection services during calendar year (CY) 1990 provided by the Pacific Northwest Laboratory (PNL) in support of the U.S. Department of Energy-Richland Operations Office (DOE-RL) and contractor activities on the Hanford site. The routine program for each service is discussed along with any significant program changes and tasks, investigations, and studies performed in support of each program. Other related activities such as publications, presentations, and memberships on standards or industry committees are also discussed. The programs covered provide services in the areas of 1) internal dosimetry, 2) in vivo measurements, 3) external dosimetry, 4) instrument calibration and evaluation, 5) radiation standards and calibration, and 6) radiological records.

The Hanford Internal Dosimetry Program provides for bioassay monitoring and associated evaluation and documentation of assessments of internal exposure and dose to Hanford personnel and site visitors. During 1990 the Internal Dosimetry Program performed 18,462 excreta and in vivo bioassay measurements. The program performed 225 assessments of potential new intakes and six reassessments of prior exposures. Nearly $97 \%$ of the measurements were classified as routine, $1 \%$ were for followup of suspected intake of radionuclides, and $2 \%$ were classified as special-purpose measurements. During the year, the contract for excreta bioassay analysis with United States Testing Company, Inc., (UST) was terminated. (Because the recovery from this termination required considerable effort it has been described in considerable detail.) Supporting tasks that were performed, in addition to the many changes required by the UST contract termination, included development of a computer code to help with the dose calculations resulting from the routine fecal program. The routine fecal sampling program was terminated.

The Hanford In Vivo Measurement Program is an integral part of personnel dosimetry at Hanford and provides for the detection of radioactive materials deposited in site employees and visitors. The program provided a total of 13,316 measurements during $C Y 1989$. Changes to facilities and equipment included 1) replacing obsolete analyzers with a new workstation, 2) acquiring new equipment for improved chest wall thickness measurements, 3) installing 
communications systems in the counting rooms, 4) construction of a remotely operated counter in the mobile whole body counter, and 5) automating the liquid nitrogen fill system. Special studies conducted and other changes incorporated into the program included 1) measurements of a Chernoybl helicopter pilot, 2) standup counter and lung counter peak background prediction studies, 3) steps taken to address the standup counter fainting problem, and 4) improvements in the reliability of planar germanium detectors by developing onsite maintenance capabilities.

The Hanford External Dosimetry Program officially received the DOE Laboratory Accreditation Program (DOELAP) Certificate of Accreditation effective January 1, 1990. This certificate accredits Hanford basic, beta/photon, and multipurpose dosimeters in selected performance categories and is effective for the next two years. During 1990, approximately 205,000 dosimeters were processed. Dose-of-record information was reported to Dosimetry Records for 80,037 personnel dosimeters. Enhancements in the routine program during the year involved 1) reporting total neutron dose only, 2) assessing dose from contaminated clothing, 3) conducting routine radiological surveys of personne 1 dosimeters delivered to the 318 Building for processing, 4) using suitcasetype containers employing control dosimeters to record any dose in transit for exchanging dosimeters with Hanford contractors, and 5) including non-exposed dosimeters with the exposed audit dosimeters. Technical evaluations were conducted of 1) glow curve analysis capabilities and retention, 2) neutron doses for 1989, and 3) field and laboratory measurements of the combination albedo and track etch dosimeter for plutonium metal, hexafluoride, plutonium oxide, and californium neutron sources.

The Instrument Calibration and Evaluation Program provides complete and reliable radiation protection instrument services to help ensure personnel safety in the Hanford workplace. Specific tasks performed under this program during 1990 included 1) conducting the routine instrument pool, 2) conducting the Hanford Instrument Evaluation Program, 3) deploying High-Range Cutie Pies, and 4) calibrating Westinghouse Hanford Company 200-Area alpha continuous air monitors. Tasks performed during the year that supported the routine program included the redesign and fabrication of a performance test beta source holder to allow for a higher activity beta source and to ensure personnel protection. 
In addition, performance check devices were designed for pancake probes and alpha detecting survey instruments.

The Radiation Standards and Calibration Project maintains radiological calibration standards, special instrument and dosimeter responsecharacterizing equipment, and calibration data handling equipment at Hanford. The project is divided into two major functions: 1) maintenance of calibration standards and capabilities, and 2) maintenance of the instrument calibration and repair data management system. Improvements to the project during 1990 included 1) completion of the characterization of a new ${ }^{252} \mathrm{Cf}$ source placed into the Room 106 Rabbit system, 2) the characterization and implement-

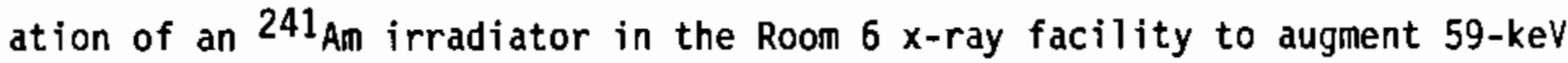
photon irradiations, 3 ) extensive remodeling of the Room $6 x$-ray irradiation facility allowing $x$-ray, high-energy ganma, and $241_{\text {Am }}$ irradiations to be performed simultaneously, 4) implementation of bar-code identification for use with the pencil dosimeter tracking system database, and 5) several enhancements to the CALDB and MAIN database software. Supporting studies included 1) the identification and correction of a well source deviation caused by slippage in the trolley system, 2) investigation of neutron background levels outside Room 106 caused by the newly placed high-level ${ }^{252} \mathrm{Cf}$ source and changes in dosimeter storage as a result thereof, 3) an assessment

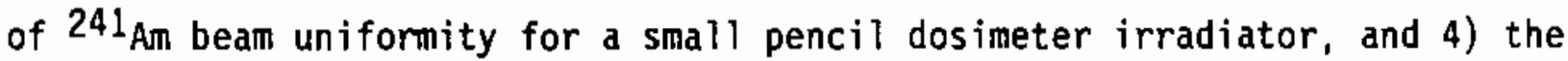
characterization of a new commercial high-level gamma irradiator installed in the Room 6 x-ray facility.

The Hanford Radiological Records Program preserves and administers all records of personnel radiological exposure and Hanford historical radiation protection and radiological dosimetry practices since the inception of Hanford in the early 1940s. During the year, the Radiological Records Program operated the occupational radiation exposure (ORE) system and the Hanford Radiation Protection Historical Files in support of DOE-RL and Hanford contractor radiological protection and dosimetry programs. The program produced reports for DOE-RL, DOE Headquarters, site contractors, and individuals and assisted epidemiology and site historical research projects. Redevelopment of the ORE (now named Radiological Exposure [REX]) System progressed through the requirements definition phase and into the preliminary design phase. Changes 
to the program included adding the ability to electronically verify wholebody-count data transmissions and restructuring the incident file. 


\section{ACKNOWLEDGMENTS}

The authors thank the staff members whose professional skills and technical expertise ensure the success of Hanford's External Dosimetry Program, Internal Dosimetry Program, In Vivo Measurement Program, Instrument Calibration and Evaluation Program, Radiation Standards and Calibrations Project, and Radiological Records Program. 



\section{ACRONYMS}

$\mathrm{ACL}$

$A D C$

ANS

ANSI

ASTM

BCSR

BOMAB

CAM

CAR

CERCLA

CLP

$C P$

CPR

CY

DEC

DOE

DOELAP

DOE-RL

EDF

EPA

FY

GI

GM

HEHF

HIEC
Analytical Chemistry Laboratory

analog-to-digital converter

American Nuclear Society

American National Standards Institute

American Society for Testing and Materials

Boeing Computer Services-Richland

bottle manikin absorption (phantom)

continuous air monitor

computer-assisted retrieval (system)

Comprehensive Environmental Response, Compensation, and Liability Act

Contract Laboratory Program

Cutie Pie (instrument)

cardiopulmonary resuscitation

calendar year

Digital Electronic Corporation

U.S. Department of Energy

Department of Energy Laboratory Accreditation Program

U.S. Department of Energy-Richland Operations Office

Emergency Decontamination Facility

U.S. Environmental Protection Agency

fiscal year

gastrointestinal

Geiger-Mueller

Hanford Environmental HeaTth Foundation

Hanford Instrument Evaluation Comanittee 


\begin{tabular}{ll} 
HMPD & Hanford multipurpose dosimeter \\
HMS & Hanford Medical System \\
HP & Hewlett Packard \\
HPDAC & Hanford Personnel Dosimetry Advisory Commission \\
HPSSC & Health Physics Society Standards Committee \\
HQ & headquarters \\
HRCP & High-Range Cutie Pie (instrument) \\
HRRP & Hanford Radiological Records Program \\
IARC & International Agency for Research on Cancer \\
ICRP & International Commission on Radiological Protection \\
IDP & Internal Dosimetry Program \\
IPU & isotopic plutonium analysis \\
I\&ED & Instrumentation and External Dosimetry (section) \\
ITAS & International Technology Analytical Services \\
ITAS-RI & International Technology Analytical Services-Richland \\
IVRRF & In Vivo Radioassay and Research Facility \\
KEH & Kaiser Engineers Hanford Company \\
LANL & Los Alamos National Laboratory \\
MDA & minimum detectable activity \\
MPBB & maximum permissible body burden \\
MQA & measurement quality assurance \\
MTE & measurement and test equipment \\
NVLAP & National Voluntary Laboratory Accreditation Program \\
NCRP & National Council on Radiation Protection and Measurements \\
NIST & National radiation exposure \\
\hline
\end{tabular}




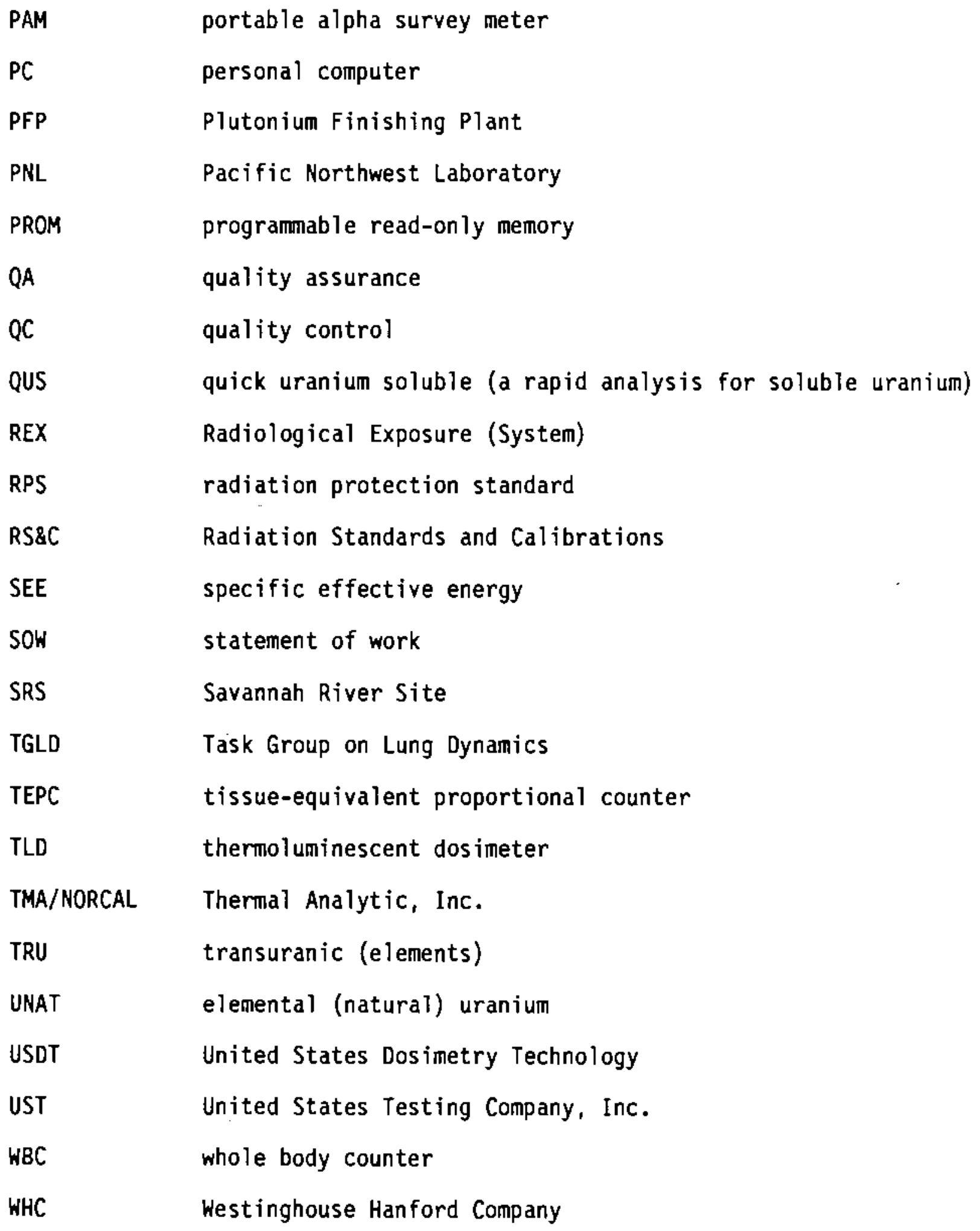





\section{CONTENTS}

ABSTRACT ..................................

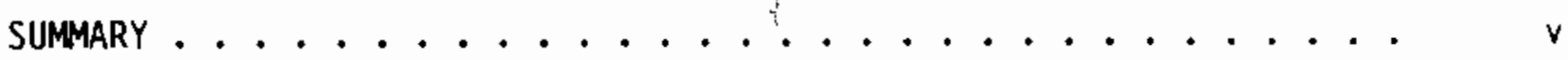

ACKNOWLEDGMENTS .............................. ix

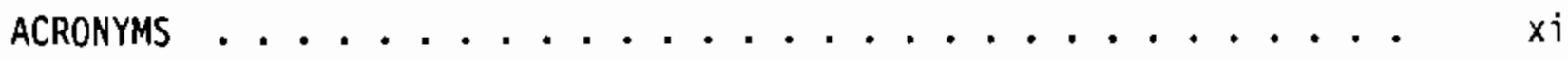

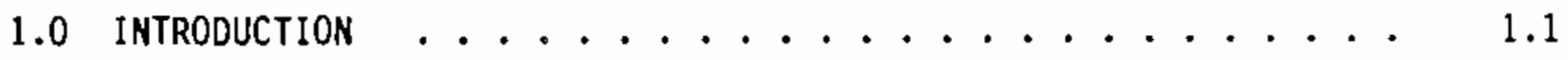

2.0 HANFORD INTERNAL DOSIMETRY PROGRAM . . . . . . . . . 2.1

2.1 EXCRETA BIOASSAY PROGRAM ................... 2.1

2.1.1 The United States Testing Company, Inc., Period . . 2.1

2.1.2 Rebuilding the Excreta Bioassay Program . . . . 2.4

2.1.3 Analytical Laboratories for the Interim Period . . 2.5

2.1.4 Sample Collection and Shipment........ 2.8

2.1 .5 Sample Analysis ............ 2.10

2.1.6 Adjustments to the Blind Audit Program . . . . . 2.11

2.1.7 The BioNasty Computer Code . . . . . . . . 2.12

2.2 ROUTINE INTERNAL DOSIMETRY PROGRAM . . . . . . . 2.12

2.2.1 Routine Fecal Program Terminated ........ 2.16

2.2.2 Computer Code, GENCOMP . . . . . . . . . 2.16

2.3 MONITORING AND ASSESSMENT ACTIVITIES . . . . . . . 2.17

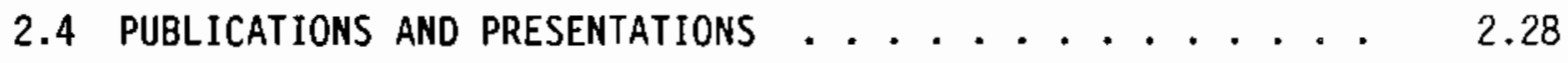

2.4 .1 Publications ............... 2.28

2.4 .2 Presentations . . . . . . . . . 2.28

2.5 PROGRAM-RELATED PROFESSIONAL ACTIVITIES . . . . . . 2.28

3.0 HANFORD IN VIVO MEASUREMENT PROGRAM .............. . . 3.1

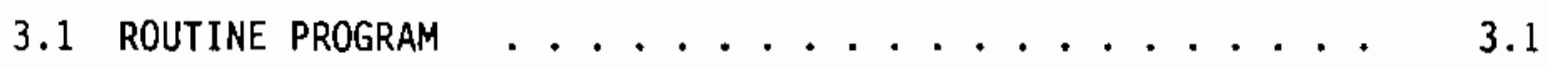

3.2 ADDITIONS OR CHANGES TO EQUIPMENT AND FACILITIES IN $1990 \cdot 3.5$ 
3.2.1 Work Stations ............. 3.5

3.2.2 Improved Measurements of Chest Wall Thickness . . 3.5

3.2.3 Counting Room Cell Communications ....... 3.5

3.2.4 Construction of a Remotely Operated Counter
in the Mobile Whole Body Counter...... . . 3.7

3.2.5 Automatic Liquid Nitrogen Fill System . . . . . 3.9

3.3 SPECIAL STUDIES $\ldots \ldots \ldots . \ldots \ldots . \ldots . \ldots . \ldots . \ldots$

3.3.1 Measurements on Chernobyl Helicopter Pilot .... 3.11

3.3.2 Standup Counter Peak Background Prediction Study . . 3.11

3.3.3 Lung Counter Peak Background Prediction Study . . . 3.11

3.3 .4 Statement of Work ............ . . 3.11

3.3.5 Standup Counter Fainting Issue . . . . . . . 3.12

3.3.6 Maintenance of the Planar Germanium Detectors . . . 3.12

3.3.7 Phantom Library . . . . . . . . . . 3.13

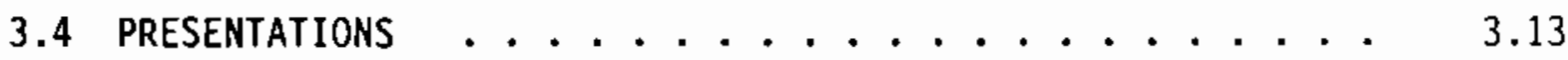

3.5 PROGRAM-RELATED PROFESSIONAL ACTIVITIES . . . . . . . 3.13

4.0 HANFORD EXTERNAL DOSIMETRY PROGRAM . . . . . . . . . 4.1

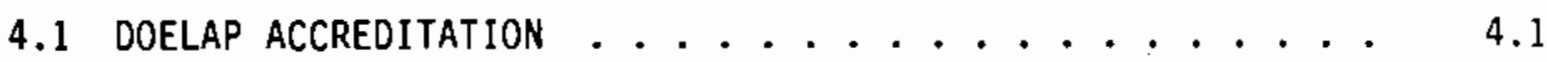

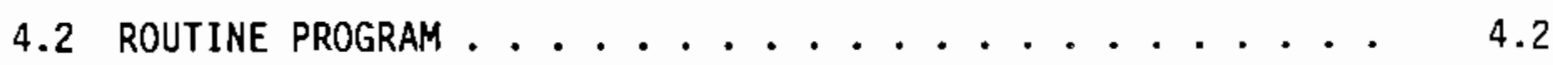

4.2.1 1990 Annual Processing Information ....... 4.2

4.2.2 Implementation of Total Neutron Dose Reporting Only 4.4

4.2.3 Hanford Practice Adopted for Contaminated Clothing . $\quad 4.4$

4.3 SUPPORTING EVALUATIONS . . . . . . . . . 4.5

4.3.1 Glow Curve Analysis ............ 4.5

4.3.2 Historical Documentation ........... 4.5

4.3.3 Evaluation of 1989 Year-End Neutron Dose Results . . 4.5

4.3.4 Study of Hanford Neutron Albedo and CR-39 . . . . . . . . . 4.7
Track Etch Dosimeter. . 
4.3.5 Extremity Dosimetry Evaluations ....... 4.8

4.4 DOCUMENTATION . . . . . . . . . . . . . . 4.9

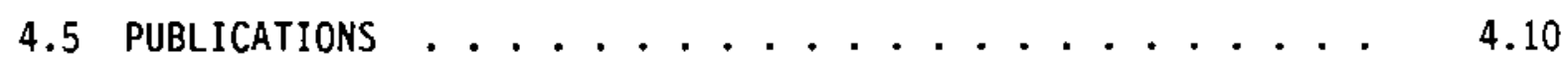

4.6 PROGRAM-RELATED PROFESSIONAL ACTIVITIES . . . . . . 4.10

5.0 INSTRUMENT CALIBRATION AND EVALUATION PROGRAM $\ldots \ldots . \ldots . \ldots$

5.1 ROUTINE PROGRAM ....................... 5.1

5.1.1 Routine Portable Instrument Pool . . . . . . 5.2

5.1.2 Hanford Instrument Evaluation Program . . . . 5.2

5.1.3 Deployment of High-Range Cutie Pies . . . . . 5.4

5.1.4 Calibration of Westinghouse Hanford Company
200-Area Alpha Continous Air Monitors ... . . 5.4

5.2 SUPPORTING INVESTIGATION AND STUDIES . . . . . . . 5.4

5.2 .1 Linear Beta Source . . . . . . . . . 5.4

5.2.2 Geiger-Mueller and Alpha Check Sources ...... 5.5

5.3 PRESENTATIONS . . . . . . . . . . . . . . . . . 5.5

5.4 PROGRAM-RELATED PROFESSIONAL ACTIVITIES . . . . . . 5.5

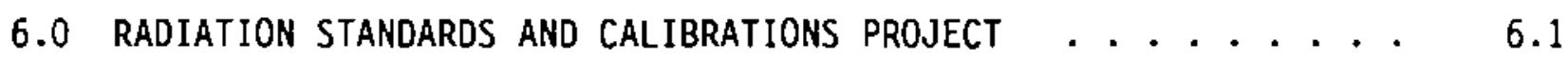

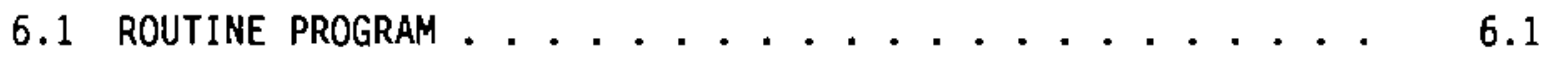

6.1.1 Maintenance of Standards and Capabilities .... 6.1

6.1 .2 Improvements to the Maintenance of Standards
and Calibration Functions ............... 6.5

6.1.3 Maintenance of the Data Management System . . . 6.6

6.1.4 Improvements to the Maintenance of the Data
Management System Function ............ 6.7

6.2 SUPPORTING INVESTIGATIONS AND STUDIES . . . . . . . 6.8

6.2 .1 Measurement Quality Assurance
for Beta Irradiations ............ 6.8

6.2 .2 Well \#2 Trolley Slippage Incident ....... 6.9 
6.2.3 Background from Placement of New High-Level

Californium-252 Source ........... . . 6.9

6.2.4 Americium-241 Beam Uniformity . . . . . . . . 6.10

6.2.5 Physical Characterization of the Commerical

Gamma Irradiator ............... 6.11

6.3 PUblications . . . . . . . . . . . . . . . 6.12

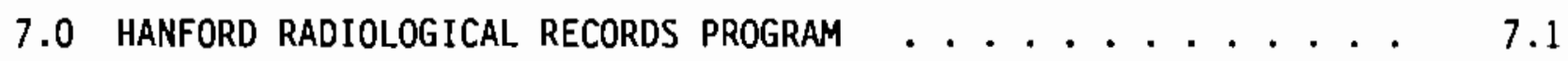

7.1 ROUTINE PROGRAM ............................. 7.1

7.1 .1 Changes to the Routine Program . . . . . . . . 7.3

7.2 SUPPORTING TASKS . . . . . . . . . . . . . . . 7.4

7.2.1 Redevelopment of the ORE System . . . . . . . 7.4

7.3 PUBLICATIONS AND PRESENTATIONS . . . . . . . . . . 7.7

7.3 .1 Publications . . . . . . . . . . . . 7.7

7.3 .2 Presentations ............... 7.7

7.4 PROGRAM-RELATED PROFESSIONAL ACTIVITIES $\ldots \ldots .7$

8.0 REFERENCES . . . . . . . . . . . . . . . . . . . . . 8.1 


\section{FIGURES}

1.1 Management Structure and Major Communication Interfaces

for Hanford Radiological Support Services Between PNL and

DOE-RL and Within PNL . . . . . . . . . . . . . . .

2.1 Routine Urine Measurements Made at the In Vivo Radioassay and Research Facjlity from 1986 through 1990 . . . . . . . .

2.2 Routine In Vivo Measurements Made at the In Vivo Radioassay and Research Facility from 1986 through 1990 . . . . . . .

3.1 In Vivo Measurements Made at the In Vivo Radioassay and Research Facility from FY 1986 through FY 1990 . . . . .

3.2 Ultrasound Instruments and Associated Computer Hardware for Measuring Chest Wall Thickness . . . . . . . . . . . 3.6

3.3 The Remotely Operated Whole Body Counter in the Mobile Whole Body Counting Facility ................

3.4 Operation of the Remotely Operated Mobile Whole Body Counting Facility . . . . . . . . . . . . . . 3.10

6.1 Americium-241 59-keV Photon Irradiator . . . . . . . . 6.6

6.2 Components of Laser Bar Code System for Pencil Dosimeter Identification ....................

7.1 ORE Redevelopment Steering Committee Charter . . . . . . 7.6 


\section{$\underline{\text { TABLES }}$}

2.1 Emergency and Expedite Bioassay Analysis Capability Provided by the PNL Analytical Chemistry Laboratory for the Interim Period .............. 2.6

2.2 Specified Minimum Detectable Activities and Follow-Up Levels for Routine Excreta Analyses During 1990 . . . . . . 2.7

2.31990 Interim Bioassay Laboratory Activities . . . . . . . . 2.10

2.4 Minimum Detectable Activities and Follow-Up Levels for Routine In Vivo Measurements During 1990 . . . . . . 2.13

2.5 Models Used to Interpret Bioassay Data During $1990 \quad \ldots . \ldots 2.16$

2.6 Excreta Measurements for Samples Requested During January-May, 1990, Under the Analytical Services Contract with UST, and Recorded in the ORE Database ........ 2.18

2.7 Excreta Measurements for Samples Requested During June-December, 1990, Between Long-Terni Contract for Analytical Services ............ 2.19

2.8 Total Excreta Measurements Requested during CY $1990 \ldots 2.21$

2.9 In Vivo Measurements Performed during $\mathrm{CY} 1990$ and Recorded in the ORE Database ................

2.10 Summary of Potential Exposure Incidents During $1990 \ldots 2.24$

2.11 Comparison of Internal Exposure Incidents and Internal Exposure Dose Assessments, 1986-1990 ......... 2.26

2.12 Internal Dose Status of Hanford Work Force at 1990 Year-End . . 2.27

3.1 Measurements Made on Hanford Personnel During FY 1990 . . . . 3.2

4.1 Personne1 Dosimeters Processed During 1990 . . . . . . . 4.2

4.2 Audit Dosimeters Processed During 1990 . . . . . . . . 4.3

5.1 Portable Instrument Usage for $\mathrm{Cr} 1990 \ldots . . . . . . . .5 .3$

6.1 Calibration Performance Summary ............ 6.4

6.2 Calibration and Uniformity Study ............ 6.11

7.1 Records Activity for Calendar Year 1990 . . . . . . . 7.3 


\subsection{INTRODUCTION}

This annual report documents. the calendar year (CY) 1990 activities of certain radiation protection sitewide services operated by the Pacific Northwest Laboratory (PNL) (a) for the U.S. Department of Energy-Richland Operations Office (DOE-RL) and the Hanford contractors. The programs covered provide services in the areas of 1) internal dosimetry, 2) in vivo measurements, 3) external dosimetry, 4) instrument calibration and evaluation, 5) calibration of radiation sources traceable to the National Institute of Science and Technology (NIST), and 6) radiological records. All of these services fall within the purview of PNL's Health Physics Department.

While some of the programs discussed in this report are involved in activities funded by other sources, only those activities funded by DOE-RL, DOE Headquarters ( $\mathrm{HQ})$, and the Hanford contractors are addressed herein. It should be noted that 1) the services provided for non-DOE-RL activities are performed only to the extent that they do not adversely affect services to DOE and its contractors, and 2) these services provide funds that support the program and reduce the costs to DOE and the Hanford contractors (i.e., Boeing Computer Services-Richland [BCSR], the Hanford Environmental Health Foundation [HEHF], Kaiser Engineers Hanford Company [KEH], PNL, and Westinghouse Hanford Company $[\mathrm{WHC}])$.

Each Hanford program listed above is presented in a separate section of the report. Each major section discusses the routine program, including any significant changes and improvements; investigations, studies, and tasks performed in support of the routine program; and other program-related activities such as publications, presentations, professional memberships, and external professional activities, if applicable. Figure 1.1 is an organizational chart showing the PNL and DOE management structure and communication interfaces for each PNL-operated program and the DOE Safety and Environment Division, which is responsible for PNL's services in this area.

(a) Pacific Northwest Laboratory is operated by Battelle Memorial Institute for the U.S. Department of Energy under Contract DE-AC06-76RLO 1830. 


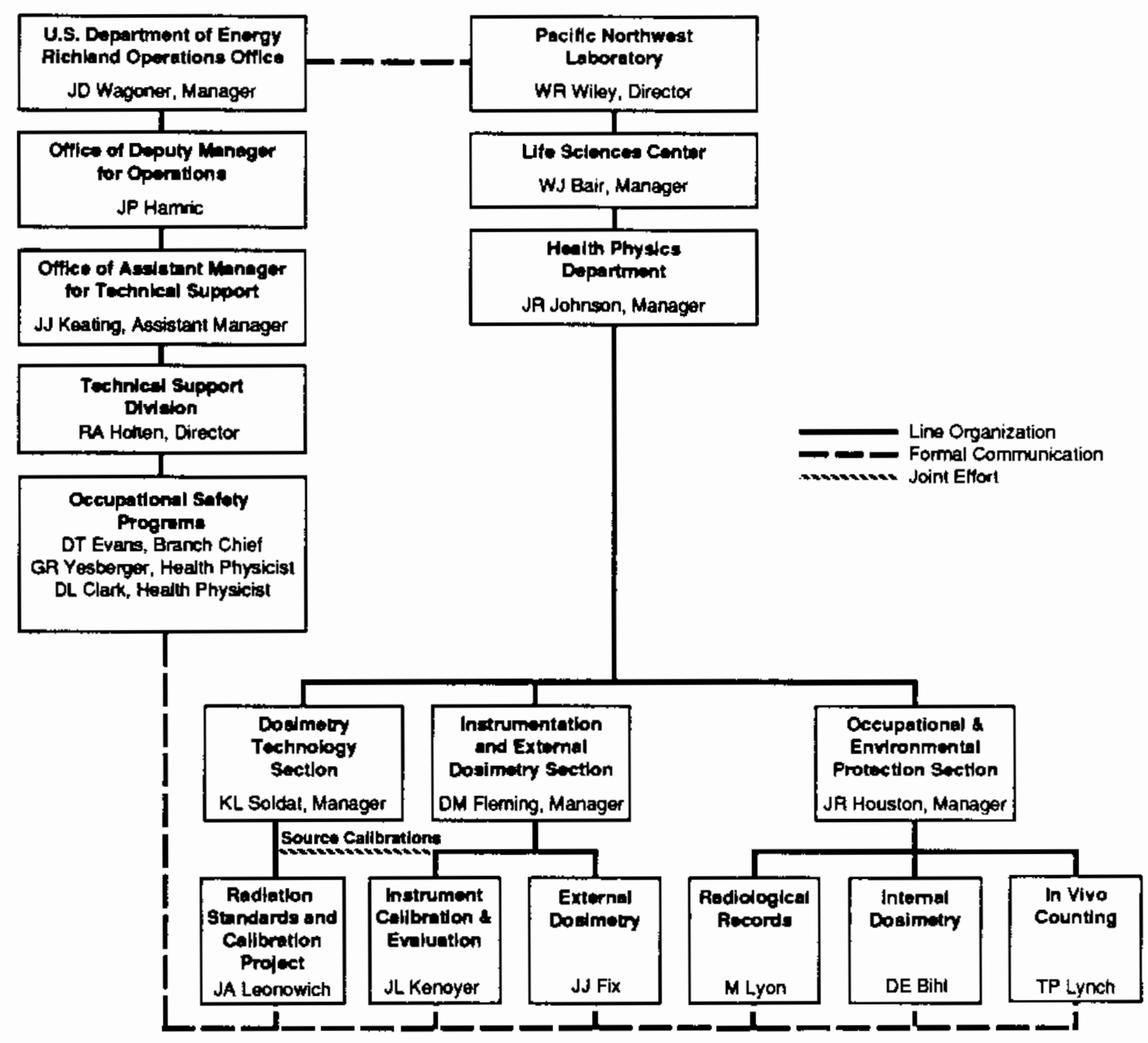

59106068.1

FIGURE 1.1. Management Structure and Major Communication Interfaces for Hanford Radiological Support Services Between PNL and DOE-RL and Within PNL 


\subsection{HANFORD INTERNAL DOSIMETRY PROGRAM}

The Hanford Internal Dosimetry Program (IDP) was initiated in late 1944 to provide for the assessment and documentation of occupational doses from intake of radionuclides by workers at Hanford. The program is administered in support of Hanford radiation protection programs as required by DOE 5480.11 (DOE 1988) and the Hanford Site Services Handbook (DOE-RL 1991). The program provides the following internal dosimetry services:

- administration of a routine bioassay monitoring program

- investigation and assessment of potential internal exposures

- monitoring performance of the excreta bioassay laboratory(s)

- selection and application of models, procedures, and practices for evaluating internal exposures

- technical support to DOE-RL and site contractors.

In addition, the program provides a 24-hour single point of contact for technical support for radiological or hazardous chemical incidents at Hanford and in the DOE Region 8 area.

Major changes occurred in the excreta bioassay program in 1990. Those changes, changes to the routine internal dosimetry progran, and a summary and statistics of bioassay results and internal exposures are discussed in the following sections.

\subsection{EXCRETA BIOASSAY PROGRAM}

Bioassay monitoring is performed on a regular basis for workers that might inhale, ingest, or absorb radionuclides into their bodies in the course of their work. Because of major changes to the excreta monitoring part of the bioassay program, it is discussed separately in this year's report. Some aspects of the in vivo monitoring part are discussed under Section 2.2, Routine Internal Dosimetry Program, in this section, and more details are provided in the Whole Body Counting Program section of this document.

\subsubsection{The United States Testing Company, Inc., Period}

United States Testing Company, Inc., (UST) - Richland Division (UST) had been performing excreta bioassays for the Hanford Site since December 1964 . 
At first the company contracted directly with the Atomic Energy Commission, then later the company became a subcontractor for DOE-RL under contract to PNL. The contract was administered through the Analytical Support Services Program.

In April 1989, the U.S. Environmental Protection Agency (EPA) suspended UST from participating in federal assistance programs and from all future direct federal procurement activities. This suspension involved UST activities under the Contract Laboratory Program (CLP), which supports work for the Comprehensive Environmental Response, Compensation, and Liability ACt (CERCLA) of 1980. In May 1989, the EPA and UST entered into an interim agreement in which UST voluntarily agreed to exclude its Richland Division from participation in EPA assistance, procurement, or interagency agreement activities funded by EPA. In April 1990, EPA terminated the agreement with UST and reinstated the suspension.

Following the suspension notice in April 1990, PNL assembled an audit team that conducted a 3-week evaluation of present and past UST operations. Although there were no noted instances that would call bioassay analytical data into question, there were significant findings on the other tasks of the contract.

On June 1, 1990, the PNL contract with UST was terminated for noncompliance with conditions of the contract. An immediate stop-work order was issued, and all exchange of data ceased. Bioassay samples in process at the time were lost, and IDP was left without access to an analytical laboratory. Rebuilding the excreta bioassay program is discussed in a following section of this report. Due to the loss of data and analytical capabilities, many dose assessments for Hanford workers were delayed during FY 1990 and extended delays in analysis of excreta samples occurred.

In response to concern voiced by the Governor of the State of Washington, the EPA, and the media about the integrity of past data from UST, the Director of PNL asked Professor Gilbert S. Omenn (University of Hashington, Dean of the School of Public Health and Community Medicine) to form an independent committee to study the matter. In addition to Professor Omenn, other committee members were Gerald van Belle (Professor of Biostatistics and Environmental Health), David Kalman (Associate Professor of 
Environmental Health), and Michael O'Brian (the university's Radiation Safety Officer). The purposes of the committee were to review the data generated by UST and to see how the data were used to ensure that correct decisions were made 1) regarding the health and safety of workers, and 2) regarding the environmental releases of contaminants and thus the health and safety of the public.

Despite the broad scope of work of the committee, the committee decided to focus first on in vitro bioassay data. This decision was made for several reasons. First, only the excreta bioassay data were obtained from UST; other data such as in vivo bioassay results were obtained independently of UST, and hence, the other data might be used to assess the quality and validity of UST data. Secondly, some excreta bioassay data obtained after a suspected exposure represent a time series of samples permitting comparison of observed and predicted levels. Third, the magnitude of the review was more limited and manageable. Fourth, allegations of misrepresentation made against UST were based on hazardous chemistry analyses, not radiochemistry analyses. However, if the excreta bioassay data were found to be invalid, then the committee could reasonably conclude that all chemistry data could also be inferred to be invalid.

The comnittee began work in June 1990 and its review of the bioassay data was ongoing at the close of the year. During that period, IDP provided the committee with UST quality control (QC) data for 1983 through 1990, data and reports on the excreta bioassay audit program, and some internal exposure case histories. The comnittee attempted to get access to UST's raw data, but those data were being held by UST as part of contractual and legal negotiations.

The internal QC program operated by UST provided for monitoring and documenting laboratory performance for the duration of the contract. Because the contract with UST was terminated June 1, 1990, the annual QC report was not received from UST, and information was only available from the first two quarterly reports. These reports showed performance to be satisfactory with the exception that approximately $25 \%$ of the yields for the plutonium and the most sensitive elemental (natural) uranium (UNAT) methods were below the minimum for all urine samples analyzed. 
In addition to the QC program operated internally by UST, IDP also submitted samples containing known quantities of radionuclides in urine. Some of the samples were submitted blind; that is they were made to appear to be normal urine samples from Hanford workers, and some were submitted openly as audit samples. This external audit sample program provided a check on UST's own internal QC program.

Fewer audit samples were submitted than in previous years due to the termination of the UST contract, but analyses for tritium, ${ }^{90} \mathrm{Sr}, 238 \mathrm{Pu}, 239 \mathrm{Pu}$, ${ }^{241} 1_{\mathrm{Am}}$, and natural uranium were conducted during fiscal year (FY) 1990, and the results were documented in an annual letter report. (a) The results of the external audit program were generally the same as for UST's internal QC program. An exception was observed for the PNL $241_{\text {Am data, which indicated a }}$ possible problem with the calculated detection level, although the number of blind samples analyzed was not sufficient to establish definitive results. Both UST and PNL results indicated a problem with relative precision for the UNAT procedure. The problems identified could not be investigated further due to termination of the contract with UST.

\subsubsection{Rebuilding the Excreta Bioassay Program}

In April 1990, following the EPA suspension of UST, the IDP staff began to develop a contingency plan to be enacted in the event of the interruption or termination of the analytical services contract. Many laboratories were contacted as potential replacement laboratories for excreta bioassay analysis, but no single laboratory contacted could meet both the required minimum detection levels and the sample analysis rate for all required types of analysis. Consequently, the use of multiple laboratories was planned in the event of UST contract termination. Also, because of the multiple replacement laboratory situation, it was determined that the use of sequential analytical procedures for different element combinations (i.e., isotopic plutonium and radiostrontium) would no longer be possible.

(a) MacLellan, J. A. 1991. "Results of the PNL Bioassay Audit Program for Fiscal Year 1990." Letter report to Distribution. Available in the Hanford Radiation Protection Historical Files, Pacific Northwest Laboratory, Richland, Washington. 
Following the actual termination of the UST contract on June 1, 1990, portions of the contingency plan were implemented as described below. The period between permanent contracts for analytical services will be referred to as the "interim period" in the subsequent discussions, and that period was still ongoing at the end of 1990 .

\subsubsection{Analytical Laboratories for the Interim Period}

Imnediate verbal arrangements were made with the PNL Analytical Chemistry Laboratory ( $A C L)$ to provide 24-hour on-call emergency excreta analys is services in support of internal dosimetry incidents. The availability of such services was deemed essential to provide adequate worker protection for continued operation of Hanford facilities. This service was tested without notice, shortly after the UST contract termination, when WHC submitted a urine sample containing metabolized plutonium for emergency analysis on June 14, 1990. The ACL successfully provided isotopic plutonium results within 24 hours of submittal. Specification of services was formally established in a September 14 statement of work (SOW), which identified the required emergency and expedite analysis capabilities as shown in Table 2.1. These services were not required in 1990 .

With the termination of the UST contract, laboratories that had been identified by the contingency plan as candidates for analyzing routine samples during the interim period were contacted and their capabilities were further assessed. Oraft SOWs were developed for each of the analyses and provided to candidate laboratories for consideration. Following an initial technical capability screening, the candidate laboratories underwent a pre-award audit by PNL Quality Assurance. Once qualified, formal arrangements for analyses were made through memorandum purchase orders, contract negotiations, or onsite work orders. As the laboratories reported that they were ready to start receiving and processing samples, performance test samples were prepared by PNL and submitted to each selected laboratory as a required demonstration of capability. Upon acceptable demonstration of performance, the first worker samples were submitted. 
TABLE 2.1. Emergency and Expedite Bioassay Analysis Capability Provided by the PNL Analytical Chemistry Laboratory for the Interim Period

\section{Analys is}

Emergency Analyses (a)

Isotopic plutonium by alpha spectrometry

Isotopic uranium by alpha spectrometry

241Am by alpha spectrometry

Total radiostrontium

Elemental uranium

\section{Expedite Analyses (b)}

Isotopic plutonium by alpha spectrometry

Isotopic uranium by alpha spectrometry

${ }^{241}$ Am by alpha spectrometry

Total radiostrontium

Elementa] uranium

Tritium
Detection Level (per sample)

Urine Feces

$\begin{array}{rl}20 & \mathrm{dpm} \\ 20 & \mathrm{dpm} \\ 20 & \mathrm{dpm} \\ 2000 \mathrm{dpm} & \\ 20 & \mu 9\end{array}$

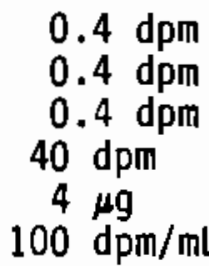

4 dpin

4 dpin

4 dpin

$400 \mathrm{dpm}$

$4 \mu \mathrm{g}$

(a) Verbal reporting time of 10 hours after receipt of sample for plutonium and strontium and as soon as possible for the others.

(b) Verbal reporting time is 9:00 a.m. of third day after receipt of sample.

A surmary of the interim laboratories and pertinent information regarding their services is given in Table 2.2. The following laboratories were finally selected to provide bioassay services:

- Los Alamos National Laboratory (LANL) to provide isotopic plutonium analyses $\left({ }^{238} \mathrm{Pu}\right.$ and $\left.{ }^{239} \mathrm{Pu}\right)$ in urine by memorandum purchase order.

- Thermal Analytical Inc. (TMA/Norcal) of Richmond, California, to provide analyses of radiostrontium in urine by negotiated contract.

- International Technology Analytical Services (ITAS) to provide urine analyses for isotopic uranium, low-level elemental uranium, ${ }^{241} \mathrm{Am}$, and isotopic curium, and fecal analys is of isotopic plutonium. Initial contacts were with ITAS-0ak Ridge, but the laboratory that was ultimately awarded the contract was in Richland (ITAS-RI).

- The Hanford $A C L$, operated by PNL to provide routine tritium analysis, and the emergency and expedite analyses of other isotopes, by work order.

- Hanford 222-5 Laboratory, operated by WHC, to provide quick, routine elemental uranium analyses of urine by an internal WHC work order. 
TABLE 2.2. Specified Minimum Detectable Activities and Follow-Up Levels for Routine Excreta Analyses During 1990

\begin{tabular}{|c|c|c|c|}
\hline Laboratory(z) & Analys is(b) & $\begin{array}{l}\text { Contractual } \\
M D A(c, d) \\
\end{array}$ & $\begin{array}{l}\text { Fol low-Up Level } \\
\text { and Sampling } \\
\text { Frequency }(d, c) \\
\end{array}$ \\
\hline \multirow[t]{2}{*}{ UST } & $\begin{array}{l}\text { Tritium } \\
{ }_{\mathrm{Sr}}^{\mathrm{S}}\end{array}$ & $\begin{array}{l}10 \mathrm{dpm} / \mathrm{mL} \\
2.0 \mathrm{dpm}\end{array}$ & \\
\hline & $\begin{array}{l}{ }^{238} \mathrm{Pu} \text { or }{ }^{239} \mathrm{Pu} \\
{ }^{239} \mathrm{Pu} \text { in feces } \\
{ }^{241} \mathrm{Am} \\
\text { Elemental uranium } \\
\text { Elemental uranium (quick } \\
\text { analys is procedure, [QUS]) }\end{array}$ & $\begin{array}{l}0.02 \mathrm{dpm} \\
0.2 \mathrm{dpm} \\
0.02 \mathrm{dpm} \\
0.05 \mu \mathrm{g} \\
0.5 \mu \mathrm{g}\end{array}$ & $\begin{array}{l}0.01 \mathrm{dpm}(A) \\
2.0 \mathrm{dpm}(A) \\
0.01 \mathrm{dpm}(A) \\
0.2 \mu g(Q, A)(f) \\
11 \mu g(B W) \\
\text { or } 4 \mu g(M)\end{array}$ \\
\hline LANL & ${ }^{238} \mathrm{Pu}$ or ${ }^{239} \mathrm{Pu}$ & $0.03 \mathrm{dpm}$ & $0.015 \mathrm{dpm}(A)$ \\
\hline TMA/Norcal & Radiostrontium (as ${ }^{98} \mathrm{Sr}$ ) & $30 \mathrm{dpm}$ & $26 \mathrm{dpm}(\mathrm{A})$ \\
\hline ITAS-RI & $\begin{array}{l}{ }^{241} \mathrm{Am} \\
238 \mathrm{U}, 234 \mathrm{U} \\
235 \mathrm{U} \\
242 \mathrm{Cm} \\
\text { Elemental uranium } \\
{ }^{239} \mathrm{Pu} \text { in feces }\end{array}$ & $\begin{array}{l}0.03 \mathrm{dpm} \\
0.03 \mathrm{dpm} \\
0.03 \mathrm{dpm} \\
0.03 \mathrm{dpm} \\
0.2 \mu \mathrm{g} \\
0.2 \mathrm{dpm}\end{array}$ & $\begin{array}{l}0.015 \mathrm{dpm}(A) \\
0.15 \mathrm{dpm}(A)(f) \\
0.015 \mathrm{dpm}(A)(f) \\
0.015 \mathrm{dpm}(A) \\
0.2 \mu g(A)(f) \\
2.0 \mathrm{dpm}(A)\end{array}$ \\
\hline PNL-ACL & Tritium & $10 \mathrm{dpm} / \mathrm{mL}$ & $80 \mathrm{dpm} / \mathrm{mL}(\mathrm{M})$ \\
\hline WHC 222-S & $\begin{array}{l}\text { Elemental uranium (quick } \\
\text { analys is procedure, [QUS]) }\end{array}$ & $0.5 \mu \mathrm{g}$ & $\begin{array}{l}11 \mu g(B W) \\
\text { or } 4 \mu g(M)\end{array}$ \\
\hline
\end{tabular}

(a) UST = United States Testing Company, Inc. LANL = Los Alamos National Laboratory

TMA/Norcal = Thermal Analytical Inc . ITAS-RI = International Technology Analytical Services

PNL-ACL = Hanford Analytical Chemistry Laboratory operated by PNL WHC = Westinghouse Hanford Company

(b) Analysis of urine samples unless otherwise indicated.

(c) Specified minimum detectable activity (MDA) based on Type I and Type II errors of $5 \%$ as described in the respective statements of work for each laboratory. (A copy of each statement of work is available in the Hanford Radiation Protection Historical Files.)

(d) Amount per total sample volume unless otherwise indicated.

(e) Investigation of a potential internal exposure is performed when this value is exceeded. Routine bioassay monitoring frequency: A-annual, BE-biennial, BW-biweekly, M-monthly, Q-quarterly.

(f) Upper level of expected environmentally derived uranium in urine for the Hanford region. 


\subsubsection{Sample Collection and Shipment}

The termination of the UST contract also left the Hanford Site without bioassay sample kits and mechanisms to collect the samples. Part of the program rebuilding involved designing and procuring sample kits and establishing methods to deliver and retrieve kits. Because the majority of bioassay samples collected during the interim period would require storage prior to shipment to offsite analytical laboratories, IDP investigated the suitability of several containers based on integrity (leakproofness), availability, and cost. The Nalgene 1-L, wide-mouth, high-density polyethylene bottle was judged the only suitable container of those tested. The first of weekly shipments of the bottles to Hanford began in late June. Prior to the receipt of weatherized cardboard totes (put into service August 13, 1990), the sample bottles were delivered in opaque white polyethylene drawstring bags. A Nalgene 250-mL bottle available through Hanford Central Stores was found to be suitable for tritium sampling.

Sample preservation prior to analysis was limited to refrigeration (for tritium) or freezing (all other analyses) of unacidified samples, due to the limitations on shipment of acidified samples plus restrictions on added chemicals compatible with subsequent separations chemistries. A freezer trailer was leased and located just south of the In Vivo Radioassay and Research Facility (IVRRF) for storage of most samples. The tritium samples were stored in two standard refrigerators purchased and situated at the Emergency Decontamination Facility.

Collection of bioassay samples was reinstated in a stepwise fashion. Due to the loss of the capability to have sequential analyses on a single sample, workers were subjected to multiple sampling requests according to the number of nuclide analyses required. Termination bioassay collection was uninterrupted for all contractors, although the workers were requested to bring their samples to IVRRF at the time of their exit in vivo exam, during the period when home delivery of sample kits was not in place. Monthly sampling of workers potentially exposed to soluble uranium was essentially uninterrupted, since collection resumed June 17, 1990, with onsite kit delivery and return provided by WHC for their own personnel. Tritium sample collection was resumed June 15, 1990, for WHC, July 1, 1990, for PNL, and July 9, 1990, for KEH, via single voiding samples collected at IVRRF. Routine 
sample collection for WHC and KEH began July 16, 1990, with onsite kit delivery and return. Samples so collected were transported to the freezer trailer for storage prior to shipment for analysis.

Home delivery of sample kits was subcontracted to United States Dosimetry Technology (USDT), a local small business, after competitive bidding. The service began with a few local deliveries the week of September 9, 1990. Resumption of PNL routine sampling occurred September 17, 1990, concurrent with the full-scale resumption of home deliveries for routine requests for all Hanford contractors.

Actual sample kit deliveries fell behind the routine schedule in the Occupational Radiation Exposure (ORE) System for all contractors, because the samples lost due to contract severance and those nomally scheduled during the interim between active bioassay collection programs for each contractor had to be recovered. In addition, the collection schedule slipped a few weeks while USDT was brought up to speed. WHC and KEH schedules recovered to within 1 month of the actual routine schedule by September; PNL schedules reached the same status in December. By year-end, actual collections were only slightly behind the ORE schedule.

As a result of the continued sample collection in the months between the UST contract termination and commencement of interim laboratory analyses, a substantial backlog of samples accumulated in the freezer trailer. The time required to work off this sample backlog is not clear but will include a substantial part of 1991 .

In addition to home delivery and pickup of sample kits, USDT delivered the samples to WHC (222-S Laboratory), ACL, or ITAS-RI for local analysis. Samples for out-of-town analysis were packaged by USDT and shipped directly to the laboratories via overnight air express carrier.

Table 2.3 shows, for each interim laboratory, the date performance test samples were provided, the date first worker samples were submitted, the total number of worker samples submitted through December 31, 1990, and the valid results received as of December 31, 1990. 
TABLE 2.3. 1990 Interim Bioassay Laboratory Activities

\begin{tabular}{|c|c|c|c|c|}
\hline Laboratory & $\begin{array}{l}\text { Performance } \\
\text { Test Samples } \\
\text { Submitted } \\
\end{array}$ & $\begin{array}{c}\text { First Worker } \\
\text { Samples } \\
\text { Submitted } \\
\end{array}$ & $\begin{array}{c}\text { Status a } \\
\text { Total Samples } \\
\text { Shipped } \\
\end{array}$ & $\begin{array}{l}\text { f } 12 / 31 / 90 \\
\text { Valid Results } \\
\text { Received } \\
\end{array}$ \\
\hline LANL & $9 / 6 / 90$ & $9 / 20 / 90$ & 1,184 & 148 \\
\hline TMA/Norcal & $10 / 10 / 90$ & $11 / 9 / 90$ & 300 & 94 \\
\hline ITAS-RI & $12 / 6 / 90$ & Pending & none & none \\
\hline PNL-ACL & $10 / 10 / 90$ & $10 / 29 / 90$ & 130 & 90 \\
\hline \multirow[t]{2}{*}{ HHC 222-S } & $9 / 28 / 90$ & $10 / 24 / 90$ & 119 & 48 \\
\hline & Total for & 11 Laboratori & 1,733 & 380 \\
\hline
\end{tabular}

\subsubsection{Sample Analysis}

Variations from the UST analytical procedures resulted from the use of the interim laboratories. These variations reflected the independent laboratories' respective procedures, and the need to analyze samples that had been preserved by freezing or refrigerated storage. Significant variations are briefly described below.

The elemental uranium procedures of both ITAS-RI and the 222-S Laboratory used laser phosphorimetry instead of the fluorimetry procedure used by UST. In addition, some differences in the aliquoting and preparation chemistry also existed.

The radiostrontium procedure of TMA/Norcal involved chemical separation of yttrium followed by counting the yttrium, rather than counting the strontium, as had been done by UST. Aliquoting of radiostrontium samples for analysis was under investigation at year-end, as a possible method for increasing laboratory throughput.

Sample age and storage conditions had an initial detrimental effect on a few of the analytical schemes; the detrimental effects were surmounted by minor procedural adjustments. Frozen urine samples for uranium analys is required stronger acidification. Uranium sorption onto container walls required a highly acidic rinse of the original container before diluting the acid rinse with the major sample volume. When partially thawed samples were inadvertently analyzed using the liquid portion only, significant plutonium 
fractionation was observed; i.e., less plutonium was contained in the thawed liquid than in the frozen portion and sediments. However, when complete samples were analyzed, no difference was observed between results from a frozen and unfrozen split sample containing actual metabolized plutonium. Hence, aliquots of plutonium samples were not taken. Highly colored urine samples caused marked quenching during liquid scintillation counting for tritium. The quenching was greatly reduced by first passing the sample through a charcoal column.

\subsubsection{Adjustments to the Blind Audit Program}

The IDP has historically monitored the analytical services laboratory through the use of spiked and blank samples. These samples are termed "open" when the identity as a $Q C$ sample but not the concentration is revealed to the laboratory, and "blind" if both sample identity and spike concentration are hidden from the laboratory. During the interim period, the number and types of $Q C$ audit samples were enhanced to provide the necessary surveillance over the participating laboratories. Each laboratory processing routine samples received a set of nine open $Q C$ samples covering the nuclide(s) and concentrations of interest for demonstration of performance capability prior to commencement of worker sample analysis. Blind audit samples at varying concentrations were then regularly submitted as normal worker samples, to help assess laboratory performance. In addition, four specially prepared open audit samples were provided to TMA/Norcal for verification of the ${ }^{90} \mathrm{Sr}$ sample aliquot process. As of December 31, 1990, the numbers and types of blind samples distributed throughout collected worker samples were: 25 plutonium, $5{ }^{241} \mathrm{Am}, 17{ }^{90} \mathrm{Sr}, 23$ quick U, 9 UNAT, 9 isotopic U, and 15 tritium.

The blind audit program was instrumental in early detection of a deviation from procedure in the isotopic plutonium (IPU) analysis, which resulted in the loss of 38 worker samples. Without the blind audit program, the deviation could have been very difficult to detect, and many more samples could have been compromised. Unfortunately, because backlogged samples of higher priority had been submitted for plutonium analysis first, 11 incident or investigate-high-routine samples were lost, which had a detrimental effect on evaluations in progress at that time. In addition, 14 termination samples were lost, requiring additional notification, via an amendment to the workers' termination letters, of lack of a valid sample. 
A blind audit sample was also used as confirmatory identification evidence when a question arose whether a single sample in a batch, or the entire batch was switched with a concurrently processed batch for plutonium analysis. Blind audit samples also served to alert Internal Dosimetry of an apparent high bias in tritium results, and an increase in the blank value potentially causing the laboratory to be unable to meet the contractual minimum detectable activities (MDAs).

\subsubsection{The BioNasty Computer Code}

As part of the solution to maintaining the Internal Dosimetry routine excreta program during the interim period, a computer code, BioNasty, was developed. BioNasty was written for the personal computer (PC) using Paradox 3.0 and SmarTerm 240 along with various $C$ language routines. With the loss of the permanent laboratory, the well-defined data transfer capabilities were also lost. The purpose of BioNasty was to supply the data transfer capabilities as well as provide additional needed capabilities for monitoring and tracking bioassay excretion requests and results. BioNasty receives the sample requests from the ORE system, then sends the needed information to both the people responsible for delivering the samples and the laboratory that will do the processing. Returning results are loaded into BioNasty, converted to be ORE compatible, and then uploaded to the ORE system. Many queries and reports were created to meet specific needs of BioNasty.

\subsection{ROUTINE INTERNAL DOSIMETRY PROGRAM}

Changes to the excreta bioassay program, including old and interim MDAs and follow-up levels, were given in Table 1.2 of the preceding subsection. The in vivo bioassay program was more stable during 1990. The MDAs and follow-up levels for in vivo measurements are listed in Table 2.4. Some changes of note are:

- All measurement results indicating activity above natural background were reported by the IVRRF staff to Internal Dosimetry regardless of magnitude; that is, the reporting level became anything detected above background as opposed to the follow-up levels listed in previous reports. Internal Dosimetry staff determine whether or not additional counts are necessary. 
TABLE 2.4. Minimum Detectable Activities and Follow-Up Levels for Routine In Vivo Measurements During 1990

\begin{tabular}{|c|c|c|}
\hline Measurement/Radionuclide ${ }^{(a)}$ & MDA, $\mathrm{nCi}$ & Follow-Up Leve? \\
\hline \multicolumn{3}{|l|}{ Whole Body Count ${ }^{(c)}$} \\
\hline $\begin{array}{r}54 \mathrm{Mn} \\
59 \mathrm{Fe} \\
60 \mathrm{Co} \\
154 \mathrm{Eu} \\
137 \mathrm{Cs}\end{array}$ & $\begin{array}{l}3 \\
6 \\
3 \\
4.5 \\
3\end{array}$ & $\begin{array}{l}\text { Any detected } \\
\text { Any detected } \\
8 \mathrm{nCi} \\
8 \mathrm{nCi} \\
9 \mathrm{nCi}\end{array}$ \\
\hline \multicolumn{3}{|l|}{ Lung Count } \\
\hline $\begin{array}{l}144 \mathrm{Ce}^{(d)} \\
154 \mathrm{Eu}^{(d)} \\
155 \mathrm{Eu}^{(d)} \\
232 \mathrm{Th}^{\mathrm{T}} \\
235 \mathrm{U} \\
238 \mathrm{U}\left({ }^{234} \mathrm{Th}\right) \\
241_{\mathrm{Am}}\end{array}$ & $\begin{array}{l}0.4 \\
0.05 \\
0.12 \\
0.4 \\
0.08 \\
1.2 \\
0.12\end{array}$ & $\begin{array}{l}\text { Any detected } \\
8 \mathrm{nCi} \\
4 \mathrm{nCi} \\
\text { Any detected } \\
\text { Any detected } \\
\text { Any detected } \\
\text { Any detected }\end{array}$ \\
\hline
\end{tabular}

(a) For selected radionuclides. Detection of radionuclides not listed resulted in follow-up.

(b) Level for which an investigation of internal exposure was considered. Any detected activity above background was reported to Internal Dosimetry.

(c) MDAs apply to the preview counter only; much lower MDAs were obtained using the gemanium array when activity was first detected using the preview counter.

(d) Beginning in the fourth quarter, these radionuclides were no longer considered part of the routine chest count.

- If activity is detected in a screening count on the preview counter, the individual changes clothes and is given a second count on the preview counter. If activity is still detected, the individual is given a 20-minute count using the array of germanium detectors in the Palmer Room. This count has a lower MDA and is not subject to interference from radon progeny. The results of this count are considered final. Activity detected from the germanium count is considered confirmed without additional counts because it has already been detected during the preview counter counts.

- ${ }^{154} \mathrm{Eu}$ and ${ }^{144} \mathrm{Ce}$ were removed as automatically determined radionuclides for chest counting. Historically they had been included because the preview counter did not adequately quantify these radionuclides. However, this function was taken over by whole body counting using the germanium detector array in the IVRRF Palmer Room. The purpose of removing them from routine chest counting is 
to eliminate false positive detections, which necessitates workers taking another long chest count.

Intakes of radionuclides are generally prevented by containment or other protective measures. Internal exposures principally and infrequentiy occur as a result of the failure of a protective system. Exceptions to this are lowlevel chronic exposure conditions that exist for depleted and low-enrichment uranium in the 306-W Specialty Machine Shop, the Uranium Oxide Plant, and the $N$ Reactor Fuel Production Facility; and for tritium in several laboratories. In these facilities, internal exposures are controlled through engineered and administrative measures; however, because complete containment cannot always be ensured, chronic low-level exposures are assumed to occur. As a result of a routine fecal sampling program started in 1988, frequent low-level intakes of plutonium were also discovered at the Plutonium Finishing Plant (PFP). Unlike the uranium facilities, the PFP is designed for containment of the plutonium; however, residual levels of airborne plutonium on the order of a few percent of the derived air concentration were measured in 1988 (Lyon et a 1. 1989).

Assessments of internal dose are performed for intakes according to practices established in the Hanford Internal Dosimetry Program. Manual. (a) To summarize, assessment of potential internal exposure is conducted for:

- any potential occupational intake reported to Internal Dosimetry by site radiation protection organizations

- any "new hire" or "beginning work" bioassay measurement that indicates any detectable intake not previously evaluated

- any routine bioassay measurement that indicates a potential occupational internal exposure, not previously evaluated, resulting in an annual internal effective dose equivalent greater than 10 mrem

- any employee, hired by DOE-RL or a Hanford Site contractor, who has incurred an offsite occupational internal exposure. (If information about the intake recejved from the facility where the intake occurred meets the recording and reporting requirements of DOE 5480.11 [OOE 1988], then that information may be accepted in lieu of a local assessment.)

(a) Pacific Northwest Laboratory (PNL). Hanford Internal Dosimetry Program Manual. PNL-MA-572, Richland, Washington. (internal manual) 
The internal dose assessment practice that was implemented in 1990 was clarified as follows:

Hanford visitors who receive "visitor" or "beginning work" bioassay measurements that detect radioactivity, or "ending work" measurements that are consistent with their beginning work measurements will not have their prior occupational dose assessed by Internal Dosimetry unless specifically requested to do so by the site contractor requesting the measurements.

This practice resulted from the fact that the responsibility for the dose assessment lies with the visitor's employer not the Hanford Site contractor and that Internal Dosimetry is unlikely to have adequate knowledge of the visitor's past intake circumstances to do reasonable internal dosimetry.

Internal dose assessments are performed using biokinetic models to interpret bioassay measurements. The standardized biokinetic models used are listed in Table 2.5, and documentation of the models and other technical bases for assessments is provided in the Technical Basis for Internal Dosimetry at Hanford (Sula, Carbaugh, and Bihl 1989). Dose conversion factors are consistent with the specific effective energy (SEE) values in Internationa] Commission on Radiological Protection (ICRP) Publication 30 (1979). The biokinetic models are implemented using the computer codes GENMOD Version 3.0 (Johnson and Carver 1981) and PUCALC Version 2.2.(a,b)

Bioassay measurement results are maintained in the ORE database, and laboratory analytical procedures are documented via the Whole Body Counting Manual, (c) in UST's Procedures for Contract 005145-A-M1, (d) and in individual copies of procedures from the interim laboratories, which were placed in the

(a) May, R. A. 1986. Plutonium Deposition Calculation from Urine Samples, Version 2.0. Copy available in the Hanford Radiation Protection Historical files, Pacific Northwest Laboratory, Richland, Washington.

(b) May, R. A. 1988. "Update of PUCALC from 2.1 to 2.2." Letter to Distribution, dated June 16, 1988. Copy available in the Hanford Radiation Protection Historical Files, Pacific Northwest Laboratory, Richland, Washington.

(c) Pacific Northwest Laboratory (PNL). Whole Body Counting Manual. PNL-MA-574, Richland, Washington. (internal manual)

(d) United States Testing Company, Inc. 1989. Procedures for Contract $005145-A-M 1$. Richland, Washington. Copies available in the Hanford Radiation Protection Historical Files, Pacific Northwest Laboratory, Richland, Washington. 
TABLE 2.5. Models Used to Interpret Bioassay Data During 1990

System

Respiratory tract

GI (b) tract

Pu urine excretion

Sr urine excretion

Other metabolic models
Model

TGLo(a) Model (ICRP 1979)

ICRP GI Tract Model (ICRP 1979)

Jones' Function (Jones 1985)

ICRP Alkaline Earth Model (ICRP 1973, 1979)

ICRP $30(1979)$

(a) TGLD = Task Group on Lung Dynamics.

(b) GI = gastrointestinal.

Hanford Radiation Protection Historical Files. Individual assessments of internal dose are documented in each individual's record in the Hanford Radiological Records Program microfilm files.

\subsubsection{Routine Fecal Program Terminated}

The routine fecal program has been described in previous reports (Lyon et al. 1989; Lyon et al. 1990). The program operated normally until the default of the contract with UST occurred on June 1, 1990. Samples collected in May were never analyzed. In September, before an interim contract could be put in place for routine analysis of fecal samples, the WHC dosimetry organization terminated the program. (a) This was done because WHC facilities were no longer processing material that could be classified as freshly separated, super class $Y$ plutonium. The fecal program had been originally developed because workers were at risk for intakes of that material. Internal dose determination was made for workers in the progran at the start of the year, assuming chronic exposure for January through September 1990, based on fecal sample results obtained from December 1989 through April 1990.

\subsubsection{Computer Code, GENCOMP}

A new code for use on PCS was written to help with the dose calculations resulting from the routine fecal program. The code is called The General

(a) Memo dated September 12, 1990. W. A. Decker, WHC, to D. E. Bihl, PNL. "Resumption of Fecal Sample Program." Copy available in the Hanford Radiation Protection Historical Files, Pacific Northwest Laboratory, Richland, Washington. 
Compartment Modeler, with the acronym GENCOMP. (a) It uses a stiff numerical algorithm to solve for a system of first order, catenary, differential equations, applicable for determining activities or amounts in a series of compartments with first order transfer characteristics. (For instance, the ICRP 30 GI tract model.) The key difference between this code and, say, GENMOD, is that it has a wide variety of options for input to the first compartment. For instance, it can accommodate a repeating pattern of $x$ days of input followed by $y$ days of no input, which more closely simulates chronic intake conditions by workers. Also, activities or amounts in each compartment can be calculated for any time during the period of intake or after intakes have stopped. GENCOMP was used to determine daily intake from annual fecal sample results assuming chronic inhalation exposure for 5 days/week for 1 year, followed by 3 days of no intake prior to excretion. GENCOMP was used to determine daily intake as part of internal dose calculations for the routine fecal program for both 1989 and 1990 doses.

\subsection{MONITORING AND ASSESSMENT ACTIVITIES}

During 1990, 18,469 in vivo and excreta bioassay measurements were scheduled in support of Hanford activities, excluding cancellations, nosamples, and samples without valid results. Of these, 97\% were classified as routine (including measurements on visitors), with $1 \%$ due to potential or confirmed intake follow-up measurements, and $2 \%$ classified as special purpose measurements.

Because of the severance of the analytical services contract on June 1 , 1990 , the excreta bioassay portion of the monitoring program suffered significant disruption. Table 2.6 summarizes the types and numbers of urine and fecal bioassays actually completed and reported for samples collected between January 1, 1990, and May 31, 1990. The contract severance resulted in the lost-in-laboratory designation of an additional 736 analyses, of which 53\% were for plutonium, $40 \%$ were for ${ }^{90} \mathrm{Sr}$, and the remainder were for uranium,

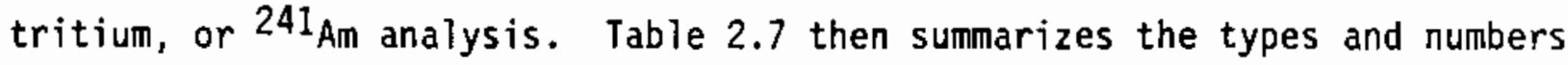

(a) May, R. A. 1990. "User Documentation for the General Compartment Modeler, Version 1.0." Copy available in the Hanford Radiation Protection Historical Files, Pacific Northwest Laboratory, Richland, Washington. 
TABLE 2.6. Excreta Measurements for Samples Requested during January-May, 1990, under the Analytical Seryices Contract with UST, and Recorded in the ORE Database $(a)$

\begin{tabular}{|c|c|c|c|c|c|}
\hline Type/Reason & $\underline{D O E}$ & KEH & PNL & WHC & TOTAL \\
\hline $\begin{array}{l}{ }^{3} \mathrm{H} \text {-urine } \\
\text { Routine schedule } \\
\text { Special request } \\
\text { Intake follow-up }\end{array}$ & $\begin{array}{l}0 \\
0 \\
0\end{array}$ & $\begin{array}{l}0 \\
0 \\
0\end{array}$ & $\begin{array}{r}53 \\
0 \\
4\end{array}$ & $\begin{array}{r}110 \\
0 \\
0\end{array}$ & $\begin{array}{r}163 \\
0 \\
4\end{array}$ \\
\hline $\begin{array}{l}{ }^{90} \text { Sr-urine } \\
\text { Routine schedule } \\
\text { Special request } \\
\text { Intake fol low-up }\end{array}$ & $\begin{array}{l}0 \\
0 \\
0\end{array}$ & $\begin{array}{r}81 \\
0 \\
0\end{array}$ & $\begin{array}{l}2 \\
1 \\
0\end{array}$ & $\begin{array}{r}431 \\
40 \\
5\end{array}$ & $\begin{array}{r}514 \\
41 \\
5\end{array}$ \\
\hline $\begin{array}{l}\text { Uranium-urine } \\
\text { Routine schedule } \\
\text { Special request } \\
\text { Intake follow-up }\end{array}$ & $\begin{array}{l}0 \\
0 \\
0\end{array}$ & $\begin{array}{r}26 \\
0 \\
0\end{array}$ & $\begin{array}{r}50 \\
12 \\
2\end{array}$ & $\begin{array}{r}240 \\
3 \\
8\end{array}$ & $\begin{array}{r}316 \\
15 \\
10\end{array}$ \\
\hline $\begin{array}{l}\text { Plutonium (b)-urine } \\
\text { Routine schedule } \\
\text { Special request } \\
\text { Intake follow-up }\end{array}$ & $\begin{array}{l}0 \\
0 \\
0\end{array}$ & $\begin{array}{r}74 \\
0 \\
2\end{array}$ & $\begin{array}{r}92 \\
0 \\
4\end{array}$ & $\begin{array}{r}593 \\
39 \\
11\end{array}$ & $\begin{array}{r}759 \\
39 \\
17\end{array}$ \\
\hline $\begin{array}{l}\text { Other TRU }(\mathrm{c}) \text {-urine } \\
\text { Routine schedule } \\
\text { Special request } \\
\text { Intake follow-up }\end{array}$ & $\begin{array}{l}0 \\
0 \\
0\end{array}$ & $\begin{array}{l}1 \\
0 \\
0\end{array}$ & $\begin{array}{l}2 \\
0 \\
3\end{array}$ & $\begin{array}{l}5 \\
0 \\
3\end{array}$ & $\begin{array}{l}8 \\
0 \\
6\end{array}$ \\
\hline $\begin{array}{l}\text { Plutonium-fecal } \\
\text { Rout ine schedule } \\
\text { Special request } \\
\text { Intake follow-up }\end{array}$ & $\begin{array}{l}0 \\
0 \\
0\end{array}$ & $\begin{array}{l}0 \\
0 \\
0\end{array}$ & $\begin{array}{l}0 \\
3 \\
0\end{array}$ & $\begin{array}{r}35 \\
40 \\
1\end{array}$ & $\begin{array}{r}35 \\
43 \\
1\end{array}$ \\
\hline $\begin{array}{l}{ }^{90} \mathrm{Sr}-\text { fecal } \\
\text { Routine schedule } \\
\text { Special request } \\
\text { Intake follow-up }\end{array}$ & $\begin{array}{l}0 \\
0 \\
0\end{array}$ & $\begin{array}{l}0 \\
0 \\
0\end{array}$ & $\begin{array}{l}0 \\
3 \\
0\end{array}$ & $\begin{array}{l}0 \\
0 \\
0\end{array}$ & $\begin{array}{l}0 \\
3 \\
0\end{array}$ \\
\hline ANALYSES TOTALS & 0 & 184 & 231 & 1564 & 1979 \\
\hline $\begin{array}{l}\text { Recounts }(d) \\
\text { Plutonium - urine }\end{array}$ & 0 & 0 & 1 & 6 & 7 \\
\hline
\end{tabular}

(a) Does not include requests for which there were no results due to any of the following: cancellation (CS), no sample recovered (NS), lost container (LC), insufficient volume (IS), iost-in-laboratory (LL).

(b) Plutonium-238 and ${ }^{239} \mathrm{Pu}$.

(c) Other transuranic (TRU) elements include ${ }^{241} \mathrm{Na},{ }^{242} \mathrm{Am},{ }^{242} \mathrm{Cm}$, and ${ }^{244} \mathrm{Cm}$.

(d) Plutonium recounts are routinely requested when a urinalys is result falls between 0.01 and $0.02 \mathrm{dpm} / \mathrm{spl}$ for either ${ }^{238} \mathrm{Pu}$ or ${ }^{239} \mathrm{Pu}$. The contractual detection levei is $0.02 \mathrm{dpm} / \mathrm{spl}$. 
TABLE 2.7. Excreta Measurements for Samples Requested during June-December, 1990, Between Long-Term Contracts for Analytical Services(a)

\begin{tabular}{|c|c|c|c|c|c|}
\hline Type/Reason & $\underline{D O E}$ & $\underline{\text { KEH }}$ & $\underline{P N L}$ & WHC & TOTAL \\
\hline $\begin{array}{l}{ }^{3} \mathrm{H} \text {-urine } \\
\quad \text { Routine schedule } \\
\text { Special request } \\
\text { Intake follow-up }\end{array}$ & $\begin{array}{l}0 \\
0 \\
0\end{array}$ & $\begin{array}{l}9 \\
2 \\
0\end{array}$ & $\begin{array}{r}76 \\
0 \\
0\end{array}$ & $\begin{array}{r}68 \\
0 \\
0\end{array}$ & $\begin{array}{r}153 \\
2 \\
0\end{array}$ \\
\hline $\begin{array}{l}{ }^{90} \text { Sr-urine } \\
\text { Routine schedule } \\
\text { Special request } \\
\text { Intake follow-up }\end{array}$ & $\begin{array}{r}12 \\
0 \\
0\end{array}$ & $\begin{array}{r}171 \\
0 \\
0\end{array}$ & $\begin{array}{l}7 \\
0 \\
0\end{array}$ & $\begin{array}{r}700 \\
0 \\
1\end{array}$ & $\begin{array}{r}890 \\
0 \\
1\end{array}$ \\
\hline $\begin{array}{l}\text { Uranium-urine } \\
\text { Rout ine schedule } \\
\text { Special request } \\
\text { Intake follow-up }\end{array}$ & $\begin{array}{l}0 \\
0 \\
0\end{array}$ & $\begin{array}{r}36 \\
0 \\
0\end{array}$ & $\begin{array}{r}112 \\
0 \\
0\end{array}$ & $\begin{array}{r}319 \\
55 \\
6\end{array}$ & $\begin{array}{r}467 \\
55 \\
6\end{array}$ \\
\hline $\begin{array}{l}\text { Plutonium-urine } \\
\text { Routine schedule } \\
\text { Special request } \\
\text { Intake follow-up (b) }\end{array}$ & $\begin{array}{r}13 \\
0 \\
0\end{array}$ & $\begin{array}{r}243 \\
52 \\
0\end{array}$ & $\begin{array}{r}130 \\
2 \\
2\end{array}$ & $\begin{array}{r}1050 \\
3 \\
15\end{array}$ & $\begin{array}{r}1436 \\
57 \\
17\end{array}$ \\
\hline $\begin{array}{l}\text { Other TRU-urine } \\
\text { Routine schedule } \\
\text { Special request } \\
\text { Intake follow-up }\end{array}$ & $\begin{array}{l}0 \\
0 \\
0\end{array}$ & $\begin{array}{l}1 \\
0 \\
0\end{array}$ & $\begin{array}{r}15 \\
0 \\
0\end{array}$ & $\begin{array}{l}4 \\
0 \\
0\end{array}$ & $\begin{array}{r}20 \\
0 \\
0\end{array}$ \\
\hline ANALYSES TOTALS & 25 & 514 & 344 & 2221 & 3104 \\
\hline $\begin{array}{l}\text { Recounts } \\
\text { Plutonium - urine }\end{array}$ & 1 & 4 & 2 & 13 & 20 \\
\hline
\end{tabular}

(a) Due to backlog of requested analyses, the results were not actually in the ORE database as of December 31, 1990. This table does not include requests for which there were no results as of December 31,1991 , due to any of the following: cancellation (CS), no sample recovered (NS), lost container (LC), insufficient volume (IS), lost-in-laboratory (LL).

(b) Stated values exclude the $2 \mathrm{KEH}$ and 9 WHC incident or investigate-highroutine samples that were lost in the laboratory due to a procedural deviation early in the program. 
of urine bioassays collected between June 1, 1990, and December 31, 1990. Of the samples collected (as tabulated in Table 2.7), 1,733 had been sent to laboratories for analysis and 380 valid results were received by the end of 1990, as shown in Table 2.2 earlier in this report. No fecal samples were scheduled during that interval. The sumnary data found in Table 2.8 results from the simple summation of data in Tables 2.6 and 2.7 .

In vivo measurements made in 1990 are summarized in Table 2.9. Not included in these figures are the 133 whole body and 10 chest measurements that were declared invalid due to radon interference (57\%), preliminary count designation (22\%), equipment failure (10\%), medically administered nuclide presence $(2 \%)$, external contamination $(<2 \%)$, and other miscellaneous reasons $(4 \%)$.

The demand for bioassay measurements continues to increase. Overall, the total number of measurements increased nearly $16 \%$ over last year, almost entirely due to the increase in in vivo measurements. Routine urine measurements increased less than 1\% from 1989 (Figure 2.1) compared with CY 1989 figures, the latter adjusted from the last annual report by the additional $11{ }^{90} \mathrm{Sr}$ and 72 TRU analyses completed successfully, which were outstanding at the time of that report. The 1990 figure does not reflect the increased number of unsuccessful sampling attempts (no-sample or lost containers), particularly during the time period when home delivery of kits was not available; for example, monthly samples for soluble uranium had an initial unsuccessful-sample rate of nearly 30\%. Overall, the unsuccessful-sample rate during the interim period averaged $19 \%$, compared with $10 \%$ for the period covered by the permanent analytical services contract. Routine in vivo measurements increased more than $21 \%$ from 1989 (Figure 2.2), including an increase in requested measurements on visitors from 290 in 1989 to 1,098 in 1990 .

Investigations of possible internal exposure to radionuclides are performed following an indication from a routinely scheduled bioassay measurement or for any potential exposure incident identified in the workplace. Potential exposure incidents are identified by workplace indicators such as air sampling, contamination surveys, nasal smears, or smears from potentially contaminated wounds. Special requests for bioassay measurements are also performed at the request of workers through the contractor dosimetry group. 
TABLE 2.8. Total Excreta Measurements Requested during CY 1990(a)

\begin{tabular}{|c|c|c|c|c|c|}
\hline Type/Reason & $\underline{\mathrm{DOE}}$ & KEH & PNL & $\underline{W H C}$ & TOTAL \\
\hline $\begin{array}{l}{ }^{3} \mathrm{H} \text {-urine } \\
\text { Routine schedule } \\
\text { Special request } \\
\text { Intake fol low-up }\end{array}$ & $\begin{array}{l}0 \\
0 \\
0\end{array}$ & $\begin{array}{l}9 \\
2 \\
0\end{array}$ & $\begin{array}{r}129 \\
0 \\
4\end{array}$ & $\begin{array}{r}178 \\
0 \\
0\end{array}$ & $\begin{array}{r}316 \\
2 \\
4\end{array}$ \\
\hline $\begin{array}{l}{ }^{90} \text { Sr-urine } \\
\text { Routine schedule } \\
\text { Special request } \\
\text { Intake follow-up }\end{array}$ & $\begin{array}{r}12 \\
0 \\
0\end{array}$ & $\begin{array}{r}252 \\
0 \\
0\end{array}$ & $\begin{array}{l}9 \\
1 \\
0\end{array}$ & $\begin{array}{r}1131 \\
40 \\
6\end{array}$ & $\begin{array}{r}1404 \\
41 \\
6\end{array}$ \\
\hline $\begin{array}{l}\text { Uranium-urine } \\
\text { Routine schedule } \\
\text { Special request } \\
\text { Intake follow-up }\end{array}$ & $\begin{array}{l}0 \\
0 \\
0\end{array}$ & $\begin{array}{r}62 \\
0 \\
0\end{array}$ & $\begin{array}{r}162 \\
12 \\
2\end{array}$ & $\begin{array}{r}559 \\
58 \\
14\end{array}$ & $\begin{array}{r}783 \\
70 \\
16\end{array}$ \\
\hline $\begin{array}{l}\text { Plutonium-urine } \\
\text { Routine schedule } \\
\text { Special request } \\
\text { Intake follow-up }\end{array}$ & $\begin{array}{r}13 \\
0 \\
0\end{array}$ & $\begin{array}{r}317 \\
52 \\
2\end{array}$ & $\begin{array}{r}222 \\
2 \\
6\end{array}$ & $\begin{array}{r}1643 \\
42 \\
26\end{array}$ & $\begin{array}{r}2195 \\
96 \\
34\end{array}$ \\
\hline $\begin{array}{l}\text { Other TRU-urine } \\
\text { Routine schedule } \\
\text { Special request } \\
\text { Intake follow-up }\end{array}$ & $\begin{array}{l}0 \\
0 \\
0\end{array}$ & $\begin{array}{l}2 \\
0 \\
0\end{array}$ & $\begin{array}{r}17 \\
0 \\
3\end{array}$ & $\begin{array}{l}9 \\
0 \\
3\end{array}$ & $\begin{array}{r}28 \\
0 \\
6\end{array}$ \\
\hline $\begin{array}{l}\text { Plutonium-fecal } \\
\text { Routine schedule } \\
\text { Special request } \\
\text { Intake follow-up }\end{array}$ & $\begin{array}{l}0 \\
0 \\
0\end{array}$ & $\begin{array}{l}0 \\
0 \\
0\end{array}$ & $\begin{array}{l}0 \\
3 \\
0\end{array}$ & $\begin{array}{r}35 \\
40 \\
1\end{array}$ & $\begin{array}{r}35 \\
43 \\
1\end{array}$ \\
\hline $\begin{array}{l}90 \text { Sr-fecal } \\
\text { Routine schedule } \\
\text { Special request } \\
\text { Intake follow-up }\end{array}$ & $\begin{array}{l}0 \\
0 \\
0\end{array}$ & $\begin{array}{l}0 \\
0 \\
0\end{array}$ & $\begin{array}{l}0 \\
3 \\
0\end{array}$ & $\begin{array}{l}0 \\
0 \\
0\end{array}$ & $\begin{array}{l}0 \\
3 \\
0\end{array}$ \\
\hline ANALYSES TOTALS & 25 & 698 & 575 & 3785 & 5083 \\
\hline $\begin{array}{l}\text { Recounts } \\
\text { Plutonium - urine }\end{array}$ & 1 & 4 & 3 & 19 & 27 \\
\hline
\end{tabular}

(a) Includes sum of Table 2.6 plus 2.7. See individual tables for restrictions. 
TABLE 2.9. In Vivo Measurements Performed during CY 1990 and Recorded in the ORE Database

\begin{tabular}{|c|c|c|c|c|c|}
\hline Type/Reason & $\underline{D O E}$ & KEH & $\underline{\operatorname{PNL}^{(a)}}$ & $\mathrm{WHC}^{(b)}$ & TOTAL \\
\hline \multicolumn{6}{|l|}{ Whole Body Count } \\
\hline $\begin{array}{l}\text { Routine schedule } \\
\text { Special request } \\
\text { Intake follow-up } \\
\text { Visitors }\end{array}$ & $\begin{array}{r}135 \\
0 \\
0 \\
285\end{array}$ & $\begin{array}{r}962 \\
13 \\
10 \\
0\end{array}$ & $\begin{array}{r}1333 \\
21 \\
10 \\
18\end{array}$ & $\begin{array}{r}7049 \\
16 \\
24 \\
793\end{array}$ & $\begin{array}{r}9479 \\
50 \\
44 \\
1096\end{array}$ \\
\hline Total & 420 & 985 & 1382 & 7883 & 10669 \\
\hline \multicolumn{6}{|l|}{ Chest Count } \\
\hline $\begin{array}{l}\text { Routine schedule } \\
\text { Special request } \\
\text { Intake follow-up } \\
\text { Visitors }\end{array}$ & $\begin{array}{l}3 \\
0 \\
0 \\
0\end{array}$ & $\begin{array}{r}456 \\
1 \\
5 \\
0\end{array}$ & $\begin{array}{r}304 \\
2 \\
11 \\
1\end{array}$ & $\begin{array}{r}1841 \\
1 \\
43 \\
1\end{array}$ & $\begin{array}{r}2604 \\
4 \\
59 \\
2\end{array}$ \\
\hline Total & 3 & 462 & 318 & 1886 & 2669 \\
\hline \multicolumn{6}{|l|}{ Special Counts } \\
\hline $\begin{array}{l}\text { Hand/wound } \\
\text { Head } \\
\text { Other (a) }\end{array}$ & $\begin{array}{l}0 \\
0 \\
0\end{array}$ & $\begin{array}{l}0 \\
0 \\
0\end{array}$ & $\begin{array}{l}0 \\
8 \\
7\end{array}$ & $\begin{array}{r}4 \\
20 \\
9\end{array}$ & $\begin{array}{r}4 \\
28 \\
16\end{array}$ \\
\hline Total & 0 & 0 & 15 & 33 & 48 \\
\hline
\end{tabular}

\footnotetext{
(a) Includes PNL and HEHF.

(b) Includes WHC, BCSR, and subcontractors such as General Telephone and Electronics. (c) Other counts would include any special organ count such as liver,
kidney, or thyroid.
} 


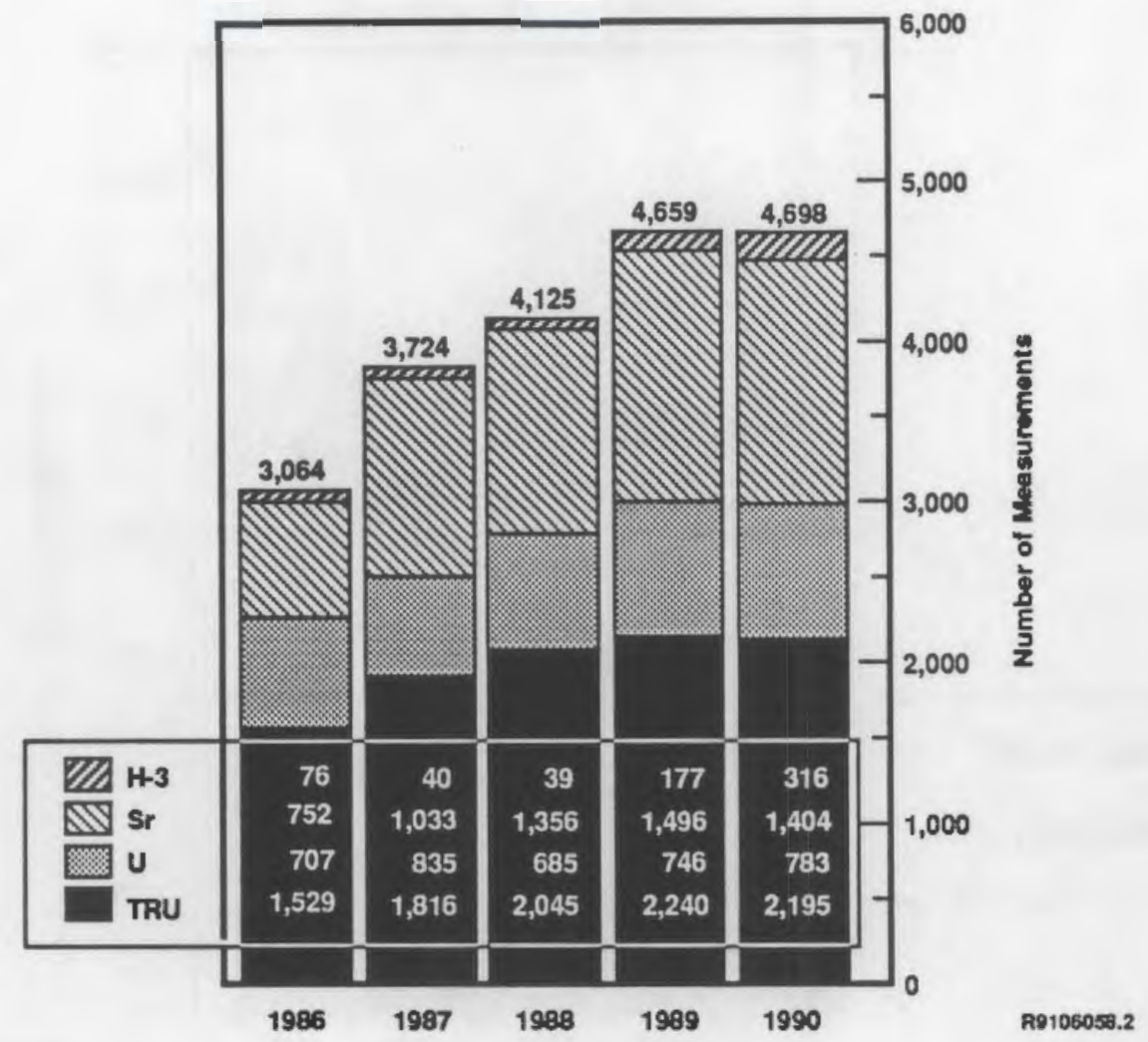

FIGURE 2.1. Routine Urine Measurements Made at the In Vivo Radioassay and Research Facility from 1986 through 1990

During 1990, 14 potential internal exposure incidents involving 29 workers were identified through workplace monitoring. Of these workers, no confirmation of intake was determined for 14 workers, intakes were confirmed for 8 workers, and evaluations are awaiting bioassay results for 7 workers. of the eight confirmed cases, only three cases involved internal dose assessments that exceeded a 50-year committed effective dose equivalent of $100 \mathrm{mrem}$. Nuclides involved were (number of incidents, number of workers involved): ${ }^{137} \mathrm{Cs}$ and or ${ }^{90} \mathrm{Sr}(8,15)$; $\operatorname{TRU}(2,7) ;{ }^{60} \mathrm{Co}$ and activation products $(2,2)$; $U(1,3)$; and ${ }^{24} \mathrm{Na}(1,2)$. Table 2.10 shows the incident breakdown by contractor and area. Annual trends for the last 5 years are included in Table 2.11. 


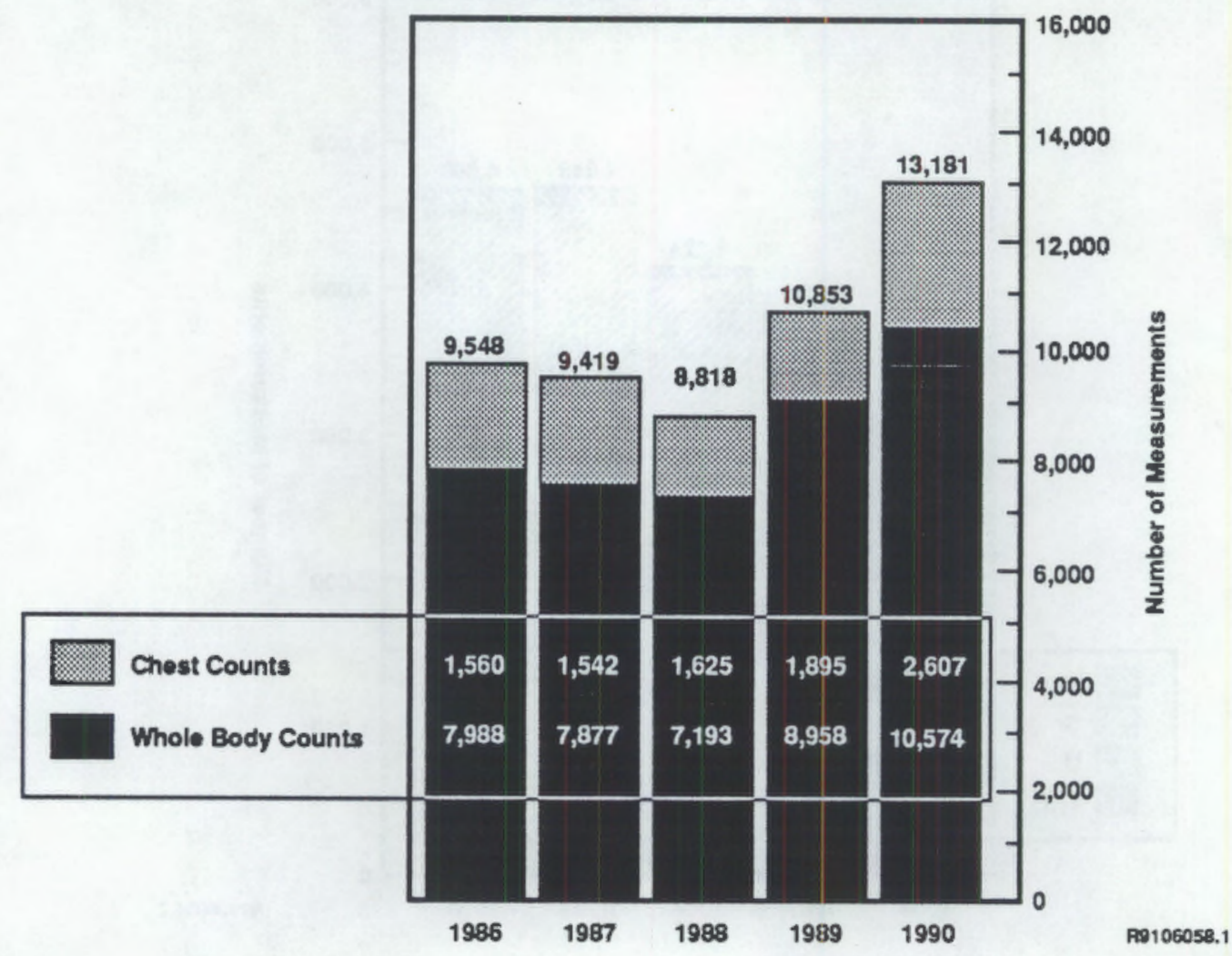

FIGURE 2.2. Routine In Vivo Measurements Made at the In Vivo Radioassay and and Research Facility from 1986 through 1990

TABLE 2.10. Summary of Potential Exposure Incidents During 1990

\begin{tabular}{|c|c|c|c|c|c|}
\hline Area & $\underline{D O E}$ & $\begin{array}{l}\text { Number } \\
\text { ndivi } \\
\text { KEH }\end{array}$ & $\begin{array}{l}\text { Incid } \\
\text { invo } \\
\text { PNL } \\
\end{array}$ & $\begin{array}{l}\text { (a) } \\
\text { WHC }\end{array}$ & Total \\
\hline $100-N$ & 0 & 0 & 0 & $3(4)$ & $3(4)$ \\
\hline 200-East & 0 & $0(2)$ & 0 & $3(4)$ & $3(6)$ \\
\hline 200-West & 0 & 0 & 0 & 0 & 0 \\
\hline 300 & 0 & $0(6)$ & $4(9)$ & $3(3)$ & $7(18)$ \\
\hline 400 & 0 & 0 & 0 & $1(1)$ & $1(1)$ \\
\hline Total & 0 & $0(8)$ & 4(9) & $10(12)$ & $14(29$ \\
\hline
\end{tabular}

(a) Number of incidents occurring in facilities under custodianship of the listed contractor. Number of workers is by worker employer. The employees listed are not necessarily involved in the incidents in that employer's facilities. 
Internal dose assessments in 1990 resulting from high routine bioassay results (i.e., those not associated with known incidents or potential chronic exposure situations, and exceeding the criteria for investigation) involved the following radionuclides or groups (and number of cases): TRU elements (28), ${ }^{137} \mathrm{Cs}$ and/or ${ }^{90} \mathrm{Sr}$ (14), uranium/thorium (49), and activation products (5). Of these cases, 2 have been held pending receipt of bioassay analytical results, 82 received no internal dose, 11 received 50 -year committed effective dose equivalents less than $100 \mathrm{mrem}$, and 1 received a 50 -year committed effective dose equivalent greater than $100 \mathrm{mrem}$.

Potential chronic intake cases evaluated involved tritium (1 case) and TRU elements (93 cases). Chronic intake assessments for an additional 82 workers potentially exposed to soluble uranium and 5 workers potentially exposed to tritium were not required because the sample results did not exceed the investigation level, defined as that result which could have indicated a potential first-year effective dose equivalent greater than $10 \mathrm{mrem}$, based on conservative assumptions. Analysis results on samples provided by workers potentially chronically exposed to natural uranium (16) or uranium of different enrichments (11) had not been completed by year's end; most likely not all of these 27 cases will require chronic intake assessments, based on the outstanding results. None of the completed chronic intake evaluations resulted in 50-year effective dose equivalents in excess of 100 mrem. Annual trends for the last 5 years are included in Table 2.11.

The internal dose status of the Hanford work force at the end of 1990 is summarized in Table 2.12. All past exposures received by current workers are included. Of the cases listed, 10 resulted in internal dose assessments of less than 100 mrem (comnitted effective dose equivalent) resulting from 1990 intakes; these doses were all assigned to the year of intake, in accordance with current Hanford practices for recording low doses. The number of cases exceeding $1 \%$ of the DOE RPS (DOE 198B) has decreased since last year by $12 \%$ to 56 . 
TABLE 2.11. Comparison of Internal Exposure Incidents and Internal Exposure Dose Assessments, 1986-1990

\begin{tabular}{|c|c|c|c|c|c|}
\hline & $\underline{1990}$ & 1989 & $\underline{1988}$ & $\underline{1987}$ & 1986 \\
\hline $\begin{array}{l}\text { Number of incidents } \\
\text { Number of workers }\end{array}$ & $\begin{array}{l}14 \\
29\end{array}$ & $\begin{array}{l}22 \\
33\end{array}$ & $\begin{array}{l}12 \\
25\end{array}$ & $\begin{array}{l}14 \\
20\end{array}$ & $\begin{array}{l}44 \\
63\end{array}$ \\
\hline Evaluations, total & $231(a, b)$ & $291^{(a)}$ & 80 & 173 & 196 \\
\hline Re-evaluations & 6 & 7 & 8 & 16 & 47 \\
\hline $\begin{array}{l}\text { New cases } \\
\text { Incidents }(c) \\
\text { Special requests } \\
\text { High routines } \\
\text { Chronic exposures (d) }\end{array}$ & $\begin{array}{r}225 \\
29 \\
1 \\
101 \\
94(\mathrm{~b})\end{array}$ & $\begin{array}{r}284 \\
33 \\
3 \\
51 \\
197\end{array}$ & $\begin{array}{r}72 \\
26 \\
8 \\
38\end{array}$ & $\begin{array}{r}157 \\
75 \\
31 \\
51\end{array}$ & $\begin{array}{r}149 \\
70 \\
4 \\
75\end{array}$ \\
\hline No dose $(e)$ & 96 & 77 & 22 & 147 & 3 \\
\hline
\end{tabular}

(a) Total includes all evaluations issued with an 1989 or 1990 identifier, plus re-evaluations indexed to the original evaluation numbers.

(b) Not included in this total are the potential uranium intake cases (27) for which analytical data have not been received, or the soluble uranium cases (82) and tritium cases (5) that were determined to be below the investigation level.

(c) Number reflects evaluations performed resulting from incidents in stated year or earlier.

(d) The number of cases listed for 1989 includes all workers who potentially experienced chronic exposures. For 1990 exposures, workers whose urinalyses did not exceed an investigation level were not evaluated.

(e) For 1986-1988, the cutoff for dose assessment was $1 \%$ of the radiation protection standard (RPS) or maximum permissible body burden (MPBB). Beginning in 1989, the screening level for dose assessment was an intake that could result in a dose of 10 mrem first-year effective dose equivalent. Consequently, the 1989 and 1990 totals reflect dose evaluations under more restrictive limits. 
TABLE 2.12. Internal Dose Status of Hanford Work Force at 1990 Year-End

\section{Percent} RPS(a)

$\underline{0} \frac{\text { Number of Workers }}{(b)}$

WHC Total

Acute Intake

$\begin{array}{cllccr}<1 & 1 & 1 & 15(1) & 18(1) & 35 \\ 1-<5(c) & 1(1) & 1 & 11 & 19(2) & 32 \\ 5-<10 & 0 & 2 & 2 & 6 & 10 \\ 10-<50 & 0 & 0 & 5 & 8 & 13 \\ 50-<100 & 1(1)(d) & 0 & 0 & 1 & 2 \\ >100 & 0 & 0 & 0 & 0 & 0\end{array}$

Chronic Intake

$\begin{array}{crrrrr}<1 & 0 & 0 & 1 & 93 & 94 \\ 1-<5(c) & 0 & 0 & 0 & 0 & 0 \\ \geq 5 & 0 & 0 & 0 & 0 & 0 \\ \text { Total } & 3 & 4 & 34 & 145 & 186\end{array}$

(a) Radiation protection standard (RPS) as stated in DOE 5480.11 (1988) $5 \mathrm{rem} / \mathrm{yr}$ effective dose equivalent.

(b) Numbers in parentheses refer to assessed doses due to offsite exposures.

(c) This table reflects the doses assigned to 1990. Beginning in 1989, a 50 -year committed effective equivalent dose of less than 100 mrem was attributed to the year of intake. For assessed doses in excess of $100 \mathrm{mrem}$, the dose table reflects the actual annual doses received in the year, instead of 50-year committed doses.

(d) Worker exceeds the DOE 5480.11 RPS for single organs and tissues of $50 \mathrm{rem} / \mathrm{yr}$, but does not exceed the RPS for effective dose equivalent. 


\subsection{PUBLICATIONS AND PRESENTATIONS}

The following publications and presentations were prepared by IDP staff during 1990.

\subsubsection{Publications}

Carbaugh, E. H., M. J. Sula, and K. M. McFadden. 1990. "Use of Probability Analysis to Establish Routine Bioassay Screening Levels." Published in the Proceedings of the 36th Annual Conference on Bioassay, Analytical, and Environmental Radiochemistry, October 23, 1990, 0ak Ridge, Tennessee.

\subsubsection{Presentations}

Carbaugh, E. H. 1990. "Evaluation of Plutonium Bioassay Monitoring Capabilities Relative to U.S. Department of Energy Performance Objectives." Presented at the Annual Health Physics Society Meeting, June 25-28, 1990, Anaheim, California.

Carbaugh, E. H. 1990. "Long-Term Follow-Up of HAN-1, An Acute Pu-Oxide Inhalation Case." Presented at the 3rd International Respiratory Tract Dosimetry Workshop, July 2, 1990, Albuquerque, New Mexico.

Carbaugh, E. H. 1990. "Use of Probability Analysis to Establish Routine Bioassay Screening Levels." Presented at the 36 th Annual Conference on Bioassay, Analytical, and Environmental Radiochemistry, October 23, 1990. Oak Ridge, Tennessee.

\subsection{PROGRAM-RELATED PROFESSIONAL ACTIVITIES}

Carbaugh, E. H.--Member of American National Standards Institute (ANSI) standard review committee N13.14, Standard for Minimum Requirements in Tritium Bioassay and Dosimetry.

Carbaugh, E. H.--Chairman American Society for Testing and Materials (ASTM) Comittee E.50.xx working group for developing a standard for dosimetry of transuranic-contaminated wounds. 


\subsection{HANFORD IN VIVO MEASUREMENT PROGRAM}

The In Vivo Measurement Program has been an integral part of personne] dosimetry at Hanford since 1959 to assist in detecting the deposition of radioactive materials in Hanford employees. Program requirements are outlined in the Hanford Site Services Handbook (DOE-RL 1991). The In Vivo Measurement Program provides for the management, operation, and maintenance of the in vivo counting facilities and equipment located in the $747 \mathrm{~A}$ Building, the $747 \mathrm{~A}$ Trailer, a mobile in vivo counting facility, and the Emergency Decontamination Facility (EDF). The routinely used measurement facilities are located at the 747A Building and include the preview counter (used for standup screening whole body measurements), the iron room and stainless steel room (each containing lung counting systems), and the Palmer Room (containing the coaxial germanium detector system). The Palmer Room was formerly known as the Utah Room. Operating hours are from 7:00 a.m. to 4:30 p.m. on weekdays. The facilities and equipment are also available during off-hours on an on-call basis. Data and results of measurements are transmitted to the Hanford Radiological Records Program (HRRP) database for permanent record. Daily operational and functional checks are performed on all routinely used counting systems, which are also periodically calibrated to ensure their accuracy. The staff participate in intercomparison programs to further improve the accuracy of operations. The activities of this program, including special studies and development work carried on during 1990, are described in the following subsections.

\subsection{ROUTINE PROGRAM}

Several types of routine in vivo measurements are made on personnel. The type of measurement made on each person is determined by the type of radioactive material to which a person is potentially exposed. Generally, if an employee does not work with TRU radionuclides, only a whole body count is performed to detect the higher-energy gamma rays emitted by fission or activated corrosion products. If the work involves IRU radionuclides, lung and whole body counts are done. If radioactivity is detected by either of these measurements, several other types of counts may be done to identify and quantify the activity in the body. 
The number and types of measurements made on personnel during 1990 are listed in Table 3.1. A total of 13,315 measurements were made for DOE-RL and the Hanford contractors in 1990, representing a 20\% increase over the number performed in 1989. Figure 3.1 graphically depicts the in vivo measurements made at the In Vivo Radioassay Research Facility (IVRRF, formerly known as the Whole Body Counting Facility) for the past 5 years. The 1990 total of 10,732 whole body counts is $18 \%$ higher than the same tally for 1989 . Lung counts for 1990 totaled 2,548, which is a $30 \%$ increase from 1989. Regulatory changes related to the determination of doses from internally deposited radioactive material are primarily responsible for the increased number of in vivo measurements.

Most of the routinely scheduled whole body exams that identified positive results this year were ultimately associated with either medically

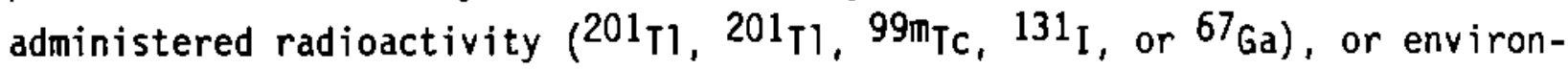
mentally derived ${ }^{137} \mathrm{Cs}$. Investigations of the ${ }^{137} \mathrm{Cs}$ results indicated that most workers having such results had not been associated with any off-normal working conditions and were regular consumers of wild game animals (notably deer, elk, and bear). Samples of meat from several of these animals were counted at the IVRRF and indicated that this was a possible source of lowlevel detectable ${ }^{137} \mathrm{Cs}$ in humans; however this was not an exhaustive study.

TABLE 3.1. Measurements Made on Hanford Personnel During FY 1990 (a)

\begin{tabular}{|c|c|c|c|c|}
\hline Contractor & $\begin{array}{l}\text { Whole Body } \\
\text { Counts }\end{array}$ & $\begin{array}{l}\text { Lung } \\
\text { Counts } \\
\end{array}$ & $\begin{array}{l}\text { Other } \\
\text { Counts }\end{array}$ & Total \\
\hline BCSR & 106 & 0 & 0 & 106 \\
\hline DOE & 403 & 0 & 0 & 403 \\
\hline WHC & 7,822 & 1,792 & 25 & 9,639 \\
\hline HEHF & 25 & 0 & 0 & 25 \\
\hline KEH & 1,039 & 423 & 1 & 1,463 \\
\hline PNL & 1,337 & 333 & $\underline{10}$ & 1,680 \\
\hline Total & 10,732 & 2,548 & $\overline{36}$ & 13,316 \\
\hline
\end{tabular}

(a) Includes routine and special counts. 


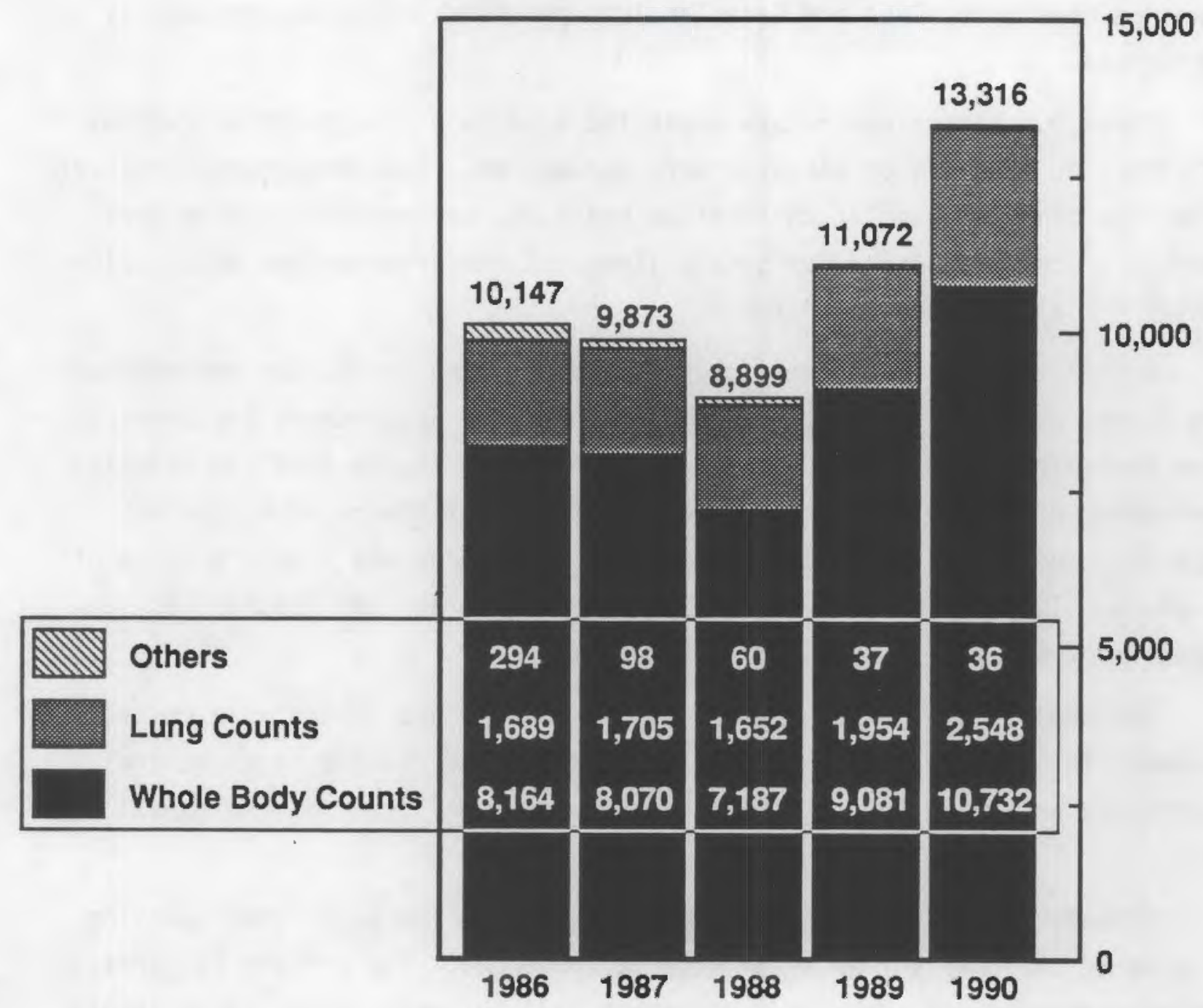

R9104096

FIGURE 3.1. In Vivo Measurements Made at the In Vivo Radioassay and Research Facility from FY 1986 through FY 1990

The four-detector coaxial germanium detector system was calibrated for scanning counts and stationary lung counts. The scanning count calibration used three Bottle Manikin Absorption (BOMAB) phantoms filled with radioactive material homogeneously distributed in a solid polyurethane matrix. The results were within $5 \%$ of the calculated activities in the phantoms. The lung calibration disclosed an apparent discrepancy between the efficiencies using the Eu-Sb lung phantoms and the ${ }^{232}$ Th lung phantoms that could not be explained by statistical variation or positioning uncertainty. The ${ }^{232}$ Th lung 
activity appeared to be "true" based on comparative measurements with the Lawrence Livermore, PNL, and Canadian lung phantoms. This discrepancy is unresolved.

Three DOE Tiger Team groups evaluated aspects of the IVRRF operations in 1990. No findings or concerns were documented. Some recommendations were made regarding labeling of calibration phantoms, primary calibration frequency, procedures, and a few safety items. Corrective actions were implemented for all the recommendations.

A change in the procedure for rescheduling lung counts was implemented. The intent was to reduce the time between a missed appointment (no shows and late arrivals) and a rescheduled appointment. The change involved reducing the number of scheduled daily lung counts to $80 \%$ of the maximum facility capacity, and using the unscheduled time for recounts and timely make-up of no-shows. The time between the missed appointment and the rescheduled appointment was reduced from 6 weeks to 2 weeks.

The Whole Body Counting Manual (a) was revised and issued as a controlled document in February 1990. The revisions addressed changes in procedures, equipment, and MDAs that occurred since the original issue of the manual in 1986.

Transfer of hard-copy historical records from the Whole Body Counting Program to the HRRP for archival storage commenced. The primary calibration records, performance check records, chest wall thickness calculation sheets, and chest wall thickness photographs were transferred. The decision was made to also transfer the routine measurement records currently stored at the 747A Trailer on magnetic tape to the HRRP; however, this transfer will not occur until a format is established for reading the tapes on machines other than the Hewlett Packard (HP) -9000 .

A fire safety inspection identified that the 747A Trailer has no sprinkler system and no connection to the central alarm system. There are no smoke detectors or heat-sensing alarms. This building is the only storage site for several years' worth of whole body counting spectral data, contained

(a) Pacific Northwest Laboratory (PNL). Whole Body Counting Manual. PNL-MA-574, Richland, Washington. (internal manual) 
on magnetic tape. Such data are stored there pending HRRP establishment of permanent spectral storage. To improve the reliability of backup procedures, additional copies were made of 1989 and subsequent data, which will be kept by BCSR under HRRP responsibility. A fire protection assessment for the IVRRF was written to estimate costs and recovery times resulting from a fire at the IVRRF.

\subsection{ADDITIONS OR CHANGES TO EQUIPMENT AND FACILITIES IN 1990}

\subsubsection{Work Stations}

A new Digital Electronics Corporation (DEC) WS-3100 work station-based analyzer system was delivered and interfaced to the HP-9000 computer. The work station replaces obsolete analyzers, expands control and output capabi1ity, and will provide backup to the HP-9000 for calculation of routine results. The system now handles four analog-to-digital converters (ADCs) and can be expanded to handle a total of 32. A second work station was ordered with capital monies.

\subsubsection{Improved Measurements of Chest Wall Thickness}

New equipment for the improved measurement of chest wall thickness was procured. This equipment will provide more accurate measurement of tissue thicknesses, more clearly identify tissue interfaces, automatically calculate results, and electronically store the image, resulting in a higher quality, less subjective interpretation of measurements. The purchased equipment included ultrasound and computer hardware and software (see Figure 3.2). Problems were found with both the computer hardware (a defective mother-board) and software (latest software versions were incompatible with the hardware). Resolution of these problems will continue into 1991.

\subsubsection{Counting Room Cell Communications}

Visual and audio communication systems were installed in the stainless steel and the Palmer Rooms, giving all three counting cells comparable communication capability. This is a worker protection feature that enables the person being counted to communicate his/her need or desire to be removed from the cell prior to count completion. Persons to be counted are instructed by the IVRRF technician in the use of the communications equipment as part of the count preparations. 


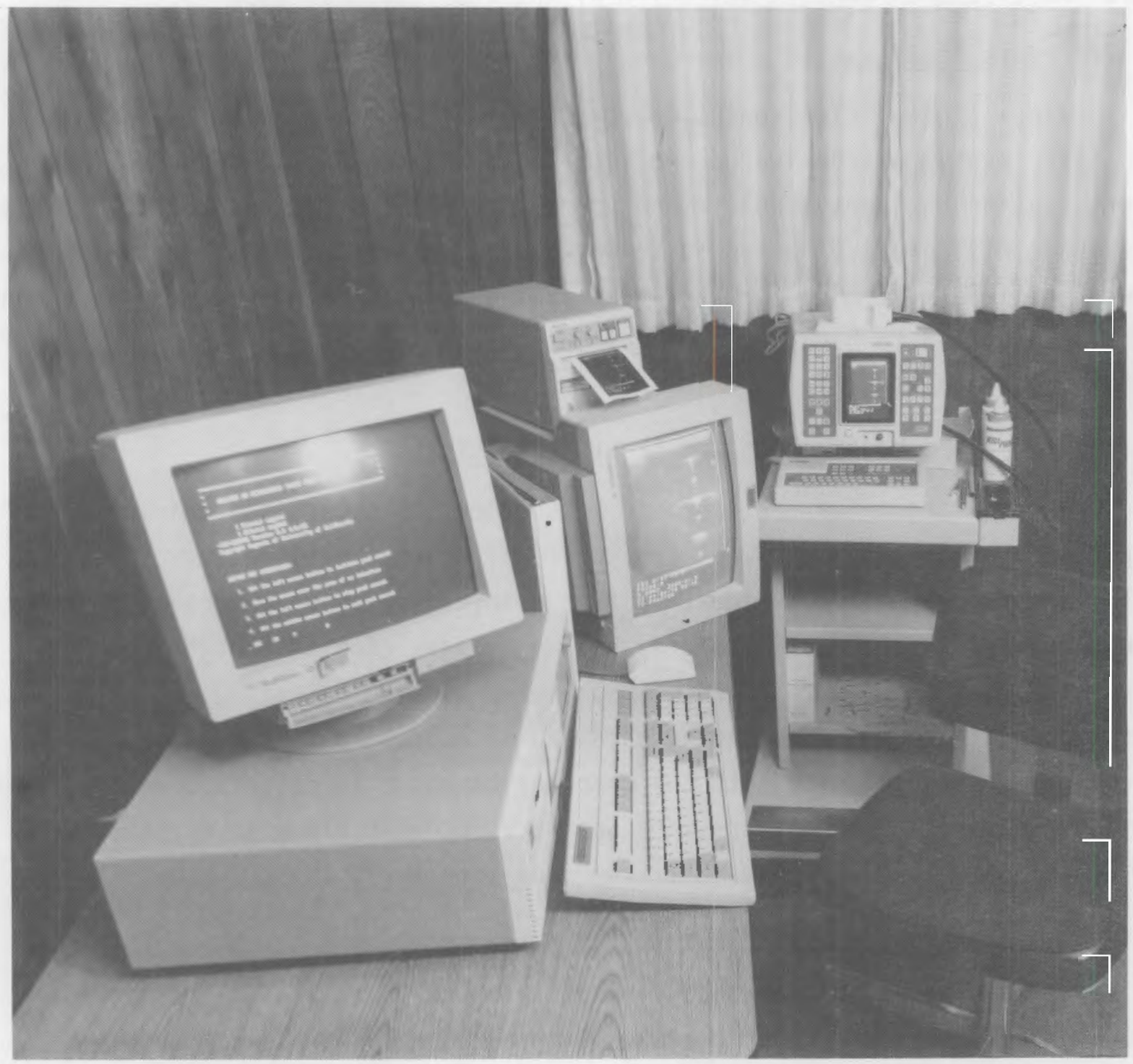

FIGURE 3.2. U1trasound Instrument and Associated Computer Hardware for Measuring Chest Wall Thickness 


\subsubsection{Construction of a Remotely Operated Counter in the Mobile Whole Body Counter}

In FY 1989, a whole body counter (WBC) similar to the preview counter was designed with minimized weight so that it could be installed in the mobile WBC facility without exceeding the load limit of the trailer. During FY 1990 , this counter was constructed and installed in the mobile unit. The unit will initially be located in the 200-East Area of the Hanford Site for remote operation. The counter will be remotely operated from the WBC control desk in the 747A Building. The concept and testing of remote operation of a WBC has been described in previous annual reports (Wilson et al. 1987 (a), p. 9; Lyon et al. 1989, p. 31; Lyon et al. 1990, p. 32).

A cut-away picture of the new counter is shown in Figure 3.3. The detectors are shielded with lead bricks encased in 3/16-inch-thick steel. The thickness of the lead behind and on the sides of the detectors and on the floor is 4 inches. The lead on the front and sides of the subject and on the ceiling is 2 inches thick. There are six NaI(Tl) scintillation detectors. Five of them are 4 inches square and 16 inches long and one is 4 inches square and 8 inches long. The array of detectors is 66 inches long and the top of the array is 72 inches above the floor. A 3/8-inch-thick piece of acrylic plastic separates the detectors and the subject being counted. The total area of 4-inch-thick detectors is 352 square inches compared to 370 square inches for the preview counter in the 747A Building. Preliminary measurements on adult male subjects in the new counter showed a $15 \%$ lower efficiency for measuring ${ }^{40} \mathrm{~K}$ in the body. This lower efficiency is due partly to the lower cross-sectional area of the detectors and partly due to the collimating effect of the shielding, which does not exist in the preview counter. The background in the $40 \mathrm{~K}$ peak was $33 \%$ lower. This lower background is probably due to the fact that there are only 6 glass photomultiplier tubes on the detectors of the new counter, whereas the preview counter has 27.

\footnotetext{
(a) Wilson, R. H., H. E. Palmer, M. J. Sula, V. L. Berndt, and J. J. Fix. 1987. Personnel Dosimetry Annual Report for 1986. Copy in the Hanford Radiation Protection Historical Files, Pacific Northwest Laboratory, Richland, Washington.
} 


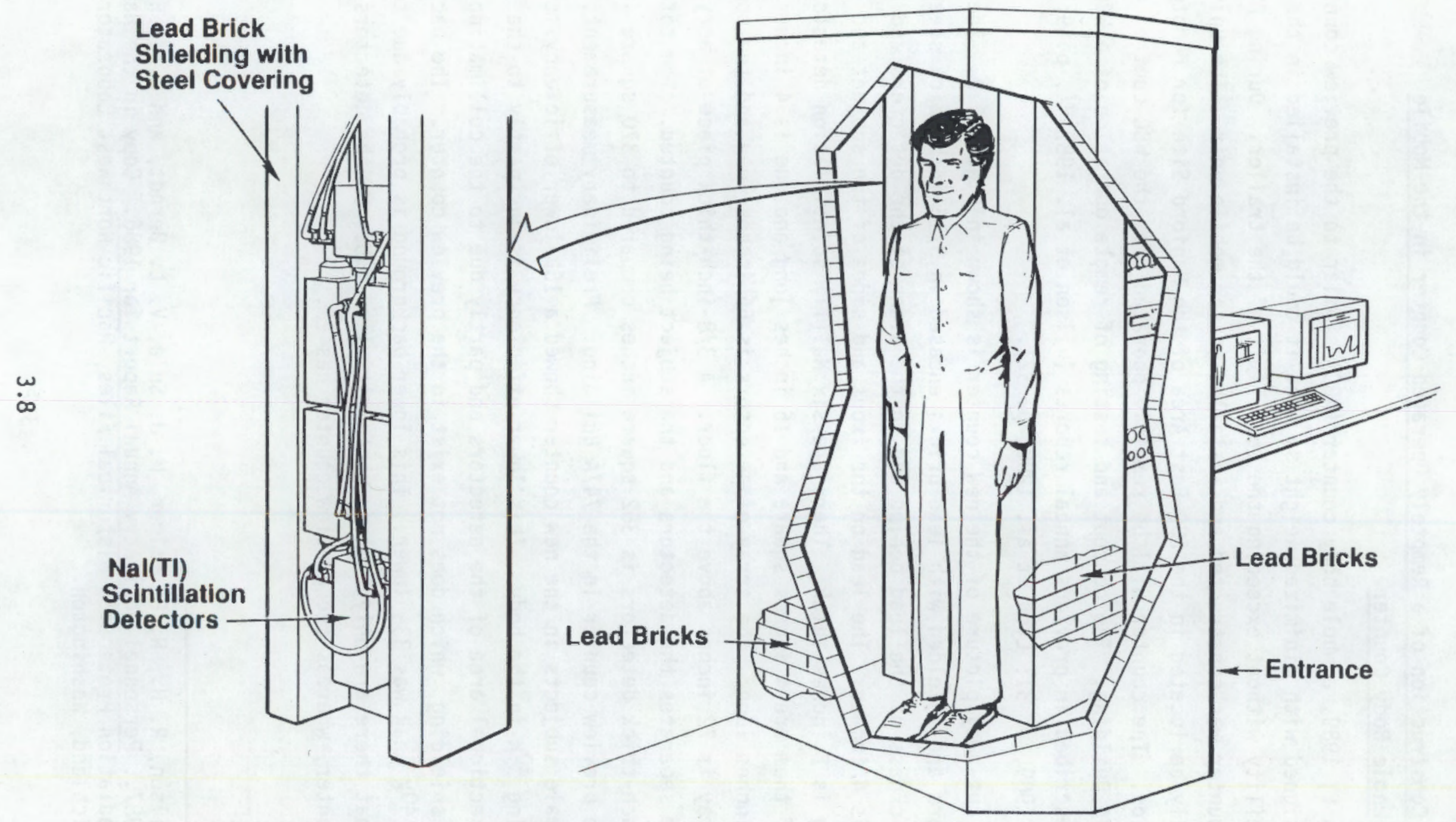

FIGURE 3.3. The Remotely Operated Whole Body Counter in the Mobile Whole Body Counting Facility 
Video equipment was procured and installed in the mobile unit and in the 747A Building allowing for identification of persons to be counted and for monitoring of persons during the count. This equipment transmits a video image every 14 seconds or less. However, telephone line noise caused the equipment to occasionally interrupt the continuous automatic sending of pictures. Much better reliability for receiving the video pictures is necessary for routine operation, so new modems were procured that can accommodate Tine noise and continue to work. These will be installed in early 1991.

Two computer-based multichannel analyzers and associated software were procured under purchase specifications that they were to communicate and control each other over telephone lines. As of the end of 1990, satisfactory operation of the analyzers in the communication mode had not been demonstrated by the vendor. Because of the very late delivery of the detectors and the multichannel analyzer systems, the milestone for completion and operation of the remotely operated whole body counter was extended to June 1991. Figure 3.4 graphically shows the operation of this remotely operated facility.

Although the counter will be calibrated to provide accurate quantitative results of internal radioactive contamination, it will be used in the 200-East Area as a screening counter. Any person who shows evidence of internal contamination will be asked to go to the 747A Building facilities to obtain a more thorough in vivo examination.

\subsubsection{Automatic Liquid Nitrogen Fill System}

An automated liquid nitrogen $\left(\mathrm{LN}_{2}\right)$ fill system was installed in the stainless steel and iron rooms and placed into operation. The system operates reliably although some line blockage from ice formation in the $\mathrm{LN}_{2}$ lines has been experienced. It was suspected that poor connections at points where dissimilar metals (copper and stainless steel) were joined may be contributing to the problem. The plugging of the lines was essentially eliminated by replacing the copper tubing with stainless steel.

A potential health and safety problem associated with the $\mathrm{LN}_{2}$ fill system was identified. The concern was that a depleted oxygen condition might develop in the counting cells from venting of a $160-\mathrm{L}$ Dewar container of $\mathrm{LN}_{2}$ in the event of valve failure. An evaluation showed that normal filling operations with the door open and no one in the cell (as is the practice) 


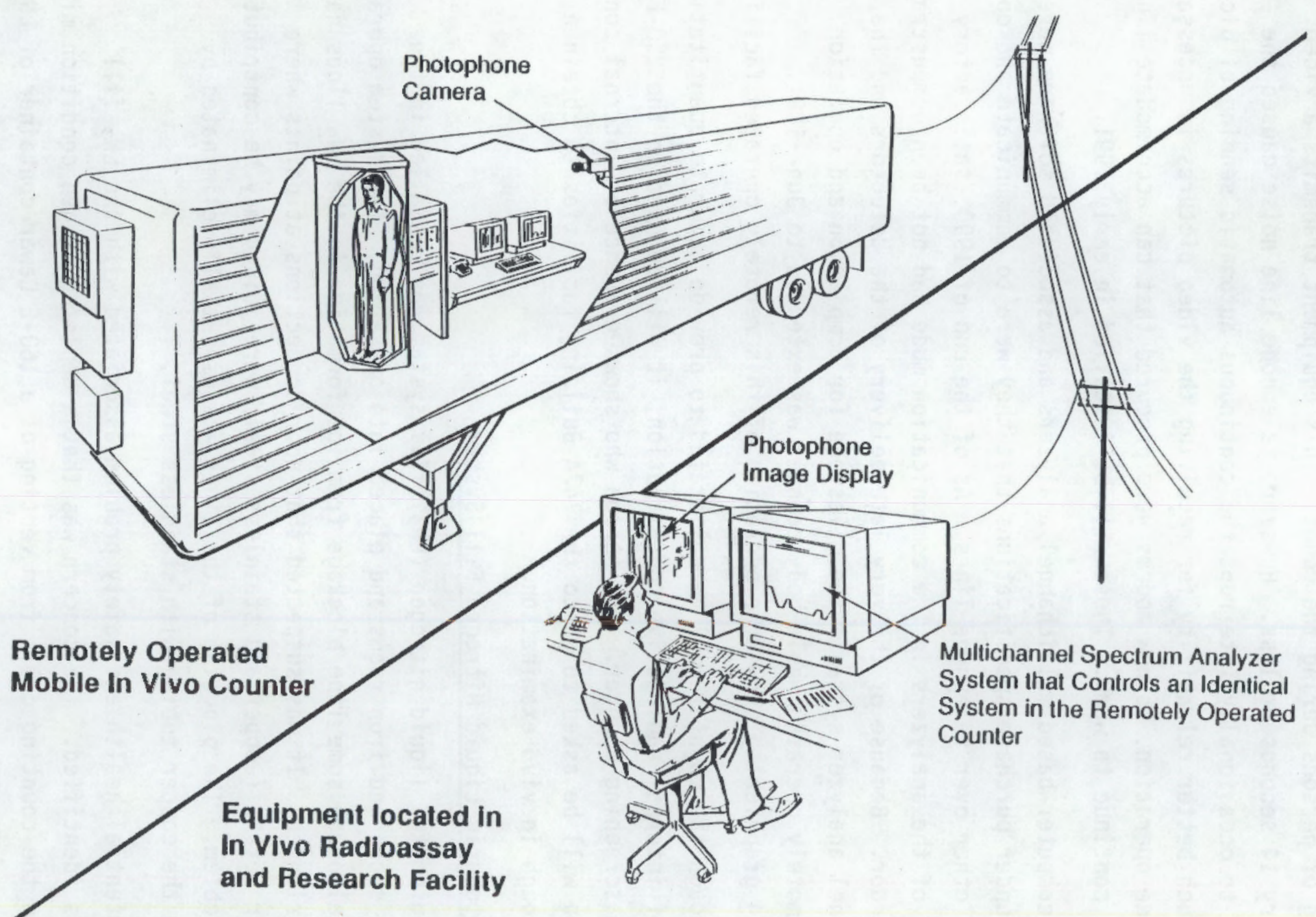

FIGURE 3.4. Operation of the Remotely Operated Mobile Whole Body Counting Facility 
posed no chance of reducing oxygen levels to potentially hazardous conditions. A study is ongoing to evaluate the worst-case $\mathrm{LN}_{2}$ release into the cells.

\subsection{SPECIAL STUDIES}

\subsubsection{Measurements on Chernobyl Helicopter Pilot}

In vivo measurements were performed on a Russian helicopter pilot who had been exposed to radioactivity during the Chernobyl accident. The measurements were performed for the Fred Hutchinson Cancer Research Center where the pilot was about to undergo a bone marrow transplant. Measurements were also

made on his Russian physician as a background subject. Small amounts of $137 \mathrm{Cs}$ were found in both subjects and a small amount of $99 \mathrm{~m} \mathrm{Tc}$ was also found in the pilot as residual activity from a recent bone scan.

\subsubsection{Standup Counter Peak Background Prediction Study}

The current method used to determine the background baseline in the photopeak regions of interest for standup counter measurements is based on 100 subjects who were measured several years ago and who had only normal levels of $40 \mathrm{~K}$ in their bodies. The factors based on the 100 subjects were compared with factors generated from several hundred contemporary measurements, and only slight differences were noted between the two sets of data. The newly derived factors will be incorporated into the algorithm in 1991, after data analys is is complete.

\subsubsection{Lung Counter Peak Background Prediction Study}

The current method of predicting the background baseline count rate in the photopeak region of interest for $241_{\text {Am }}$ using four detectors in the stainless steel room was evaluated. The concern was that uranium progeny peaks in the background region might cause the ${ }^{241}$ Am photopeak background to be overestimated. The study showed that the peak background prediction was within $1 \%$ of the actual peak background, thus no changes in the algorithm are planned.

\subsubsection{Statement of Work}

Work commenced on developing a SOW that would specify the services required of the Whole Body Counting Program by the Internal Dosimetry Program. The Sow will specify a wide range of technical and administrative requirements for the program, comparable to a contract for outside work. Major effort went 
into the application of statistics to multiple-peak spectra to define the critical level and MDAs for each radionuclide in a single in vivo measurement. A draft SOH was written in 1990 and will be finalized in 1991 .

\subsubsection{Standup Counter Fainting Issue}

A potential health and safety concern associated with the standup counter has been the very rare incident of a person fainting during the standup count. In the 5 years of standup counter operation, a fainting rate of about 1 in 6,400 (0.01\%) has been observed. No single reason was found for the fainting; in one case the subject was pregnant, fatigue was a suspected contributor in another, and inebriation in a third case. Consultation with HEHF medical staff identified the major concern to be the need to prevent jnjury from a fall after a person has fainted and, if a person remains unconscious, to ensure that the airway remains open. Several steps were taken to address these issues including padding the cubicle walls to prevent injury from a fall, arranging training for the IVRRF staff in cardiopuTmonary resuscitation (CPR), and measuring the room's oxygen and airflow levels (results were normal).

\subsubsection{Maintenance of the Planar Germanium Detectors}

Improving the reliability of planar germanium detectors has been the goal of ongoing efforts at the IVRRF. In prior years, the failure of a detector required its return to the manufacturer for repair, a process which resulted in its loss for as long as 8 months. To remedy this, the IVRRF instrument technician was sent to the factory for special training in detector maintenance so that detectors might be repaired onsite. In 1990, IVRRF staff continued to gain experience in identifying causes of detector failure and discovering how to improve the reliability of the detectors. Staff have learned that the quality of components within the detectors is critical. Thermal cycling was found to be an effective method of improving resolution. Sites have been identified where vacuum integrity is most likely to be compromised. The detectors are now 6 to 8 years old and their age may be a contributing factor to reduced reliability.

Throughout the year the stainless steel room lung counter system was operated as a four-detector system, due to the lack of a full complement of six detectors being functional for it. Problems experienced included ice 
blockage in the $\mathrm{LN}_{2}$ fill lines, poor resolution in some detectors, high voltage bias failure, and the degradation of the molecular sieve material.

\subsubsection{Phantom Library}

A collection of anthropomorphic phantoms is maintained by PNL for intercalibration and intercomparison of in vivo measurement systems. In 1990, the solid BOMAB phantom containing ${ }^{137} \mathrm{Cs}$ was sent to the DOE Feed Materials Production Center at Fernald, Ohio, and to the International Atomic Energy Agency in Vienna. Substantial interest in this library has been expressed by DOE-HQ and the Nuclear Regulatory Commission and future expansion is expected, both with regard to the number of phantoms and facilities using the library.

\subsection{PRESENTATIONS}

The following presentation was presented by In Vivo Measurement Program staff.

Lynch, T. P. 1990. "In Vivo Measurements of Radioactive Material." Presented as part of the Professional Enrichment Program at the Annual Meeting of the Health Physics Society, June 24, 1990, Anaheim, California.

\subsection{PROGRAM-RELATED PROFESSIONAL ACTIVITIES}

Lynch, T. P. Member of ASTM Task Group E-10.04-27 for developing a standard on the estimation of low-energy photon emitters in a wound. 



\subsection{HANFORD EXTERNAL DOSIMETRY PROGRAM}

The Hanford External Dosimetry Program is a multifaceted effort involving all Hanford contractors. Dose-of-record information from external radiation for Hanford personnel is provided by this program in compliance with DOE requirements as set forth in DOE 5480.11 (1988) and DOE 5480.15 (1987a). Program dosimeter results provide the means used by contractor personnel to project, control, and measure radiation doses received by personnel. Program staff also provide sitewide nuclear accident dosimetry in compliance with DOE 5480.11 (1988) requirements and environmental dosimetry in support of the PNL and WHC environmental surveillance programs.

\subsection{DOELAP ACCREDITATION}

G. R. Yesberger of DOE-RL presented the DOE Laboratory Accreditation Program (DOELAP) Certificate of Accreditation to the. Hanford External Dosimetry Program at the Hanford Personnel Dosimetry Advisory Conmittee (HPDAC) meeting (a) on March 22, 1990. This certificate recognized the program's successful completion of the DOELAP performance testing and onsite technical appraisal required by DOE 5480.15 (1987a). Program accreditation is effective until January 31, 1992.

Sixteen concerns and ten observations were noted during the DOELAP onsite technical appraisal, December 12-13, 1989. These were included in the 1989 annual report (Lyon et al. 1990). A formal program response was required for each of these concerns. This was completed during 1990 with the adoption of program practices and documentation that address each of the concerns. None of the concerns questioned the quality of Hanford personnel dose estimates but were directed at improving documentation, training, and security of the Hanford External Dosimetry system. Two routine program practices were changed and three new practices were adopted. The new practices are:

(a) Fix, J. J. 1990. "Minutes of Hanford Personnel Dosimetry Advisory Cormittee Meeting on March 22, 1990." Letter to Distribution, dated March 27, 1990. Copy in the Hanford Radiation Protection Historical Files, Pacific Northwest Laboratory, Richland, Washington. 
- Effective January 1, 1990, all dosimeters delivered to the 318 Building facility receive a radiological survey prior to handling.

- Effective in July 1990, Hanford implemented the use of suitcases to exchange dosimeters with Hanford contractors. Background control dosimeters are placed in each suitcase to record any dose received by dosimeters during transit in the suitcases.

- Effective in January 1990, non-dosed dosimeters, in addition to the dosed dosimeters, were included with the audit dosimeters routinely assigned to Hanford contractors. These audit dosimeters are included with the personnel dosimeters during routine processing.

The two changed practices are discussed below.

\subsection{ROUTINE PROGRAM}

\subsubsection{Annual Processing Information}

PNL processed approximately 205,000 dosimeters during 1990. This total includes the processing of 80,037 personnel dosimeters (dosimeters actually worn by personnel) for which an official dose was reported to the Hanford Radiological Records Program. (A zero result is considered an official dose.) A summary of the minimum, maximum, and average monthly processing volume for each personnel dosimeter type is shown in Table 4.1. The highest monthly processing volume occurred in January 1990 when about 20,000 dosimeters, including annually exchanged basic and multipurpose dosimeters, were processed.

TABLE 4.1. Personnel Dosimeters Processed During 1990

\begin{tabular}{|c|c|c|c|c|}
\hline \multirow[b]{2}{*}{ Dosimeter } & \multicolumn{3}{|c|}{ Monthly Processing } & \multirow{2}{*}{$\begin{array}{c}\text { Annual } \\
\text { Total } \\
\end{array}$} \\
\hline & Minimum & Maximum & Average & \\
\hline Basic & 538 & 9,008 & 2,116 & 25,397 \\
\hline Beta/photon & 9 & 148 & 38 & 458 \\
\hline Multipurpose & 1,890 & 9,240 & 3,472 & 41,665 \\
\hline Extremity & 889 & 1,166 & 1,043 & $\underline{12,517}$ \\
\hline Total & & & & 80,037 \\
\hline
\end{tabular}


The total number of dosimeters processed $(205,000)$ vastly exceeds the number of personnel dosimeters $(80,037)$ actually worn because of QC practices used to ensure the accuracy of the reported personnel dose. These control practices include:

- processing a minimum of two QC dosimeters with every 50 personnel dosimeters and every 25 dosimeters when determining chip sensitivity factors

- reprocessing, prior to issue, any personnel dosimeter that has been stored more than 75 days to minimize environmental dose buildup

- reprocessing any dosimeter with an observed reader count greater than 650 counts in any dosimeter position

- conducting acceptance testing of new dosimeter inserts and/or holders

- updating chip-sensitivity factors for dosimeters (which requires two processings: before irradiation and after).

Each year numerous internal audit dosimeters are processed to ensure the integrity of dosimeter processing. During 1990, a total of 3,207 internai audit dosimeters were processed. A breakdown of the internal audit dosimeters is shown in Table 4.2. Control charts are used to evaluate the results for each of the audit dosimeter categories. Charts are prepared for every dosimeter and radiation type for each of the 17 dosimeter processings (monthly, quarterly, and annually) conducted each year. A QC report is prepared for each processing. Copies are distributed to all Hanford contractor radiation

TABLE 4.2. Audit Dosimeters Processed during 1990

\begin{tabular}{|c|c|c|c|c|}
\hline \multirow[b]{2}{*}{ Dosimeter } & \multicolumn{4}{|c|}{ Dose Category (a) } \\
\hline & Shallow & Deep & Fast Neutron & Blank \\
\hline Basic & NA & 400 & NA & 180 \\
\hline Beta/photon & 130 & 65 & NA & NÁ \\
\hline Multipurpose & 419 & 498 & 549 & 686 \\
\hline Rings & NA & 280 & NA & Controls \\
\hline
\end{tabular}

(a) NA $=$ Not Applicable 
protection organizations. Copies of the QC report and the control charts are also provided to the Hanford Radiation Protection Historical Files.

Several changes within the routine program occurred during 1990 . These are described in the following sections.

\subsubsection{Implementation of Total Neutron Dose Reporting Only}

Effective with the January 1990 monthly dosimeter exchange, External Dosimetry initiated reporting of the total neutron dose only. Previously neutron doses had been reported separately as fast neutron and slow neutron components. The total neutron dose component is determined using the DOELAP-accredited simplified neutron algorithm (Lyon et al. 1990). The total neutron dose is determined by adding both the slow and fast neutron dose components. The total neutron dose is reported in the computer field used previously to report the fast neutron dose. Quality control relationships between slow and fast neutron chip signals were incorporated into the dose determination code to better ensure that neutron dose is not calculated for a highly thermalized spectrum. Specifically, if the ratio of (Chip 3 Chip 5)/(Chip 4 - Chip 5) exceeds a value of 1.38 , the result is flagged for additional evaluation. Many of these results are identified with a ncte code 50 (Lyon et al. 1990), indicating that the dosimeter response shows a neutron spectrum significantly more thermalized than the calibration spectrum. Records with note code 50 flags require follow-up contractor investigations to determine the correct dose to record.

\subsubsection{Hanford Practice Adopted for Contaminated Clothing}

At the February 15, 1990, meeting of the HPDAC, (a) a Hanford practice for assessing skin dose from contaminated clothing was adopted. This completed efforts by the External Dosimetry Program to develop Hanford practices for contaminated skin and clothing for compliance with the requirements of DOE 5480.11 (1988) for non-uniform exposure. The practice for contaminated skin was adopted previously by the HPDAC (Lyon et a1. 1990).

(a) Fix, J. J. 1990. "Minutes of Hanford Personnel Dosimetry Advisory Committee on February 15, 1990." Letter to Distribution. Copy in the Hanford Radiation Protection Historical Files, Pacific Northwest Laboratory, Richland, Washington. 


\subsection{SUPPORTING EVALUATIONS}

\subsubsection{Glow Curve Analys is}

External Dosimetry Program staff further improved the glow curve analysis capability to include routine computer code evaluation of glow curve data for all dosimeters processed. The evaluation significantly improves the QC used for each dosimeter processed. In response to discussion at the

November 13, 1990, HPDAC meeting, (a) glow curve data are being maintained for a period of 2 years (i.e., previous and current year's data). One year of glow curve data requires approximately 1 gigabyte of storage. This capability provides resources to evaluate, upon request, any dosimeter processing within 2 years of the date of actual processing.

\subsubsection{Historical Documentation}

A report describing and evaluating Hanford external dosimetry practices from 1944 through 1989 was published during 1990 (Wilson et al. 1990). The report describes the technical details of personnel dose assessment from external sources of radiation throughout the entire history of Hanford operations.

\subsubsection{Evaluation of 1989 Year-End Neutron Dose Results}

The HPDAC, at the November 2, 1989, meeting, (b) requested the External Dosimetry Program to evaluate the determination of neutron dose by completing three actions by February 1, 1990:

- determine annual fast neutron dose for three groups of WHC personnel located at the PFP consisting of operators, vault, and health physics support staff

- recalculate annual dose for the three groups using the historical algorithm and PNL chip sensitivity factors

(a) Fix, J. J. 1990. "Minutes of Hanford Personnel Dosimetry Advisory Committee Meeting on November 1, 1990." Letter to Distribution dated November 13, 1990. Copy in the Hanford Radiation Protection Historical Files, Pacific Northwest Laboratory, Richland, Washington.

(b) Fix, J. J. 1989. "Minutes of Hanford Personnel Dosimetry Advisory Committee Meeting on November 2, 1989." Letter to Distribution, dated November 6, 1989. Copy in the Radiation Protection Historical Files, Pacific Northwest Laboratory, Richland, Washington. 
- recalculate annual dose for the three groups using the simplified algorithm and PNL chip sensitivity factors.

The results of these evaluations were discussed by the HPDAC at the February 15, 1990, meeting. (a) The evaluations showed that there was little difference, on average, between fast neutron dose calculated using the historical algorithm with UST- and PNL-determined chip sensitivity factors. However, significantly greater doses were calculated with the simplified algorithm. This situation presented the HPDAC with a dilemna involving several complex issues. The objective of the committee was to provide the best estimate of personnel dose. There were reasons to believe that the historical algorithm tends to underestimate dose and that the simplified algorithm tends to overestimate dose. Three additional actions were recommended by the HPDAC to better resolve this issue.

- External Dosimetry would send 10 multipurpose dosimeters to the Savannah River Site (SRS) for exposure to their PuF 4 source. The exposed dosimeters would then be returned to PNL for analysis. (Hanford's PuF, source was eliminated in the latter 1970s for security reasons.)

- A parallel study of CR-39 and albedo dosimeters, similar to the study done during 1988 (Lyon et al. 1989), should be redone for selected WHC personnel. A 3-month study was proposed. CR-39 dosimeters are not affected by thermal neutrons or by photons and hence, in principal, could enhance the determination of personnel fast neutron dose.

- Additional field measurements should be conducted using tissueequivalent proportional and He-3 counters with the objective of 1) measuring the actual neutron dose and 2) determining calibration correction factors that could be used for specified WHC work environments.

The External Dosimetry Program implemented actions in each of these areas. Hanford dosimeters were sent to SRS for irradiation but have not been returned as of the date of this report. Parallel field studies were planned at PFP but not completed during 1990 because of the lack of any plutonium processing activities. However, an effort was initiated during December 1990 in which a maximum of 10 WHC employees were to receive combination Hanford

(a) Fix, J. J. 1990. "Minutes of the Hanford Personnel Dosimetry Advisory Committee Meeting on February 15, 1990." Letter to Distribution. Copy in the Hanford Radiation Protection Historical Files, Pacific Northwest Laboratory, Richland, Washington. 
albedo and CR-39 dosimeters each month. This effort is scheduled to continue for many months. Extensive field measurements were completed at PFP as discussed under the following section.

\subsubsection{Study of Hanford Neutron Albedo and CR-39 Track Etch Dosimeter}

Measurements from selected neutron sources were conducted to further evaluate the best alternative currently available to Hanford for conducting personne1 neutron dosimetry. These measurements complement previous field measurements conducted at Hanford work locations (Fix et al, 1981; Fix et al. 1982) $(a, b, c$,$) Measurements were taken at PFP from three plutonium neutron$ sources. In addition, measurements were taken of the NIST-traceable ${ }^{252} \mathrm{Cf}$ source in the 318 Building. For the plutonium fluoride and ${ }^{252} \mathrm{Cf}$ sources, selected thicknesses of plexiglass were used to moderate the neutron spectrum. Hanford albedo neutron and CR-39 track etch dosimeters were used in all of these measurements. Tissue-equivalent proportional counters (TEPCs) were used to determine the actual neutron dose rate.

Although numerous field measurements indicate that the historical Hanford fast neutron dose algorithm calculates reasonable doses for Hanford work environments, the perfornance of this algorithm was inadequate to meet the dosimeter performance requirements of the DOELAP. This failure was directly attributable to error propagation in the algorithm, which resulted in a greater than acceptable variance. The average dose, calculated from 15 dosimeters as used in the perfornance testing, was reasonably close to the given dose. The algorithm performance was able to meet the performance requirements of ANSI Standard N13.11-1983 (1983), American National Standard Criteria for Testing Personnel Dosimetry Performance, as used in the National Voluntary Laboratory Accreditation Program (NVLAP) for commercial processors.

(a) Nichols, L. L. 1988. "Neutron Dose and Spectral Measurements at 234-5 Building." Letter to W. A. Decker, Dated May 17, 1988.

(b) Cummings, F. M., and L. L. Nichols. 1986. "Neutron Field Measurements at the 234-5 Building." Internal Report dated October, 1986.

(c) Roberson, P. L., F. M. Cummings, and J. J. Fix, 1985. "Neutron and Ganmia Field Measurements at the 234-5 Facility." Internal Report dated September 20, 1985. 
This situation led to the implementation of a simplified neutron dose algorithm effective with the October 1989 dose results discussed in the 1989 annual report (Lyon et al. 1990).

Measurements at PFP of the plutonium sources were completed during July 1990. Field conditions that were experienced and are important to the evaluation of these data include:

- Significant background neutron radiation was present for the plutonium metal and oxide measurements.

- Placement of dosimeters and instruments at $50 \mathrm{~cm}$ from the different sources resulted in some perturbation of the neutron fluence.

- Dose rates from the sources varied by more than 4 orders of magnitude, which resulted in pulse pile-up problems at the high dose rates and long count times for the low doses.

In spite of these difficulties, valuable information was obtained, showing that, for the source irradjations, the CR-39 track etch dosimeter provided more accurate doses over the entire spectrum of source configurations. The doses calculated with the track etch dosimeter compared closely with the TEPC measurements. The doses were lower than those obtained with the Hanford albedo dosimeter using either the simplified or historical algorithms. For the highly themalized fields (i.e., source configurations using plexiglass shielding), doses calculated with the simplified algorithm could be overestimated by an order of magnitude.

\subsubsection{Extremity Dosimetry Evaluations}

External Dosimetry staff participated in two meetings of an ad hoc working group formed by DOE-HQ to develop a DOELAP performance standard for extremity dosimetry. A pilot test of the draft performance standard is scheduled in 1991. Evaluation of extremity dose was conducted for a project involving $90_{Y}$ purification. Measurements were conducted of simulated steps of the purification process using exoelectron dosimeters, thin TLD-700 chips in which an active 6-mil layer is placed on an inert substrate, beta spectroscopy measurements and the standard 35-mil TLD-700 chip used in the routine extremity dosimeter. The primary objective of these efforts was the determination of an improved calibration factor for use in calculating the extremity dose to be recorded for staff working with this project. Based on 
these measurements, the calibration factor used for routine extremity dosimetry was increased by a factor of 4 for this specific project.

\subsection{DOCUMENTATION}

Formal documentation of the Hanford External Dosimetry Program is contained in two internal PNL manuals:

1. Location of Criticality Alarms and Nuclear Accident Dosimeters at Hanford. PNL-MA-583, Pacific Northwest Laboratory, Richland, washington.

2. Hanford External Dosimetry Program. PNL-MA-568, Pacific Northwest Laboratory, Richland, Washington.

In addition to these documents, the External Dosimetry Program staff maintain eight internal technical documents to document the design, algorithm, calibration, and dose response characteristics of the different dosimeters, as well as procedures for evaluating the nuclear accident and environmental dosimeters. These documents are listed as follows:

Volume I Baumgartner, W. V. 1990. "Quality Assurance"

Volume II Endres, A. W. "Personnel Dosimeter Features, Calibration and Dose Assessment" (draft)

Volume III Schur, J. A. 1989. "Data Processing"

Volume IV Paul, T. J. 1990. "Nuclear Accident Dosimetry"

Volume V Baumgartner, W. V. 1991. "Dosimeter Reader Systems"

Volume VI Nichols, L. L. 1989. "Field Measurements"

Volume VII Rathbun, L. A. 1990. "Environmental Dosimetry"

Volume VIII Peters, J. D. 1990. "Laboratory Procedures."

These documents are used to administer the External Dosimetry Program. In addition, letter reports are prepared and submitted to HPDAC for review and comment for significant program issues. Copies are included in the minutes of these comnittee meetings and provided to the Hanford Radiation Protection Historical Files maintained by the Hanford Radiological Records Program. 


\subsection{PUBLICATIONS}

The following publications were prepared by the Hanford External Dosimetry Program staff during 1990.

Fix, J. J. 1990. Hanford External Dosimetry. PNL-7006, Pacific Northwest Laboratory, Richland, Washington.

Wilson, R. H., J. J. Fix, W. V. Baumgartner and L. L. Nichols. 1990. Description and Evaluation of Hanford Personnel Dosimeter Program from 1944 through 1989. PNL-7447, Pacific Northwest Laboratory, Richland, Washington.

\subsection{PROGRAM-RELATED PROFESSIONAL ACTIVITIES}

Fix, J. J.--Chairman of Health Physics Society Standards Committee Working Group to develop a standard titled "How to Estimate the Overall Accuracy in Occupational Dose Determinations."

Fix, J. J.--Chairman of DOELAP Oversight Board as identified in DOE 5480.15, "Department of Energy Laboratory Accreditation Program for Personnel Dosimetry."

Fix, J. J.--Member of $\mathrm{DOE}$ ad hoc working group to develop extrenity dosimeter performance standard.

Fix, J. J.--Member of Health Physics Society Standards Committee Working Group to revise ANSI N319 titled "Personnel Neutron Dosimeters (Neutron Energies less than $20 \mathrm{MeV}$ )."

Fix, J. J.--Member of ad hoc dosimetry working group to support International Agency for Research on Cancer (IARC) project to pool existing epidemiological studies.

Rathbun, L. A.--Member of ASTM Task Group E-10-04-16, "How to Perform Field Measurements of Beta Spectra." 


\subsection{INSTRUMENT CALIBRATION AND EVALUATION PROGRAM}

The operation of a complete radiation protection instrument program is an integral part of Hanford radiation protection programs. The Instrument Calibration and Evaluation Program provides a complete radiation protection instrument service, thereby equipping the Hanford contractors with highquality, reliable, accurate instrumentation capable of performing at the level necessary to ensure personnel safety as required by DOE 5480.11 (1988). Calibrations are performed using the guidance in ANSI N323-1978 (ANSI 1978). The routine program activities fall under the four base tasks that comprise the 1990 CY program: 1) Routine Portable Instrument Pool, 2) Hanford Instrument Evaluation Program, 3) Deployment of High-Range Cutie Pies (HRCPs), and 4) Calibration of WHC 200 Area continuous air monitors (CAMs). The following subsections discuss details of and activities performed under these four base tasks and other support tasks of importance performed during 1990.

\subsection{ROUTINE PROGRAM}

The routine program provides for a complete radiation protection instrument program. This consists of procuring new and replacement instruments; overseeing an instrument pickup and delivery service; keeping records; and surveying, decontaminating, maintaining, and calibrating instruments. The routine program also includes the following:

- maintaining traceability of radiological and electronic calibration systems to NIST

- operating a program to service radiation protection emergency kits

- modifying and updating written calibration procedures as new instruments are introduced and calibration techniques are improved

- procuring, acceptance testing, calibrating, and distributing pencil dosimeters

- performing specification development and acceptance testing on all instruments purchased for pool use and as required by Hanford contractors

- fabricating and certifying instrument performance check sources for Hanford contractors. 


\subsubsection{Routine Portable Instrument Pool}

Table 5.1 illustrates the usage of portable instruments on the Hanford Site during $\mathrm{CY}$ 1990. Listed are instrument types, the number of instruments, and the percent of the total number of instruments for each contractor (i.e., PNL; KEH; and WHC 100, 200, and 300/400 Areas). The instrument types are described in detail in PNL's internal radiation protection instrument manual. (a)

During 1990 a number of new instruments were procured to replace instruments damaged or disposed of as a result of contamination: 30 Eberline Model R0-3B CPs were procured; 100 Bicron count rate meters were received; and 100 pancake probes were fabricated by PNL Craft Service personnel and are now in the instrument poot.

\subsubsection{Hanford Instrument Evaluation Program}

The Hanford Instrument Evaluation Committee (HIEC) was established to provide a mechanism for Hanford intercontractor information exchange to ensure that the highest quality portable and semi-portable radiological protection instrumentation program is maintained at Hanford. Responsibilities of the committee include the following:

1. Discuss and propose solutions to ongoing or potential radiological instrumentation problems and needs onsite.

2. Identify new radiological instrumentation available from manufacturers that may be useful to the Hanford Site operations.

3. Oversee procurement of the instruments and review evaluations of the performance by contractor organizations.

4. Establish or review minimum acceptable operational criteria for portable and semi-portable radiological instrumentation used for safety on the Hanford Site.

5. Promote information exchange between contractors on radiological protection instrumentation usage and problems/resolutions.

Representatives from all of the Hanford contractors and a representative from DOE-RL are on this committee. Meetings are nomally held every other month.

(a) Pacific Northwest Laboratory (PNL). Radiation Protection Instrument Manual. PNL-MA-562, Richland, Washington. (internal manual) 
TABLE 5.1. Portable Instrument Usage for CY 1990

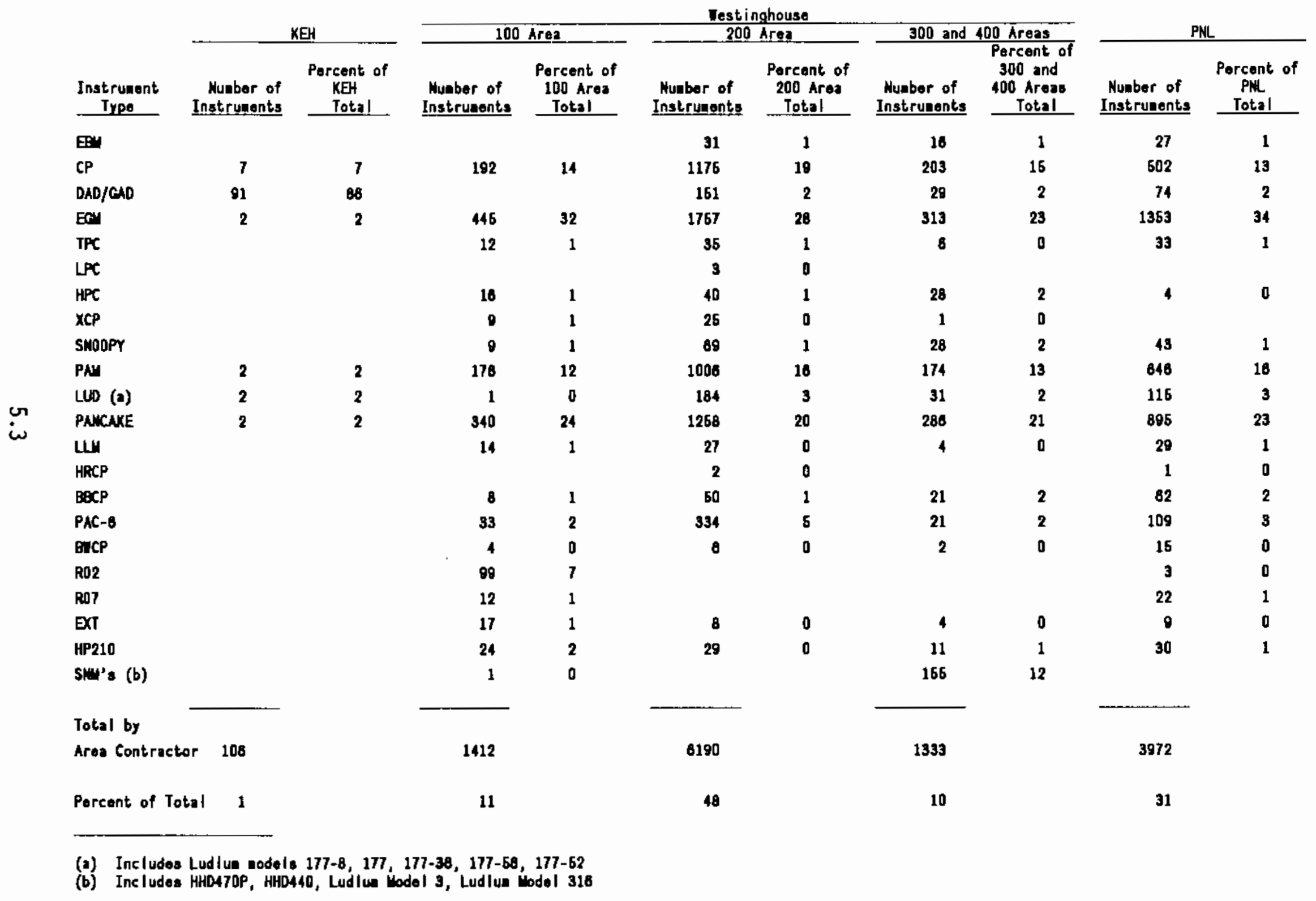




\subsubsection{Deployment of High-Range Cutie Pies}

The HRCP is an air ionization chamber with a pistol-shaped handle used to measure high levels (up to $50 \mathrm{mrem} / \mathrm{h}$ ) of beta and gamma radiation. This instrument was originally designed by Instrumentation and External Dosimetry (I\&ED) personnel and is now commercially available from Victoreen, Inc. In CY 1990, progress continued on solving initial design problems. Additional integrated circuitry was added to remove timing errors associated with the control signals being decoded by the instrument programmer. In addition, adjustments had to be made to the instrument programmer to properly burn valid calibration data into the programmable read-only menory (PROM) devices. Finally, the instrument programmer, which corrected the timing errors, needs to be modified slightly to correct reading fluctuations caused by the probe improperly decoding the control signals to it. These corrections should allow the instrunent to be placed in service in CY 1991 .

\subsubsection{Calibration of Westinghouse Hanford Company 200-Area Alpha Continuous Air Monitors}

In August of CY 1990, PNL began to calibrate $100 \%$ of the WHC 200 Area alpha CAMS. This completed a transition initiated in a September 1989 letter from A. J. Rizzo, Assistant Manager for Operations, DOE-RL, to J. E. Nolan, WHC President. The letter stated that responsibility for calibration of all 200 Area alpha CAMs would be transferred to PNL by December 31, 1989. The need to purchase 30 new Eberline model alpha 5A CAMs extended the scheduled transfer date into 1990. A support document to assist in the transition was written and meetings were held every 2 to 4 weeks between WHC and PNL personnel, which provided a smooth transition of the calibration responsibility.

\subsection{SUPPORTING INVESTIGATION AND STUDIES}

\subsubsection{Linear Beta Source}

The concept and new design for a $\mathrm{Sr} / \mathrm{Y}-90$ beta source holder to replace the "Fan Source" holder was completed by I\&ED personnel in CY 1989 (Lyon et al. 1990). The fabrication of 30 holders was completed by PNL Craft Services for PNL, WHC, and several offsite DOE facilities and operations (United Nuclear Corporation Geotech, the Savannah River Plant, the Gaseous 
Diffusion Plant at Paducah, and the $Y-12$ Plant at 0ak Ridge) during the $C Y$ 1990. Source distribution continued in CY 1990.

\subsubsection{Geiger-Mueller and Alpha Check Sources}

I\&ED personnel began designing and testing check sources for GeigerMueller (GM) survey meters and alpha survey meters in CY 1990 . These check sources allow the GM survey meter users and portable alpha survey meter (PAM) users to source check their instruments on a daily or more frequent basis. This routine source check verifies that the survey instrument is still functioning properly and calibrated at the time of use. Initial distribution of several GM check sources should occur in CY 1991.

\subsection{PRESENTATIONS}

I\&ED staff made one presentation during 1990:

Fleming, D. M., J. B. Martin, and K. L. Swinth. 1990. "Practical Limitations on Alpha Contamination Monitoring." Annual Meeting of the Health Physics Society, June 24, 1990, Anaheim, California.

\subsection{PROGRAM-RELATED PROFESSIONAL ACTIVITIES}

D. M. Fleming--Member of Task Group 4, writing a National Council on Radiation Protection and Measurements (NCRP) Handbook titled "Calibration of Survey Instruments for the Assessment of Ionizing Radiation Fields and Radioactive Surface Contamination."

F. E. Owen--Member of the Working Group American Nuclear Society/Health Physics Society Standards Committee (ANS/HPSSC) ANSI 6.8, writing the standard titled "Area and Process Monitors." 



\subsection{RADIATION STANDARDS AND CALIBRATIONS PROJECT}

The Radiation Standards and Calibrations Project maintains radiological calibration standards, special instrument and dosimeter responsecharacterizing equipment, and calibration data-handling equipment at Hanford. This activity provides the means to characterize response to various radiation fields encountered at Hanford and ensures that calibration fields are described in accordance with recommended standards and guidelines. The project also has quality assurance (QA) responsibilities for routine calibration of instruments and dosimeters utilized to meet these goals.

Under this project, staff perform the following tasks:

- Review calibration standards, regulations, and handbooks.

- Ensure that the calibrations procedures used are in agreement with technically accepted methods.

- Maintain basic radioactive sources and instruments that serve as radiological standards.

- Provide traceability of the calibration sources to NIST.

- Majntain a data management system for instrument repair and calibration records.

Project activities conducted during CY 1990 are discussed in the following sections.

\subsection{ROUTINE PROGRAM}

Two major functions comprise the project's routine program: 1) maintenance of radiological standards and capabilities, and 2) maintenance of a computerized data management system. These functions and related improvements are discussed in the following subsections.

\subsubsection{Maintenance of Standards and Capabilities}

The radiological standards and capabilities maintained for the various entities of Hanford Radiological Protection Support Services include gamma, beta, and neutron sources and $x$-ray generating devices. These standards and capabilities are configured to deliver precisely known and easily reproduced quantities of radiation dose or exposure to environmental or personnel 
dosimeters and instruments for providing NIST-traceable calibration and/or response characterization. Photon and beta sources are periodically checked against NIST through either the use of transfer standard instruments submitted by NIST or from direct measurements by NIST personnel within the PNL facility. Neutron sources undergo direct calibration at the NIST facility prior to being placed into service at PNL.

Available photon sources include various activities of ${ }^{137} \mathrm{Cs},{ }^{60} \mathrm{Co}$, and a multitude of $x$-ray techniques. A conmercial high-level irradiator that provides a collimated beam from a ${ }^{137} \mathrm{Cs}$ source is housed in Room 6 in the basement of the 318 Building. A rail system is provided to support a moveable trolley capable of supporting dosimeters or instruments. The accurate positioning of the device being tested is aided by a laser alignment system. Also in this area, an x-ray machine capable of performing the majority of the NISTspecified $x$-ray techniques is maintained. These photon sources are calibrated annually and verified quarterly. Each source is measured in the most commonly used geometries.

A second high-level ganma irradiator is maintained in Room 8 of the 318 Building. This system consists of a highly shielded source-storage mechanism, a turntable for source selection, a closed-loop source-transport system, and a well-collimated field produced by a conical beam port. The selected source is transported pneumatically to the irradiation position. An operational control panel is positioned outside the irradiation room and is well shielded against radiation exposure. A rail system is installed as a trolley support track over a 6-m range on the floor parallel to the beam axis. A laser, centered on the beam axis, is intersected by a cross laser at the 100-cm distance to provide alignment. All four sources in the high-level irradiator are calibrated annually and verified quarterly.

Room 106 in the 318 Building houses a pneumatic source transfer and storage system, commonly called a Rabbit system, which contains a ${ }^{60}$ Co source, two levels of ${ }^{137} \mathrm{Cs}$ photon sources, and two levels of ${ }^{252} \mathrm{Cf}$ neutron sources, used for low-scatter irradiation geometries. These sources are used in an open-air panoramic geometry as opposed to a collimated beam, thereby allowing the irradiation of dosimeters or instruments in a 360-degree plane around the source position. The three photon sources are calibrated annually and verified quarterly. The neutron sources were initially calibrated at the 
NIST prior to installation and currently do not undergo periodic measurement quality assurance (MQA) tests by NIST. Consideration is being given to establishing neutron MQA tests in the future if NIST can provide a suitable method to intercompare sources or instruments in a timely manner.

Four wells containing isotopic sources (two ${ }^{137} \mathrm{Cs}$, one ${ }^{60} \mathrm{Co}$, and one ${ }^{252} \mathrm{Cf}$ ) are housed in Room 121 of the 318 Building. These wells are used primarily in the routine calibration program for portable instruments. Computer programs are used to control a trolley system that moves the source vertically to any desired point within the $9-m$ well depth, based on the calibration of the wells. The programs allow for selection of 1) the desired gamma exposure rate (or, for neutrons, the dose-equivalent rate), 2) the source-to-instrument distance, or 3) stepping through the exposure rate points of the desired instrument calibration with only minimal operator involvement. The distance from the plane of the well surface to the detector center is entered as an offset and is included in the selected overall distance. The wells can also be operated in a "compensated mode" in which ambient temperature and pressure conditions are taken into account to provide appropriate exposure rates for instruments that have a response sensitive to such parameters. All photon wells receive extensive annual calibration in addition to the less extensive quarterly calibration verifications that are directly related to routinely used instrument calibration points. The photon sources are calibrated annually and verified quarterly. Each quarter, because of the relatively short half-life of ${ }^{252} \mathrm{Cf}$, the neutron well is recalibrated to establish new dose equivalent rates at a series of specified source-todetector distances. The procedure for each quarterly recalibration is the same.

Room 113 of the 318 Building houses a set of Buchler secondary beta standards $\left({ }^{204} \mathrm{Tl},{ }^{147} \mathrm{Pm}\right.$, and $\left.{ }^{90} \mathrm{Sr} /{ }^{90} \mathrm{Y}\right)$ contained in a semi-automated irradiation jig system. Irradiations are performed in support of the Hanford personnel dosimetry program as well as a number of other DOE-sponsored projects. These sources have historically been calibrated directly by NIST personnel and no periodic calibration or verification procedures are currently established.

A11 annual and quarterly calibrations were completed as scheduled in 1990. The ${ }^{137} \mathrm{Cs}$ and ${ }^{60}$ Co photon source calibrations were compared with the originally established dose rates corrected for decay and all were within $\pm 2 \%$ 
of those established values (see Table 6.1). Baseline values for a newly acquired ${ }^{241} \mathrm{Am}$ source were established during the fourth quarter of 1990 and consequently are not comparable to previous values. Measurements for the ${ }^{252} \mathrm{Cf}$ well source are not compared with the original NIST calibrated value, because geometry factors severely affect the dose rates. Instead, a SNOOPY neutron detector, standardized to the same source in an open air geometry, was used to provide the calibration verification data.

The photon MQA results from measurements performed during the summer of CY 1989 were reported in May 1990. The agreement for the x-ray and photon beams ranged from $+0.6 \%$ to $-2.1 \%$ of the NIST values and this sufficiently supports traceability goals.

TABLE 6.1. Calibration Performance Summary (Annual calibrations are in boldface type)

\begin{tabular}{|c|c|c|c|c|}
\hline \multirow{2}{*}{ Source No. } & \multicolumn{4}{|c|}{ Measured/Known Dose Rates } \\
\hline & $\begin{array}{c}\text { Qtr. } \\
1 \\
\end{array}$ & $\begin{array}{c}\text { Qtr. } \\
2 \\
\end{array}$ & $\begin{array}{c}\text { Qtr. } \\
2 \\
\end{array}$ & $\begin{array}{c}\text { Qtr. } \\
4\end{array}$ \\
\hline \multicolumn{5}{|l|}{${ }^{137} \mathrm{Cs}$} \\
\hline $318-001$ & 1.012 & 1.000 & 0.997 & 1.003 \\
\hline $318-029$ & 1.010 & 1.002 & 1.000 & 1.001 \\
\hline $318-030$ & 0.988 & 1.014 & 0.996 & 1.011 \\
\hline $318-031$ & 1.005 & 1.007 & 0.995 & 0.997 \\
\hline $318-040$ & 1.003 & 1.004 & 1.001 & 0.999 \\
\hline $318-044$ & 1.001 & 1.004 & 1.001 & 1.000 \\
\hline $318-131$ & 0.995 & (a) & 1.006 & 1.004 \\
\hline \multicolumn{5}{|l|}{${ }^{60} \mathrm{Co}$} \\
\hline $318-027$ & 0.996 & 0.982 & 0.994 & 0.987 \\
\hline $318-036$ & 1.000 & 0.997 & 1.004 & 1.003 \\
\hline $318-037$ & 1.002 & 0.998 & 1.004 & 1.003 \\
\hline $318-164$ & 1.000 & 1.011 & 1.055 & 0.998 \\
\hline
\end{tabular}

(a) This source was originally scheduled for annual calibrations only. Quarterly calibrations began during the third quarter of 1990 . 
The MQA measurements of the beta sources by NIST personnel were not possible during 1990 as a result of personnel and organizational changes at NIST. Because of the delay, the sources were measured internally for a consistency check using an instrument similar to that used by NIST. The results of the consistency check agreed to within $\pm 1 \%$ of the last calibration results (corrected for decay). This good agreement lends additional support to the system accuracy until such time as the regular MQA can be performed.

\subsubsection{Improvements to the Maintenance of Standards and Calibration Functions}

The characterization of the new ${ }^{252} \mathrm{Cf}$ source (source no. 318-167) placed into the Room 106 Rabbit system during CY 1989 was completed. Verification of the calculated dose rates using a total dose meter, a TEPC, a ${ }^{3} \mathrm{He}$ tube, and thermoluminescent dosimeters (TLDs) showed that rates were within $\neq 2 \%$ of anticipated dose equivalent rates. Measured room return (backscatter) for this source (placed in the tower position) was consistent with proportions found from other ${ }^{252} \mathrm{Cf}$ sources used in the system. The new source is now being used for all routine Hanford, DOELAP, and NVLAP irradiations. The replaced ${ }^{252}$ Cf source (source no. 318-038) was transferred to Well \#3 in Room 121 during the fourth quarter of 1990 . In its new position, this source will be used for some of the lower-level routine instrument calibrations. A third ${ }^{252}$ Cf source (source no. 318-016) was reinstalled for use within the Rabbit system to provide a low-intensity neutron field in the free-field geometry of Room 106.

Plans were developed for modifying the Room 106 tower system to provide a better method of placing and removing the $\mathrm{D}_{2} \mathrm{O}$ sphere about the source. The current practice of placing the sphere on the source position is extremely difficult and requires direct contact with the potentially toxic cadmium shell. The planned modifications include placing an additional track assembly on the tower for a sphere storage cart and adding a jack assembly for raising the sphere into and lowering it out of its irradiation orientation. Construction of this system is expected to commence in CY 1991.

The $x$-ray facility (Room 6) underwent extensive remodeling during the fourth quarter which now allows x-ray, high-energy gamma/photon, and ${ }^{241}$ Am irradiations simultaneously. Also, the new ${ }^{241}$ Am irradiator (source no. 318-184) was calibrated for its baseline characterization. This unit 
(see Figure 6.1) provides backup and/or supplemental support for irradiations requiring $59-\mathrm{keV}$ photons. It, unfortunately, provides a very low dose equivalent rate and therefore exposures using this device are unusually long.

\subsubsection{Maintenance of the Data Management System}

Maintenance and updating of the instrument tracking system, including the HP-9000 computer, its peripherals, and the data management software comprise this portion of the routine program. All software established for use in support of the Hanford Radiological Protection Support Services function is written in house using Hewlett Packard's ALLBASE/HP-UX database system. This software was used to create and access two databases; CALDB and PENCIL. CALDB is used to track the routine maintenance, repair, and calibration information for various classifications of radiation monitoring equipment as well as identification and location information. PENCIL tracks personnel pencil (self-reading) dosimeters.

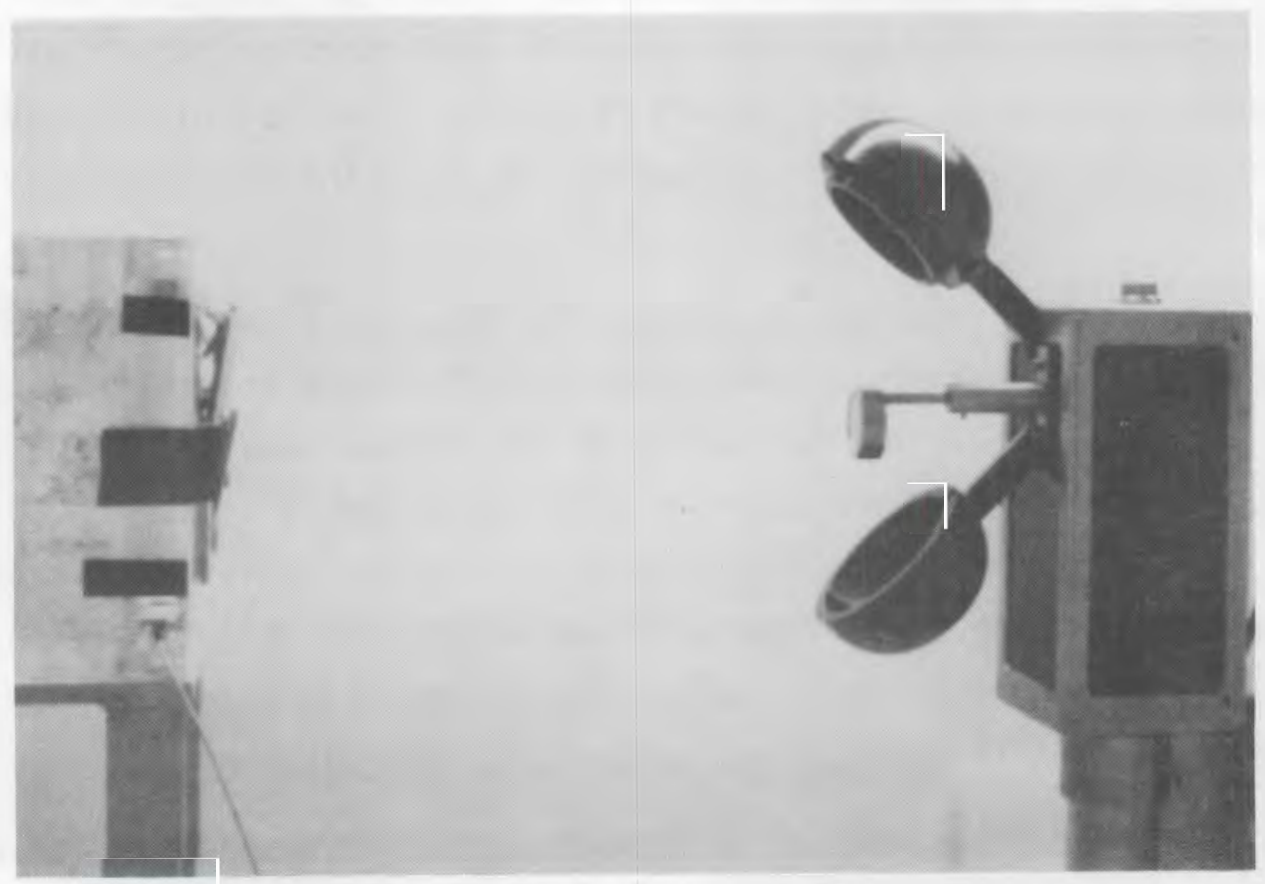

FIGURE 6.1. Americium-241 59-keV Photon Irradiator 


\subsubsection{Improvements to the Maintenance of the Data Management System Function}

The final tasks still operating on the previously used HP-1000 computer were transferred to the upgraded HP-9000 Model 825 and the HP-1000 was entirely eliminated from the system. User terminals in the control room adjacent to Room 106 and in the computer room were replaced and use of the available disc and tape storage media was streamlined to improve efficiency.

The PENCIL database and associated programs interface to a laser bar code system, which expedites the entry of dosimeter identification codes and reduces input errors. During the year, bar code labels were received for placement on the dosimeters and a new laser-gun bar code reader was purchased. (See Figure 6.2).

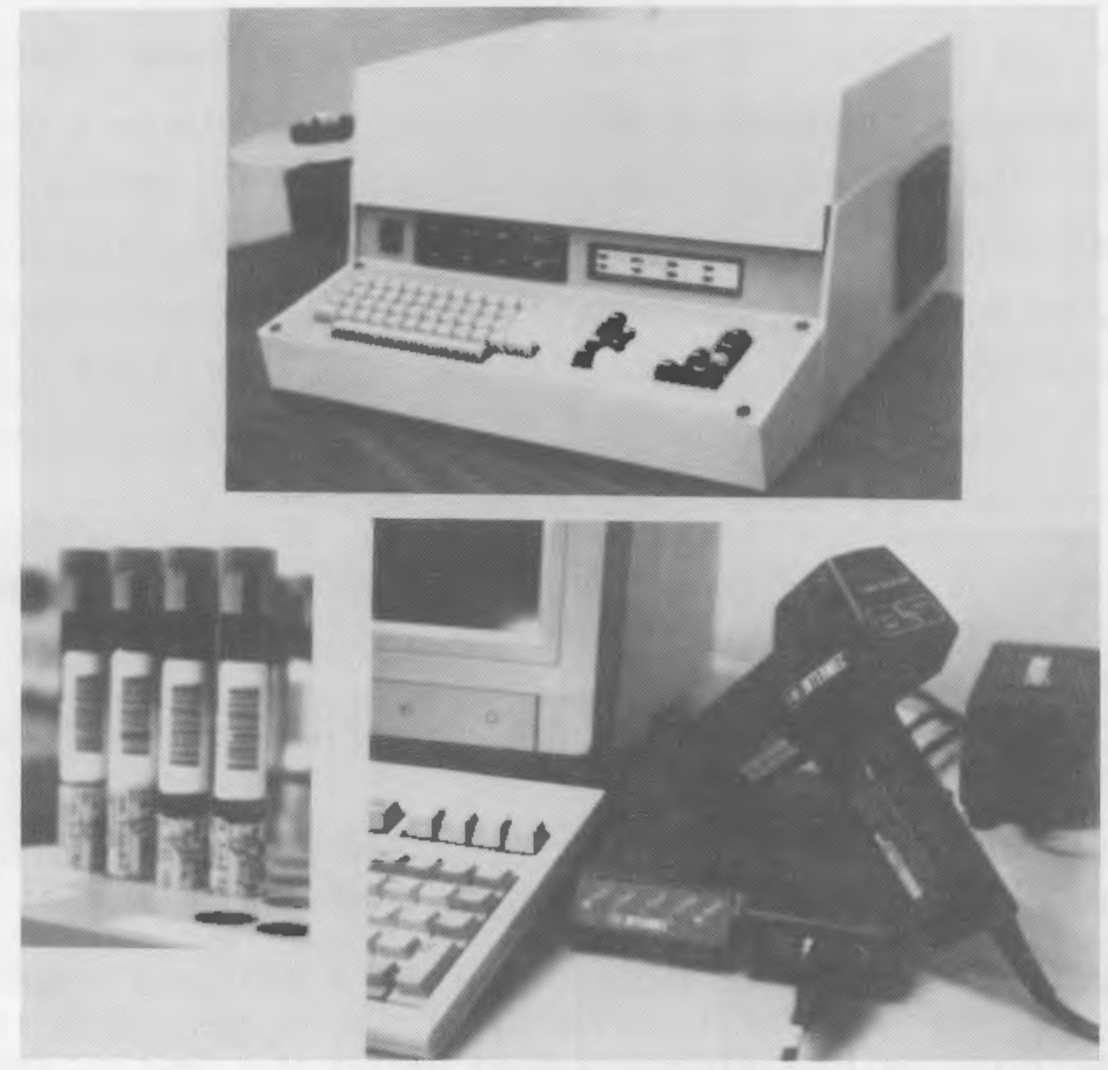

FIGURE 6.2. Components of Laser Bar Code System for Pencil Dosimeter Identification. Clockwise from top: Bar Code Label Maker, Laser Bar Code Reader, Bar Code-Labeled Self-Reading Dosimeters. 
Other data management maintenance included trouble-shooting of, and enhancements to, other system programs in support of the CALDB database. Most notable were 1) an expansion and upgrade to the QA portion of the MAIN program to improve the control of measurement and test equipment (M\&TE) used to calibrate instruments, 2) addition of the hand and foot monitors to the database, and 3) improvements to the CAM programs.

\subsection{SUPPORTING INVESTIGATIONS AND STUDIES}

The following special studies were performed to overcome identified problems and/or improve the QA programs for dosimeter and instrument calibrations.

\subsubsection{Measurement Quality Assurance for Beta Irradiations}

In order to verify the consistency (or traceability) of Radiation Standards and Calibrations (RS\&C) measurements with national standards, RS\&C routinely participates in an MQA program for beta irradiations conducted by NIST. Under this program in the past, NIST personnel have visited the RS\&C facility to directly measure the values of absorbed dose rate for specific beta sources. The sources selected for measurement are identical to sources that NIST maintains as reference standards. This process is carried out periodically to ensure that the RS\&C measurements stay within agreed-upon control limits (usually $\neq 2 \%$ ). This year was to have been the next scheduled year for this to take place. However, due to a change in personnel within their organization, NIST was unable to carry out this activity.

NIST has proposed an alternative test method similar to that normally used for photon MQA. This method will follow these steps:

- NIST sends a high-quality transport ionization chamber whose response to radiation is not known by RS\&C staff.

- RS\&C staff determine the response (signal per unit of radiation) for the transfer standard and report the results.

- NIST provides a report of the ratio of PNL's measured response obtained with the national standard. A good agreement (within $\star 2 \%$ ) of these values will satisfy the goal of the MQA testing process. 
NIST has established a target date for this procedure in early 1991, pending their establishment of the necessary procedure and cross checks with their reference standards.

\subsubsection{Well \#2 Trolley Slippage Incident}

During the second-quarter calibration of the Well \#2, 10-Ci ${ }^{137} \mathrm{Cs}$ source (source no. 318-030), a 30\% disagreement was indicated between the measured exposure rate values and the computer-listed values at the upper positions of source placement. An investigation showed a slippage of about $7 \mathrm{~cm}$ in the trolley system connecting the source to the elevator assembly. Well \#2 users were notified and the system was consequently repaired and readjusted. Following the repair, the system calibration was again within $\pm 2 \%$ of the expected exposure rates.

The suspected cause of the slippage was a worn transducer, which caused an error in the positioning of the source within the well. As the source moved upward in the well (i.e., closer to the detector position), the error became more discernable. At the typical distances utilized within the well for the calibration of Cutie Pie (CP) instruments, errors ranged from $2 \%$ to $25 \%$. Since the usual accuracy of calibration for these instruments is $\pm 20 \%$, the induced error would only be marginally detectable at the high-scale exposure rates and insignificant during low-scale calibrations. Any resulting adjustments made to compensate for this unsuspected error would lead to a conservative over-response in field use, and therefore, no hazards were presented by use of instruments calibrated under these conditions.

6.2.3 Background from Placement of the New High-Leve1 ${ }^{252} \mathrm{Cf}$ Source

A new $1.47-\mathrm{mg}{ }^{252} \mathrm{Cf}$ source (source no. 318-167) was placed into the Rabbit system of Roon 106. It replaced a source that was more than 5 years old and had decreased significantly in intensity. Given the higher intensity of this new source, there was some concern regarding the amount of neutron radiation penetrating outside of Room 106. Initial measurements of adjacent rooms and hallways performed using a SNOOPY neutron detector indicated no measurable evidence of this concern. However, TLDs placed in the adjacent control room did indicate an increased neutron background beginning in April, a month in which heavy use of the source took place for calibration purposes. This increase, although proportional to the response of previous dosimeters 
exposed to the weaker source, was high enough to raise some concern about storing dosimeters in the vicinity of the control room.

The increased dosimeter response measured in April did not immediately raise great concern because of a suspected over-response of the dosimeters to the filtered neutrons passing through the concrete walls. To further investigate the problem, however, TEPC measurements were performed in the control room to obtain a more exact assessment. The results of this assessment indicated that, during the use of this source in its bare condition, the dose equivalent rate may be above $1 \mathrm{mrem} / \mathrm{h}$ within the control room. These measurements indicate that there is sufficient evidence for 1) not storing multipurpose (neutron sensitive) dosimetry within the control room area during prolonged use of the ${ }^{252} \mathrm{Cf}$ source no. 318-167, and 2) limiting operator occupancy of the control room to maintain personnel exposure as low as reasonably achievable (ALARA). No other problems regarding the use of this source were identified during 1990.

\subsubsection{Americium-241 Beam Uniformity}

Calibration of an $241_{A m}$ (59-keV photon) source used for the characterization of personnel pencil dosimeters was requested during the first quarter of CY 1990. The calibration was performed using a Capintec PM-30 ion chamber at a source-to-detector distance of $25 \mathrm{~cm}$. In addition to providing an exposure rate at the $25-\mathrm{cm}$ position directly in front of the source, a uniformity study was also provided to ensure that dosimeters placed in four positions on either side of the center in a semicircular pattern would receive relatively similar exposures. The data, shown in Table 6.2, indicate an exposure rate of $87 \mathrm{mR} / \mathrm{h}$ at the center position (\#5). The other positions are numbered from 1 to 9 from left to right looking away from the source. Non-uniformity was found to extend from a 2.4\% over-response to a $4.6 \%$ under-response. This nonuniformity was not considered problematic given the $\$ 15 \%$ variability accepted in the response of the pencil dosimeters. 
TABLE 6.2. Calibration and Uniformity Study (241 Am Source No. 318-078) as of February 5,1990

\begin{tabular}{cccc} 
Position & $\begin{array}{c}\text { Distance to } \\
\text { Source }(\mathrm{cm})\end{array}$ & $\begin{array}{c}\text { Measured } \\
\mathrm{mR} / \mathrm{h}\end{array}$ & $\begin{array}{c}\text { Relative to } \\
\text { Position } \# 5\end{array}$ \\
\cline { 2 - 3 } 1 & 25 & 83.0 & 0.954 \\
2 & 25 & 86.0 & 0.988 \\
3 & 25 & 87.1 & 1.001 \\
4 & 25 & 86.9 & 0.999 \\
5 & 25 & 87.0 & 1.000 \\
6 & 25 & 89.1 & 1.024 \\
7 & 25 & 86.8 & 0.997 \\
8 & 25 & 83.4 & 0.959 \\
9 & 25 & 83.4 & 0.959
\end{tabular}

\subsubsection{Physical Characterization of the Commercial Ganma Irradiator}

The commercial ganma irradiator employed in Room 6 of the 318 Building was introduced initially as a backup to the Room 8 high-level irradiator. One of its potential uses includes providing DOELAP-type ${ }^{137} \mathrm{Cs}$ irradiations for Hanford dosimeters. To do this, the irradiator must provide a radiation field subject to certain criteria. A study was performed to verify that it could perform as required by the stated criteria. The study concluded the following:

- The exposure rate was consistent with (i.e., traceable to) radiation standards maintained by NIST.

- The radiation field at the surface of the irradiation phantom $(50 \mathrm{~cm}$ from the source) was uniform to within $\pm 2 \%$ over the 10 -cm $x$ $10-\mathrm{cm}$ central area.

- Contribution of scattered photons at the surface of the irradiation phantom was minimal.

- The ratio of the shallow- to the deep-dose equivalent produced by the source was nearly unity.

The commercial irradiator was determined to be a viable alternative if the Room 8 irradiator ever becomes damaged or if the volume of requested irradiations becomes too extensive to accommodate using only one irradiator. 


\subsection{PUBLICATIONS}

The following publication was prepared by Radiation Standards and Calibration Project staff during 1990:

Murphy, M. K., R. J. Traub, J. C. McDonald, and C. D. Hooker. 1990. "Physical Characterization of a ${ }^{137} \mathrm{Cs}$ Field Used for Proficiency-Test Irradiations." Health Physics (accepted for 1991 publication). 


\subsection{HANFORD RADIOLOGICAL RECORDS PROGRAM}

The Hanford Radiological Records Program (HRRP) supports DOE-RL and Hanford contractor radiation protection programs by preserving and administering radiological exposure records for all Hanford workers and visitors, past and present. The program is also responsible for the Hanford Radiation Protection Historical Files. Program personnel operate the computer systems and library equipment necessary to input, store, and retrieve the records and produce the required reports.

The records program utilizes the ORE system which includes a database with personnel exposure data that are readily retrievable via a system of PCs and terminals. The ORE system also includes all of the supporting exposure documentation on microfilm that is indexed into a computer-assisted retrieval (CAR) system. The CAR system allows for rapid retrieval of the documents for any individual using identifiers including payroll number, social security number, and/or name.

The historical records include documents such as policies, procedures, reports, important comnunications, etc., that define the Hanford radiological dosimetry and radiation protection programs since the inception of the Hanford Site. The historical records are microfilmed and indexed into a second CAR system. These records are retrievable by author, date or range of dates, document number (if applicable), title, and up to three key words.

The program is operated under the applicable sections of ANSI N13.61972 (1972), DOE 1300.1, 1324.2, 5480.11 and 5484.1 Chg 3 (1980a, 1980b, 1988, 1989, 1987b) as assigned by the Hanford Site Services Handbook (D0E 1991). It also complies with the applicable sections of the Privacy Act (1974) and the Freedom of Information Act (1966).

\subsection{ROUTINE PROGRAM}

The HRRP is organized into three major functional areas: data handling, report issuance, and the library. The data-handling function provides for the entry of data elements into the ORE database and the validation of all data entry. Validation is accomplished by establishing audits to be matched to 
entries of results, resolving unmatched results, and interacting directly with contractor personnel.

The report-issuance function provides for the generation and issuance of routine exposure status reports to the contractors, quarterly manrem and annual statistical reports to $D O E$, annual reports to employees, and special reports requested by former employees, as well as those requested by the contractors and DOE-RL. Both the data-handling and report-issuance functions are performed by the Radiological Records data processing center. This function requires close liaison with DOE-RL, the contractors, and other personnel dosimetry functions.

The library function provides for the maintenance of the individual exposure records that are not reducible to database elements, as well as the Hanford Radiation Protection Historical Files. The library staff file and retrieve current hard-copy documents, prepare documents for long-term storage, and track and account for documents through the microfilming and indexing process. The library contains the individual exposure record documentation for all Hanford personnel since 1945 (almost five million microforms). There are also some exposure records remaining from the Hanford dupont era. These and the Historical Files microforms are retrievable through two CAR systems that are maintained by the library staff.

Although the results from the dosimeter and excreta processing, as well as the in vivo counts, are received by electronic transmission or magnetic tape, a large amount of data that are placed in the records are received in hard-copy form. These data are entered manually by the data processing center staff. The hard copies are then sent to the library for entry into the CAR system. Table 7.1 presents $C Y 1990$ statistical information on many of the documents that were entered into the database and microfilmed and indexed into the CAR system. 
TABLE 7.1. Records Activity for Calendar Year 1990

Document

Personal Radiation Exposure History Forms (used to document exposure history prior to Hanford)

Employee and Dosimetry Change Forms (used to document personnel or dosimetry changes)

Employee and Dosimetry Change Forms (used to document employee terminations)

Temporary Dosimeter Assignment Forms (used for visitors and sub-contractors as well as employees who forgot their dosimeters)

Investigation of Dosimeter Result Forms and Change Letters (used to estimate exposure for lost, damaged, or otherwise suspect dosimeter results)

Special Process Forms (used to document data for specially processed dosimeters)

Request for Special Excreta Sample Analyses (used to initiate the collection of samples for analysis)

Requests for Exposure Summaries (summaries requested for current and prior Hanford employees)

Letters Sent to Request Prior Exposure (to request summaries for new employees with prior exposure)

Microfilm Reels Indexed into CAR (personnel and historical documents. Each reel contains over 2,000 images)
Number

4,300

19,876

2,893

4,697

793 38

\subsubsection{Changes to the Routine Program}

Due to the redevelopment of the ORE System, changes made to the database are being held to only those changes necessary to keep the system functional, required by additions or changes to DOE orders, or that reduce costs. The only significant changes that were made during CY 1990 were to allow electronic verification of IVRRF data transmissions and the restructuring of the Hanford Radiological Incident File. 


\section{Verification of IVRRF Data Transmission}

Since the provision for electronic data transmission from the IVRRF was installed, verification of the data transmission has been done manually. A paper copy of the data as entered into the ORE system was printed and verified by a records clerk. The new program allows the IVRRF to access the ORE database, request the data they want to verify, and download it to their computer for verification.

\section{Restructuring of the Incident file}

In a meeting with the DOE program sponsor it was determined that the Incident file, as it is now constituted, was no longer needed. Other organizations are now accumulating this material. It was decided that the Hanford Radiological Incident file would be discontinued and all incident records not related to personnel exposure or contamination and not identifiable to an individual would be purged. Library personnel will remove the excess material as time permits.

\subsection{SUPPORTING TASKS}

\subsubsection{Redevelopment of the ORE System}

Funding allocations were approved for FY 1990 for the start of the ORE system redevelopment. The effort is expected to take over 2 years and will contain four major phases. These sequential phases include:

1. Systems Requirements Analysis - This analys is involves defining the requirements of the new system, including interaction with all the users and data suppliers to determine their needs. From this effort a requirements document will be produced that will be used as the basis for designing and constructing the new system.

2. Preliminary Design - This step is based on the requirements analysis, and includes the development of the functional specifications for the new system, an alternatives analysis, and the production of an alternatives analys is document. The alternatives analys is will determine which hardware/software application will best suit the requirements. This phase also includes the final cost/benefit analysis, as well as schedules and plans for the detailed design and construction, verification, installation, and startup phases.

3. Detailed Design and Construction - This phase includes the detailed design and programming of the new system defined in the previous two phases and is expected to take at least 12 months. The detailed design portion will include tasks such as the functional 
system design; program design; design testing and analysis;

development of system test, certification test, and acceptance test plans; development of a conversion plan; and development of a training plan. The construction portion will include tasks such as coding: unit, integration, and system testing; and development of conversion and acceptance test materials.

4. Certification and Implementation - This phase includes conversion of data from the old to the new system and certification that the installation is correct. Correct installation will be verified by modular, integration and system testing. Once testing has shown that the new system meets the acceptance criteria, parallel runs of the new system will be conducted with the old ORE system. When a successful parallel run has been completed the new system will be established as the production system. Training of records personnel and users is included in this phase.

Early in the year the ORE Redevelopment Steering Committee was chartered by DOE-RL. A copy of the charter is included as Figure 7.1. The steering committee is made up of user representatives from each contractor and representatives from the HRRP and DOE-RL.

The requirements analysis phase was started in January 1991, with completion expected in June. The steering committee decided what would fall within the boundaries of the redeveloped system. The new system was divided into two parts: the Radiological Records and Radiological Records Support. (a)

The Radiological Records part will include the reference records (i.e., the exposure and other necessary records that are maintained in the ORE database) and the CAR-archival material (i.e., the paper records that back up the database and are otherwise desirable or necessary to maintain).

The Radiological Records Support part would include the following:

- Preliminary data - dosimetry results and certain other data that are preliminary and are not to be inserted into the database but are needed by the contractors

- Tracking system - used for tracking whether individuals have received a scheduled in vivo exam or submitted a valid in vitro sample as scheduled; also used for individual dosimeter tracking

- Scheduling - scheduling of bioassay in vivo and in vitro exams

(a) Lyon, M. 1990. "ORE Redevelopment Steering Committee - Meeting Minutes." Memorandum to Distribution, dated March 7, 1990. Copy available in the Hanford Historical Radiation Protection Files, Pacific Northwest Laboratory, Richland, Washington. 
CHARTER

ORE REDEYELOPMENT STEERING COMMITTEE

MISSION

The mission of the ORE Redevelopment Steering Cosmittee is to provide oversight and leadership to the redevelopment program of the Occupational Radiation Exposure (ORE) Systerm database and computer assisted retrieval (CAR) system.

FINCTION

The ORE Redevelopment Steering Committee will review, comant on, and approve ail documents produced as a part of the redevelopment effort. They witl review and approve all changes to requirements, design specifications, and implementation plans that have been approved by the committee. The steering Conamittee will also authorize the new system installation and be responsible for final acceptance of the new system.

ORGANIZATION

The Steering Comattee members, except the DOE-RL member, shall be appointed by the Contractor management. Membership will include one member from each major ORE user organization (WHC, PNL, KE,H, HEHF), one nember representing the Hanford Radiological Records Program, and one member representing DOE.RL. The DOE-RL member shall be Chairperson of the Steering Comnittee. The member representing the Radiological Records Program shall be Secretary and keep the minutes.

Each member should have a backup that shoutd attend when the regular member is not able to attend. The backup member should be kept up to date on the redevelopment status so the are able to actively and knowledgeably participate in meetings when required to.

The Steering Conmittee may appoint consultants as required to assist it in accomplishing the mission.

ISSUE RESOLUTION

Issues that require resolution will be considered at the meeting where they are raised. The discussion witl be included in the minutes or the meeting. The issue will then be reviewed at the next meeting, a statement of the issue decided on, and the statement voted upon. A majority vote will be required for the statement to be accepted. If a majority vote is lacking the Chairperson will rake the final decision.

\section{MEETINGS}

The Steering Committee shall meet as needed, but at. least manthly. Any member may initiate action to convene through the Chairperson.

Announcements of meetings will be sent to Stearing Conmittee members, to members and designees of the Hanford Dosimetry Computer integration Committee (HOCIC). and to designated BCSR personnel involved in the redevelopment effort. HOC IC members and designees may attend at their discretion. BCSR personnel involved in the redevelopment effort should attend a 11 meetings.

an agenda should be distributed to Steering Committee and HOCIC menters at least one week prior to the meeting for regularly scheduled meetings. For meetings called on an ad hoc basis, an agenda should be distributed if time permits; or the subject(s) to be considered should be included in the meeting announcement.

The Steering Committee may request presentations by persons or groups that have expertise or involvement in matters under consideration.

Minutes shall be kept of all meetings. Copies of the minutes shall be distributed to Steering Comatittee nembers, to members and designees of the HDC IC, and BCSR personnel involved in the redevelopment effort.

AUTHORITY

This Stepring Comittee is established by the DOE-RL Safety and Environment ofvision. It has the authority to exercise those functions listed aoove.

1. Letter R. A. Molten to Contractors, Richland Washington, Redeveiopment of the Dasimetry Computer Sustem, $\$ 1 / 21 / 89$.

\section{FIGURE 7.1. ORE Redevelopment Steering Committee Charter}


- Work Restrictions, Respirator Fit, and Work Clearances - These items will fall within the boundaries of the new system until the Hanford Medical System (HMS) is redeveloped by HEHF; they would then be handed over to HEHF to be included in the HMS. Because the timing of the HMS redevelopment is not certain, these contractor services will be provided by the new records system so there is no period of time when they are not available.

A major part of the requirements analysis was meeting with the ORE system users and data suppliers to determine how the data flows. Data flow diagrams were then produced. The development team then met again with the users to ensure they had modeled the data flow properly. These diagrams were reproduced in the requirements analysis document. (a) From the data flow diagrams and interviews the set of requirements that would be needed for the new system to function was developed. The requirements analys is was approved by the Steering Committee and issued in June 1990. This completed the System Requirements Analysis phase.

The first draft of the alternatives analysis document was issued in November. This first draft tied the user requirements to a framework for analyzing hardware/software configurations. The content was intended to be familiar enough to the steering committee that they could clearly see the role the requirements play in making the hardware/software decisions. Therefore, this draft did not discuss specific recomendations or technical information leading to any decisions. Further efforts would be required in CY 1991 .

\subsection{PUBLICATIONS AND PRESENTATIONS}

The following publications and presentations were prepared by the HRRP staff during 1990 .

\subsubsection{Publications}

Berndt, V. L., and M. Lyon, 1990. "A Computer Systen for Historical Radiological Documentation." Records Management Quarterly 24(3):27-32.

\subsubsection{Presentations}

Berndt, V. L. 1990. "Computer Assisted Retrieval: Two Applications." Presented at the Region $X$ Meeting, Association of Records Managers and Administrators, March 7, 1990, Boise, Idaho.

(a) Carriera, R. J. 1990. Occupational Radiation Exposure System (ORE) Requirements Analysis. BCS-Richland, Richland, Washington. 


\subsection{PROGRAM-RELATED PROFESSIONAL ACTIVITIES}

Lyon, M.--Chairman of the Health Physics Society Standards Committee Working Group to review ANSI N13.6, American Standard Practice for Occupational Radiation Exposure Records Systems. 


\subsection{REFERENCES}

American National Standards Institute (ANSI). 1972. Practice for Occupational Radiation Exposure Records Systems. ANSI N13.6, New York.

American National Standards Institute (ANSI). 1978. Radiation Protection Instrumentation Test and Calibration, ANSI N323, (R-1983), New York.

American National Standards Institute (ANSI). 1983. American National Standard, Criteria for Testing Personnel Dosimetry Performance, ANSI N13.11, New York.

Fix, J. J. 1990. Hanford External Dosimetry. PNL-7006, Pacific Northwest Laboratory, Richland, washington.

Fix, J. J., G. W. R. Endres, F. M. Cummings, J. M. Aldrich, M. R. Thorson, and R. L. Kathren. 1981. Hanford Personnel Dosimeter Supporting Studies FY-1980. PNL-3536, Pacific Northwest Laboratory, Richland, Hashington.

Fix, J. J., G. W. R. Endres, F. M. Curmings, J. M. Aldrich, M. R. Thorson, and R. L. Kathren. 1982. Hanford Personnel Dosimeter Supporting Studies FY-1981. PNL-3736, Pacific Northwest Laboratory, Richland, Washington.

Freedom of Information Act. 1966. Public Law 89-487, July 4, 1966.

International Commission on Radiological Protection (ICRP). 1973. Alkaline Earth Metabolism in Adult Man. ICRP Publication 20, Perganon Press, New York.

International Commission on Radiological Protection (ICRP). 1979. Limits for Intakes of Radionuclides by Workers. ICRP Publication 30, Part 1 and Suppliments, Pergamon Press, New York.

Johnson, J. R., and M. B. Carver. 1981. "A General Model for Use in Internal Dosimetry." Health Physics 41:341-348.

Jones, S. R. 1985. "Derivation and Validation of a Urinary Excretion Function for Plutonium Applicable Over Tens of Years Post Intake." Radiation Protection Dosimetry 11(1):19-27.

Lyon, M., J. J. Fix, J. L. Kenoyer, J. A. Leonowich, H. E. Palmer, and M. J. Sula. 1989. Hanford Radiological Protection Support Services Annual Report for 1988. PNL-6952, Pacific Northwest Laboratory, Richland, Washington.

Lyon, M., J. L. Kenoyer, D. E. Bihl, J. A. Leonowich, J. J. Fix, and H. E. Palmer. 1990. Hanford Radiological Protection Support Services Annual Report for 1989. PNL-7417, Pacific Northwest Laboratory, Richland, Washington.

Privacy Act, 44 Fed. Reg. 510772 (1974).

Sula, M. J., E. H. Carbaugh, and D. E. Bihl. 1989. Technical Basis for Internal Dosimetry at Hanford. PNL-6866, Pacific Northwest Laboratory, Richland, Washington. 
U.S. Department of Energy (DOE). 1980a. Micrographics Management. DOE 1300.1 , U.S. Department of Energy, Washington, D.C.

U.S. Department of Energy (DOE). 1980b. Records Disposition. DOE 1324.2, U.S. Department of Energy, Washington, D.C.

U.S. Department of Energy (DOE). 1987a. DOE Laboratory Accreditation Program for Personnel Dosimetry. DOE 5480.15, Washington, D.C.

U.S. Department of Energy (DOE). 1987b. Environmental Protection, Safety, and Health Protection Information Reporting Requirements. D0E 5484.1 (change dated June 15, 1987), U.S. Department of Energy, Washington, D.C.

U.S. Department of Energy (DOE). 1988. Radiation Protection for Occupational Workers. DOE 5480.11, Washington, D.C.

U.S. Department of Energy-Richland Operations Office (DOE-RL). 1991. Hanford Site Services Handbook. RLPI 9-50.5, Richland, Washington.

Wilson, R. H., J. J. Fix, W. V. Baumgartner, and L. L. Nichols. 1990. Description and Evaluation of the Hanford Personnel Dosimeter Program From 1944 Through 1989. PNL-7447, Pacific Northwest Laboratory, Richland, Washington. 


\section{DISTRIBUTION}

No. of

Copies

\section{OFFSITE}

2 DOE/Office of Scientific and Technical Information

DOE Field office, Albuquerque

D. L. Carathers

Mason \& Hanger

Pantex Plant

P.0. Box 30020

Amari110, TX 79120

L. M. Coco

Mound Laboratory

EG\&G

Mound Applied Technologies

P.0. Box 3000

Miamisburg, $\mathrm{OH} \quad 45342$

J. M. Graf

Los Alamos National Laboratory

P.0. Box 1663

Los Alamos, NM 87545

R. M. Rogers

EG\&G Rocky Flats

Rocky Flats Plant

P.0. Box 464

Golden, CO 80402-0464

DOE Field Office, Chicago

A. E. Keuhner

Brookhaven National Laboratory

Upton, NY 11973

R. E. Toohey

Argonne Nationa] Laboratory

9700 South Cass Avenue

Argonne, IL 60439
No. of

Copies

DOE Field Office, Idaho

H. D. Christiansen

Westinghouse Idaho Nuclear Company, Inc.

P.0. Box 4000

Idaho Falls, ID 83404

DOE Field Office, Nevada

8. P. Smith

Reynolds Electrical and Engineering $\mathrm{Co}$. , Inc.

P.0. Box 98521

Las Vegas, NV 89193

DOE Field Office, Oak Ridge

J. S. Bogard

Oak Ridge NationaT Laboratory

Martin Marietta Energy

Systems, Inc.

P.0. 80x 2008

Oak Ridge, TN 37831

J. B. Hunt

$Y-12$ Plant

Martin Marietta Energy

Systems, Inc.

P.0. Box 2008

Oak Ridge, TN 37831

DOE Field office.

San Francisco

C. T. Prevo

Lawrence Livermore Nationa] Laboratory

P.0. Box 808

Livermore, CA 94550 
No. of

Copies

DOE Field Office, Savannah River

D. A. Stevenson

Westinghouse Savannah River Company

Savannah River Plant

P.0. Box 616

Aiken, SC 29802

\section{ONSITE}

4 DOE Field Office, Richland

D. L. Clark

D. T. Evans

R. A. Holten

G. R. Yesberger

2 Hanford Environmental Health Foundation
R. L. Kathren
M. J. Swint

Kaiser Engineers Hanford

D. J. Foust

3 Westinghouse Hanford Company

W. A. Decker, Jr.

R. E. Heineman

T. J. Kelly
No. of

Copies

42 Pacific Northwest Laboratory

W. J. Bair

D. E. Bihl (2)

L. G. Faust

D. H. Fleming

J. J. Fix (2)

T. J. Froelich (2)

D. P. Higby

G. R. Hoenes

J. R. Houston (2)

J. R. Johnson

J. A. Leonowich (2)

M. Lyon (10)

T. P. Lynch (2)

J. B. Martin

J. C. McDonald

I. C. Nelson

R. K. Piper

J. M. Selby

K. L. Soldat

Publishing Coordination

Technical Files (5)

Radiation Protection Historical Files (c/o V. L. Berndt) (2) 